San Jose State University

SJSU ScholarWorks

Master's Theses

Master's Theses and Graduate Research

Spring 2010

\title{
Emissions and Impacts from Prescribed Fire in a Longleaf Pine Ecosystem
}

Scott James Strenfel

San Jose State University

Follow this and additional works at: https://scholarworks.sjsu.edu/etd_theses

\section{Recommended Citation}

Strenfel, Scott James, "Emissions and Impacts from Prescribed Fire in a Longleaf Pine Ecosystem" (2010). Master's Theses. 3792.

DOI: https://doi.org/10.31979/etd.6tx2-2gjs

https://scholarworks.sjsu.edu/etd_theses/3792

This Thesis is brought to you for free and open access by the Master's Theses and Graduate Research at SJSU ScholarWorks. It has been accepted for inclusion in Master's Theses by an authorized administrator of SJSU ScholarWorks. For more information, please contact scholarworks@sjsu.edu. 


\title{
EMISSIONS AND IMPACTS FROM PRESCRIBED FIRE IN A LONGLEAF PINE ECOSYSTEM
}

\author{
A Thesis \\ Presented to \\ The Faculty of the Department of Meteorology and Climate Science \\ San José State University
}

\author{
In Partial Fulfillment \\ of the Requirements for the Degree \\ Master of Science
}

by

Scott J. Strenfel

May 2010 
(C) 2010

Scott J. Strenfel

ALL RIGHTS RESERVED 
The Designated Thesis Committee Approves the Thesis Titled EMISSIONS AND IMPACTS FROM PRESCRIBED FIRE IN A LONGLEAF PINE ECOSYSTEM

by

Scott J. Strenfel

\section{APPROVED FOR THE DEPARTMENT OF METEOROLOGY AND CLIMATE SCIENCE}

\section{SAN JOSÉ STATE UNIVERSITY}

May 2010
Dr. Craig B. Clements
Department of Meteorology and Climate Science
Dr. Robert D. Bornstein
Department of Meteorology and Climate Science
Dr. Frank R. Freedman
Department of Meteorology and Climate Science 


\title{
ABSTRACT \\ EMISSIONS AND IMPACTS FROM PRESCRIBED FIRE IN A LONGLEAF PINE ECOSYSTEM
}

\author{
by Scott J. Strenfel
}

Prescribed fire is a frequently utilized land-management tool in the Southeastern US. In this study, effects of seasonal-related variations and of turbulence generation on emissions and impacts from prescribed fires were evaluated. High frequency in situ data were obtained from three summer (July 2008) and three winter (January 2009) fires within the active burn perimeter and downwind by use of a $10 \mathrm{~m}$ instrumented tower and $2 \mathrm{~m}$ tripod, respectively. Two cases were selected to evaluate the performance of the EPA-approved short-range regulatory dispersion model, AERMOD, for prescribed fire applications.

Results showed that summer fuels were much greener than winter fuels and did not burn as efficiently, thus resulting in enhanced particulate and $\mathrm{CO}$ emissions during summer fires compared to winter. Statistically significant correlations between turbulence, modified combustion efficiency, and pollutant concentrations were found. For both cases, AERMOD was able to reproduce the observed period and hourly averaged downwind particulate concentrations. 


\section{ACKNOWLEDGEMENTS}

I would like to acknowledge the members of my thesis committee: Drs. Craig Clements, Robert Bornstein, and Frank Freedman. Serving as my advisor, Dr. Clements needs to be acknowledged for all the assistance and tireless help he provided. Dr. Bornstein was critical in the writing phase of the project as his notes from previous classes proved invaluable. Dr. Freedman is an expert in air dispersion modeling and I am grateful he allowed me to use up much of his valuable time to perfect the modeling section of this thesis.

Next, I would like to thank J. Kevin Heirs and the fire crew at the Joseph W. Jones Ecological Research Center at Ichauway, Georgia. They helped set up towers, calibrate instruments, download data, and were the most gracious of hosts. The field research I got to perform, and the experiences I learned, will and have undoubtedly prepared me for future field campaigns.

I would like to thank fellow colleagues Caroline Kiefer and Daisuke Seto for their assistance regarding work in the field. Their endless insights and conversation proved helpful for preparing this thesis. The faculty and students of San José State University deserve credit for their support and knowledge.

Finally I would like to thank the EPA for funding this work. Support for this research was provided by EPA grant \# XA-96499308-0 and an additional grant from the Joseph W. Jones Ecological Research Center. 


\section{TABLE OF CONTENTS}

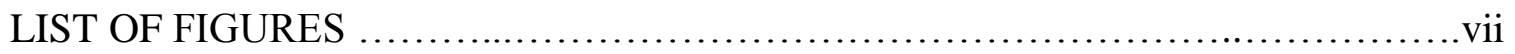

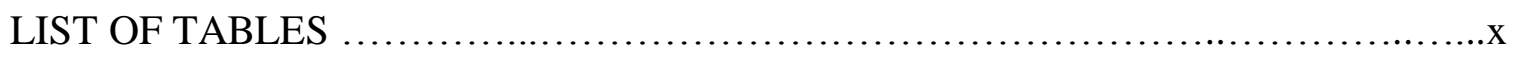

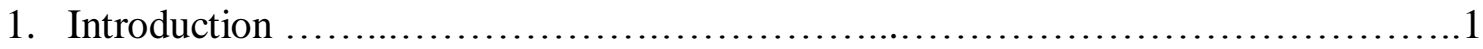

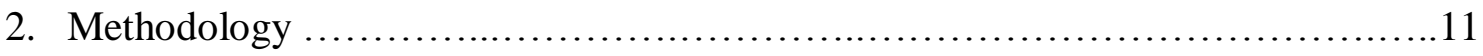

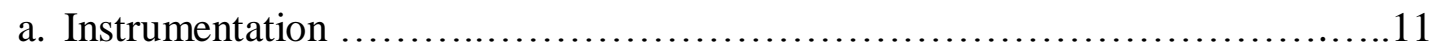

b. Burn Implementation .....................................................

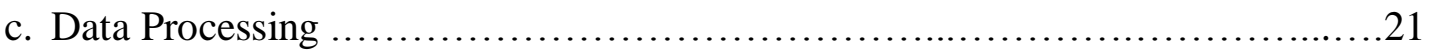

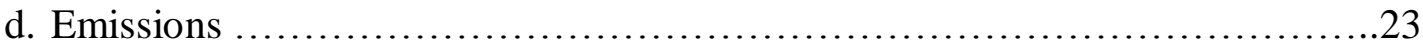

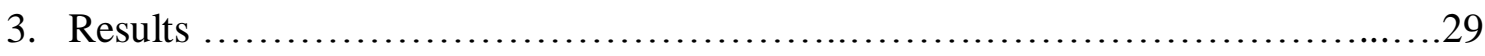

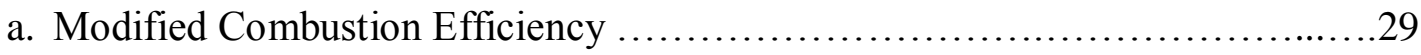

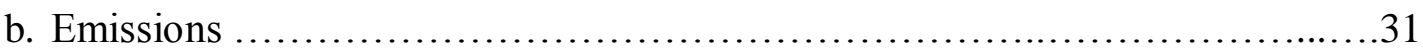

c. Observed Fire-Atmosphere Interactions ......................................55

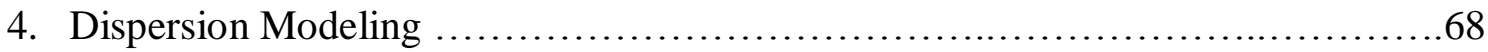

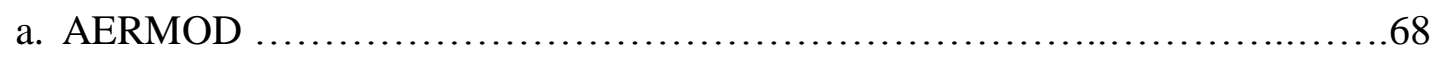

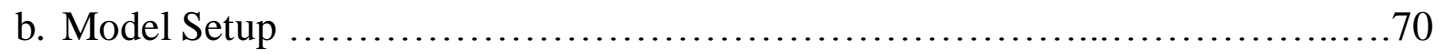

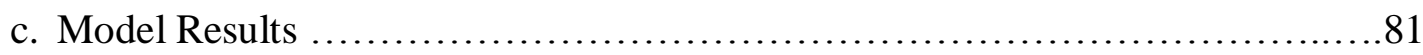

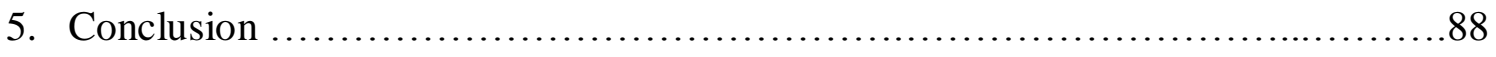

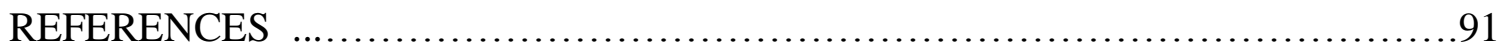

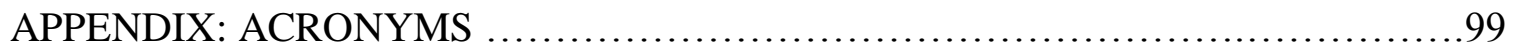




\section{LIST OF FIGURES}

1. Schematic drawing of tower configuration and experimental design $\ldots \ldots \ldots \ldots \ldots 12$

2. Photograph of moist wiregrass fuel and backing fire front on 16 July 2008 1045 EST 16

3. Photograph of dry wiregrass fuel and fire front on 12 January 2009 $1258 \mathrm{EST}$ 16

4. Joseph W. Jones Ecological Research Center at Ichauway, Georgia landcover map

5. Experimental designs and instrument locations for data collected during the three summer fires

6. One min average concentration data 25

7. Schematic diagram of the process used to evaluate the EFs for each prescribed burn .28

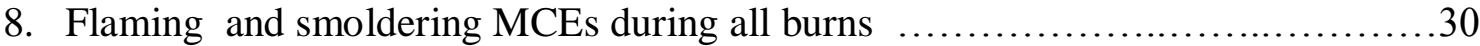

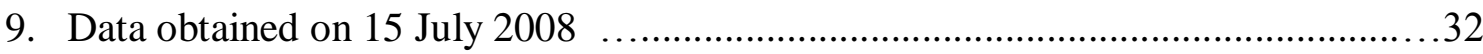

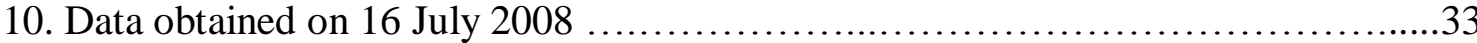

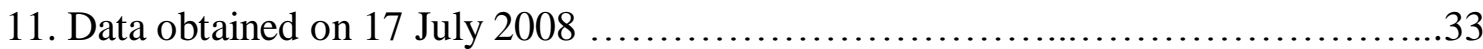

12. Data obtained on12 January 2009 .........................................

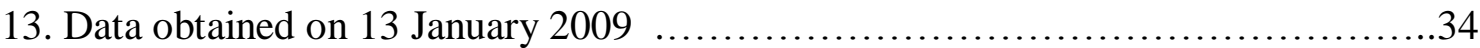

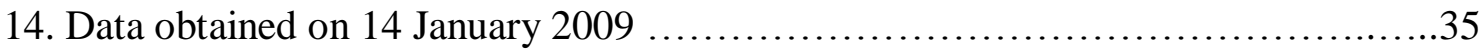

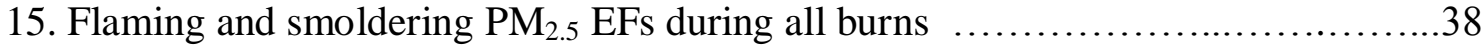

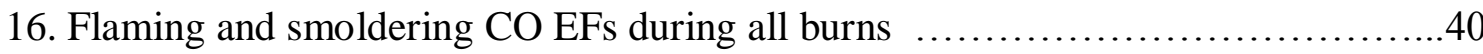


17. Flaming and smoldering $\mathrm{CO}_{2} \mathrm{EFs}$ during all burns

18. Scatter plot of $\mathrm{PM}_{2.5} \mathrm{EF}_{\mathrm{t}}$ versus MCE for the 15 July 2008 burn $\ldots \ldots \ldots \ldots \ldots \ldots . \ldots . \ldots . \ldots$

19. Scatter plot of $\mathrm{PM}_{2.5} \mathrm{EF}_{\mathrm{t}}$ versus MCE for the 12 January 2009 burn $\ldots \ldots \ldots \ldots \ldots . . . .50$

20. Scatter plot of $\mathrm{PM}_{2.5} \mathrm{EF}_{\mathrm{t}}$ versus $\mathrm{MCE}$ for all summer burn data ...................52

21. Scatter plot of $\mathrm{PM}_{2.5} \mathrm{EF}_{\mathrm{t}}$ versus $\mathrm{MCE}$ for all winter burn data $\ldots \ldots \ldots \ldots \ldots \ldots \ldots \ldots . \ldots 54$

22. Scatter plot of MCE versus TKE for all winter burn data $\ldots \ldots \ldots \ldots \ldots \ldots \ldots \ldots . \ldots . \ldots . \ldots . \ldots$

23. Scatter plot of tower $\mathrm{CO}_{2}, \mathrm{CO}, \mathrm{PM}_{2.5}$, and $\mathrm{BC}$ concentrations versus TKE for all

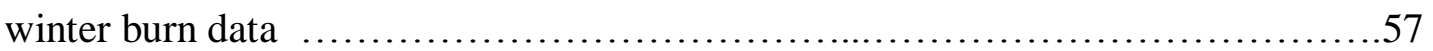

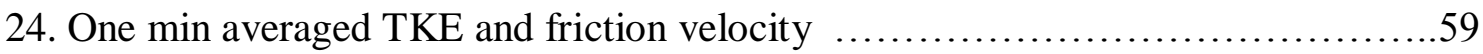

25. One min averaged tower TKE, turbulent variances, and vector wind

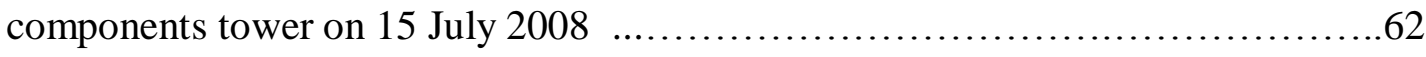

26. One min averaged tower TKE, turbulent variances, and vector wind

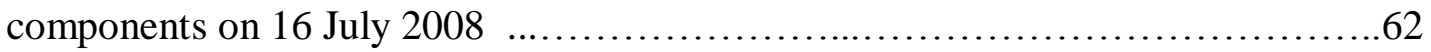

27. One min averaged tower TKE, turbulent variances, and vector wind components on 17 July 2008 .63

28. One min averaged tower TKE, turbulent variances, and vector wind components on 12 January 2009 .66

29. One min averaged tower TKE, turbulent variances, and vector wind components on 13 January 2009 .66

30. One min averaged tower TKE, turbulent variances, and vector wind components on 14 January 2009 
31. Timeseries of AERMET derived sensible heat flux from 13 to 18 July 2008 .72

32. Timeseries of AERMET derived sensible heat flux from 10 to 15 January $2009 \ldots 73$

33. Wind speed and direction (averaged to $1 \mathrm{~min}$ ) measured at the tripod during the duration of the burn on 15 July 2008

34. Wind speed and direction (averaged to $1 \mathrm{~min}$ ) measured at the tripod during the duration of the burn on 12 January 2009 .74

35. Five divided sections of the burn unit representing the 15 July 2008 prescribed

Burn

36. Four divided sections of the burn unit representing the 12 January 2009

prescribed burn

37. Period averaged $\mathrm{PM}_{2.5}$ concentration distribution at $2 \mathrm{~m}$ for the prescribed fire AERMOD simulation on 15 July 2008

38. Hourly averaged $\mathrm{PM}_{2.5}$ observations and AERMOD output for the 15 July 2008 Burn .84

39. Period averaged $\mathrm{PM}_{2.5}$ concentration distribution at $2 \mathrm{~m}$ for the prescribed fire AERMOD simulation on 12 January 2009 .86

40. Hourly averaged $\mathrm{PM}_{2.5}$ observations and AERMOD output for the 12 January 2009 burn 


\section{LIST OF TABLES}

1. Select fuel and fire characteristics of 2008 and 2009 experimental burns ..........18

2. Distance along mean wind direction observed during the burn duration from the most downwind edge of the unit to the tripod

3. Start and end times (EST) of flaming and smoldering stage emissions for all

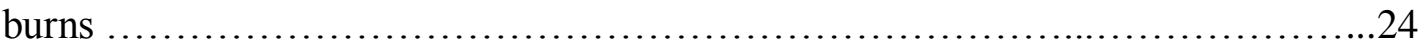

4. Summer and winter Modified Combustion Efficiency (MCE) ....................31

5. Maximum tower $(10 \mathrm{~m})$ and tripod $(2 \mathrm{~m})$ concentrations measured during

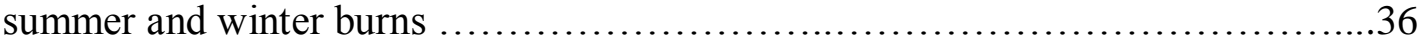

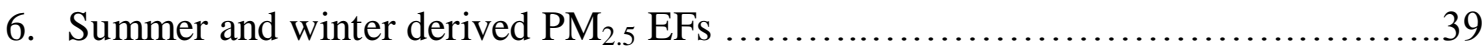

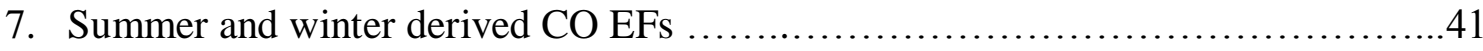

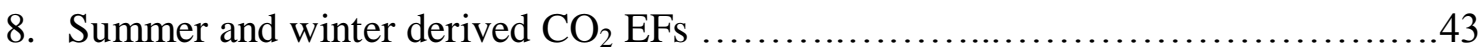

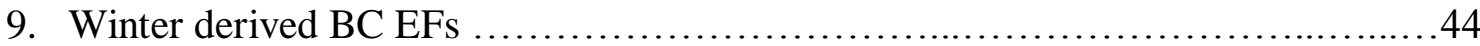

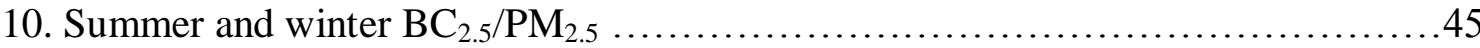

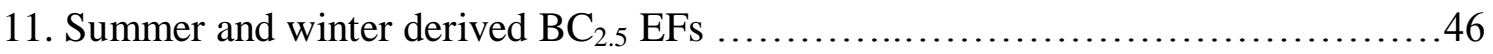

12. Pearson correlation coefficients between MCE, instantaneous fuel consumption (Fuel C) and one min averaged concentrations of $\mathrm{CO}_{2}, \mathrm{CO}$, and $\mathrm{PM}_{2.5}$ for

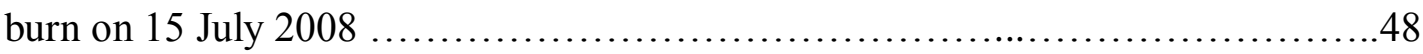

13. Pearson correlation coefficients between MCE, instantaneous fuel consumption (Fuel C) and one min averaged concentrations of $\mathrm{CO}_{2}, \mathrm{CO}$, and $\mathrm{PM}_{2.5}$ for all summer burn data combined 
14. Pearson correlation coefficients between TKE, MCE, and one min averaged concentrations of $\mathrm{CO}_{2}, \mathrm{CO}, \mathrm{PM}_{2.5}$, and $\mathrm{BC}$ for all winter burn data

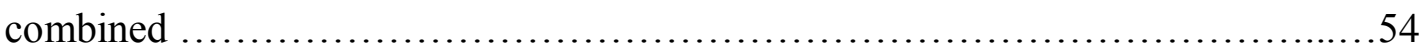

15. AERMOD burn unit section number and size delineation for the 15 July 2008 and 12 January 2009 prescribed fires 


\section{Introduction}

Biomass burning produces substantial amounts of trace gases and particulates that impact air quality and climate. Aerosols emitted from biomass burning reflect incoming solar radiation and can enhance the reflectivity of clouds, contributing an estimated net radiative forcing of about $2 \mathrm{~W} \mathrm{~m}^{-2}$ globally (Penner et al. 1992; Crutzen and Ramanathan 2003). Annually, $\mathrm{CO}_{2}$ emissions from all fire types can equal up to approximately half of global $\mathrm{CO}_{2}$ emissions from fossil-fuel combustion (Andreae and Merlet 2001; van der Werf et al. 2006; IPCC 2007; Schultz et al. 2008). Much of these emissions are from accidental wildfires and deforestation-related fires (Bowman et al. 2009); however, emissions from prescribed fires represent an important source of primary pollutants and secondary pollutant precursors (Lee et al. 2005). Prescribed fires are intentionally set to maintain ecosystem health, and to prevent destruction from high-intensity wildfires by reducing fuel loadings. It is estimated greater than one million acres are consumed annually by prescribed fire in Georgia, and eight million acres in southern states combined (Wade and Lundsford 1998; Lee et al. 2005).

The goal of any prescribed management program is the preservation of biodiversity. Since the natural biota has evolved under the historical fire regime, a prescribed fire program should be implemented to mimic the history of the region (Whelan 1995); however, a historical fire regime reconstruction is a difficult task since the temporal and spatial patterns and seasonality of fires must be evaluated. If the historical fire regime is unknown or cannot be replicated, then efforts should be made to evaluate how well the biota adapts to a departure from the historical regime. 
Emissions from fires occur during both the flaming and smoldering stage. Prior to flaming, fuels are preheated and dried by radiation and convection from the fire front. The heat released from the flame enables highly volatile compounds, including hydrocarbons, to vaporize from the fuel (Ward and Hardy 1991). Flaming is initiated once an ignition source is present and the fuel-to-oxygen mixture reaches flammable proportions. The flammable vaporized compounds ejected from the surface material must rapidly oxidize to sustain the flame envelope. Chemical reactions during flaming rapidly liberate heat, which preheats adjacent fuels and causes further vaporization of low-vapor-pressure fuels and pyrolysis of solid fuels (Ward 2001). Pyrolysis is defined as a heat-induced chemical alteration of solid fuel. Fire, thus, is a self-sustainable reaction as the initial ignition heating provides the activation energy required for sustained ignition and propagation (Whelan 1995).

Smoldering combustion begins when there are insufficient fuel gases available to maintain the flame envelope. Oxygen must diffuse directly to the fuel surface to maintain combustion. Flaming and smoldering combustion have distinct emissions characteristics, chemical reactions, and Combustion Efficiencies (CEs, see Appendix for list of acronyms). Combustion efficiency is a measure of the oxidation capacity of the reactions and is evaluated by determining the amount of carbon released from the fuel in $\mathrm{CO}_{2}$ form. During idealized complete combustion (i.e., $\mathrm{CE}=100 \%$ ), all organic material is oxidized in the reactions to produce $\mathrm{H}_{2} \mathrm{O}, \mathrm{CO}_{2}$, and heat. A simplified chemical equation for complete simple sugar (D-glucose) combustion is given by

$$
\mathrm{C}_{6} \mathrm{H}_{12} \mathrm{O}_{6}+6 \mathrm{O}_{2} \rightarrow 6 \mathrm{CO}_{2}+6 \mathrm{H}_{2} \mathrm{O}+Q
$$


where $\mathrm{Q}$ is the amount of heat released during the reaction. Chemically, plant material is much more complex, and naturally, complete combustion cannot occur due to oxygen deficiencies; thus, products of incomplete combustion, products that are incompletely oxidized, are formed (i.e., $\mathrm{CO}, \mathrm{CH}_{4}, \mathrm{NH}_{3}$ ).

Combustion efficiencies are generally highest during flaming combustion and depend heavily on oxygen availability. Intense heating from the flame increases turbulent mixing, which advects oxygen into the oxygen-deficient regions. The influences of turbulence on emissions are poorly understood. During smoldering combustion, $\mathrm{CEs}$ decrease and more carbon is released as non- $\mathrm{CO}_{2}$ compounds (i.e., products of incomplete combustion) relative to flaming.

During combustion, $\mathrm{CO}$ and $\mathrm{CO}_{2}$ account for more than $95 \%$ of the carbon released from the biomass (Ward and Hardy 1991). Typically less than $5 \%$ of the carbon is released as Particulate Matter (PM) (Ward et al. 1992; Andreae and Merlet 2001), where PM is defined as solid or liquid particles suspended in the air. Biomass burning produces both solid and liquid particles. The majority of coarse mode PM particles (> 1 $\mu \mathrm{m}$ in diameter) are mechanically produced (Reid et al. 2005). These particles consist of the mechanical break up of plant material, soot, and crustal material lofted due to enhanced turbulence generation.

Fine PM mode ( $<1 \mu \mathrm{m}$ diameter $)$ is divided into two modes: the nuclei-mode and accumulation mode (Winiwarter 2004). Extreme flame temperature causes compounds to vaporize from plant material. Substances with low vapor pressures condense to form nuclei-mode particles with diameters ranging from a few $\mathrm{nm}$ up to $0.1 \mu \mathrm{m}$. These 
particles are quite numerous and act as Condensation Nuclei $(\mathrm{CN})$ for other vaporized compounds; however, nuclei-mode particles account for only a fraction of PM total mass. After formation, nuclei-mode particles begin to grow by agglomeration and condensation into the accumulation mode.

Accumulation mode particles absorb other substances and are regularly found with heavy metals (e.g., Ward and Hardy 1991; Cachier et al. 1995; Lee et al. 2005). Particle formation and content varies depending on the fuel type, CE, oxygen availability, and turbulence to name a few (Radke et al. 1988). For example, Ward (1979) found the oxygen content of the fuel is inversely proportional to PM production. Janhall et al. (2009) found particle mass emissions were strongly dependent on fuel type, but could not establish the same relationship between fuel type and particle number emissions.

Reid et al. (2005) compiled all relevant literature on biomass burning particulates to examine if there was a consensus concerning the size of particulates emitted from fires. Results from numerous studies suggest the properties of particulates are well understood. Although numerous methods were applied in the literature to deduce the size properties of particulates, most reports yielded similar results. Count median diameters of particles in fresh smoke ( $<4$ hours) from biomass burning was determined to be in the $0.1-0.16$ $\mu \mathrm{m}$ range, and the volume median diameters of smoke particles was in the $0.25-0.3 \mu \mathrm{m}$ range.

In most studies larger particle sizes were observed during the smoldering phase of small to moderately sized fires, when CE decreases. It is theorized that a lower fraction of vaporized compounds are able to oxidize, leaving more available to condense 
on CN. During some fires however, larger particles were observed during the flaming stage (Hays et al. 2002), where it is believed that extensive oxygen deprivation prevents fuel gases from oxidizing. Additionally, Reid and Hobbs (1998) demonstrated fire intensity, which is a measure of the heat liberated by combustion, may be as important a parameter as combustion efficiency in determining particle size properties of fresh smoke emissions.

Smoke particles have been shown in the literature to be made up of Particulate Organic Material (POM), Black Carbon (BC) or "soot", and inorganic compounds. From all available data, Reid et al. (2005) found fresh-dry particulate mass consists of about 80 $\%$ POM, 5 - $9 \%$ BC, and 12 - $15 \%$ inorganic material. Additionally, fine-mode particle mass consists of about 50 - $70 \%$ carbon, where about $55 \%$ is Organic Carbon (OC) and about $8 \%$ is BC. Organic carbon is defined as the carbon in POM.

Adverse health effects from PM exposure have been well documented (e.g., Dockery et al. 1993; US EPA 1997; MacNee and Donalson 1999; Pope 2000; Samet et al. 2000). It is estimated 40,000 premature deaths in the US are due to respiratory illness and heart attacks linked to PM exposure (US EPA 1997). Dockery et al. (1993) found a statistically significant increase in the mortality rate between adults living in the most polluted cities as compared with the least polluted. This study was expanded by Pope et al. (1995) by linking ambient pollution data from 151 US cities with greater than 500,000 adults residing in those cities. They used a multivariate analysis to control for smoking, education, and other risk factors and found a positive correlation between mortality and PM exposure. 
Samet et al. (2000) collected PM data from 20 U. S. cities and concluded the estimated increase in the relative death rate from cardiovascular and respiratory causes was $0.68 \%$ for each increase of $10 \mu \mathrm{g} \mathrm{m}^{-3} \mathrm{PM}_{10}$, where $\mathrm{PM}_{10}$ is defined as $\mathrm{PM}$ with aerodynamic diameters $10 \mu \mathrm{m}$ or less. Pope (2000) compiled numerous studies and concluded short-term increases of $10 \mu \mathrm{g} \mathrm{m}^{-3} \mathrm{PM}_{10}$ were associated with $0.5-1.5 \%$ increases in daily mortality.

Particulates with aerodynamic diameters less than $2.5 \mu \mathrm{m}\left(\mathrm{PM}_{2.5}\right)$ cause more damage than larger sized particles because they penetrate deeper into lung tissue (US EPA 1997). Additionally, MacNee and Donalson (1999) suggest most of the adverse health effects from PM exposure are due to ultrafine particles having less than $0.1 \mu \mathrm{m}$ diameters. Although there are many sources of PM (e.g., fossil fuel burning, mechanically generated dust, wood stove burning) wild and prescribed fires generate more than $600,000 \mathrm{Mg}$ of PM per year, which have shown to be damaging to human health and can lead to premature death (US EPA 1995).

The Clean Air Act, last amended in 1990, requires the US Environmental Protection Agency (EPA) to set National Ambient Air Quality Standards (NAAQS) for PM. The EPA $24 \mathrm{~h}$ averaged NAAQS for $\mathrm{PM}_{10}$ is currently $150 \mu \mathrm{g} \mathrm{m}^{-3}$. Since $\mathrm{PM}_{2.5}$ is more damaging to human health than $\mathrm{PM}_{10}$, the standards are stricter. The EPA $24 \mathrm{~h}$ and annual averaged NAAQS for $\mathrm{PM}_{2.5}$ are currently 35 and $15 \mu \mathrm{g} \mathrm{m}^{-3}$, respectively. The US EPA 2001 national emissions inventory suggests that in the US, about $35 \%$ of $\mathrm{PM}_{2.5}$ emissions are from biomass burning (Tian et al. 2009), and these emissions have also been shown to have significant impacts on ambient $\mathrm{PM}_{2.5}$ concentrations (Marmur et al. 
2005). The EPA regularly enforces NAAQS but does not directly regulate the use of fire within individual States (US EPA 1998). States are required to mitigate public health and welfare impacts from prescribed fires. In Georgia, for example, a burn permit must be obtained from the Georgia Forestry Commission (GFC) before a prescribed burn is implemented. Permits are issued by the GFC if meteorological conditions and regional air quality are acceptable.

Liu (2004) used a dataset of historical fire records collected by numerous US governmental agencies to estimate fire emissions over the contiguous US. An effort was made to quantify the spatial and temporal variability of these emissions. Results show both wild and prescribed fire emissions are greatest over the Pacific coastal states. In the southeastern coastal area prescribed fire emissions were greater than wildland fire emissions; however, a major shortcoming in this analysis is the burned-area data obtained only includes burns on federal lands. Burnings on state, private, and department of defense lands are not included; accordingly, there are significant underestimations of southeastern prescribed fire emissions because many prescribed burns in the region are conducted on private land. Moreover, the area held by private parties is much greater than federally owned land area. For example in Georgia, forests cover more than $66 \%$ of total land and more than $92 \%$ of forestland is owned by private parties (Tian et al. 2008).

Tian et al. (2009) used different emission inventories to evaluate impacts of $\mathrm{PM}_{2.5}$ from biomass burning in Georgia, US. Biomass burning data from the Visibility Improvement State and Tribal Association of the Southeast (VISTAS) 2002 inventory and the US EPA 2001 inventory were evaluated. The VISTAS 2002 contains biomass 
burning data from wildfires, prescribed burning, agricultural burning, land clearing, and residential wood combustion, while EPA 2001 contains data from the first four sources only. Biomass consumption in VISTAS 2002 is estimated from burned area records obtained from state and federal agencies. Annual emissions from both inventories were processed to provide hourly gridded emissions. Emissions from biomass burning are nearly equally distributed among the four sources in EPA 2001, while prescribed fire represents about $70 \%$ of all biomass emissions in VISTAS 2002. Again, there is most likely an underestimation in prescribed fire emissions as data from burns on privately held land are not included.

Tian et al. (2009) assessed air quality impacts in January, March, May, and July 2002 with the Community Multiscale Air Quality (CMAQ) model. Domain-averaged impacts from biomass burning emissions contribute 3.0, 5.1, 0.8, $0.3 \mu \mathrm{g} \mathrm{m}{ }^{-3}$ of $\mathrm{PM}_{2.5}$ during January, March, May, and July 2002, respectively. This equates to $25 \%, 40 \%, 9$ $\%$, and $5 \%$ of the total $\mathrm{PM}_{2.5}$ during January, March, May, and July 2002, respectively. Moreover, $\mathrm{PM}_{2.5}$ impacts from prescribed burning dominate total biomass burning impacts. Since prescribed fires are planned by forest managers, steps can be taken to reduce $\mathrm{PM}_{2.5}$ impacts on local and regional air quality.

There are many ways managers can attempt to reduce emissions and impacts from fires. Tian et al. (2008) evaluated how emissions and impacts would change due to the Fire Return Interval (FRI). The FRI is defined as the amount of time between burnings, and an optimal FRI should be employed by managers to mitigate emissions. Emissions from fires with a 5 y FRI are approximately $72 \%$ larger than equivalently-sized fires 
with a 2 y FRI; thus, longer FRIs would reduce long-term regional pollutant concentrations while short FRIs would reduce short-term and local pollutant concentrations. Chances of increased daily $\mathrm{PM}_{2.5}$ levels are higher with longer FRIs but annual averaged impacts would be lower than short FRIs. To adhere to $24 \mathrm{~h}$ NAAQS requires burning more frequently (i.e., smaller FRIs).

Southeastern prescribed burns are typically carried out in winter and spring, when fires are more easily controlled (Whelan 1995; Tian et al. 2008). From 1994 to 2005 prescribed fires consumed 0.86 million acres on average in Georgia, where about $86 \%$ of these fires were scheduled between December and April. Most fires $(\approx 37 \%)$ occurred in March (Tian et al. 2008). Burning during summer is less common due to increased atmospheric instability.

Tian et al. (2008) used VISTAS 2002 in conjunction with CMAQ to evaluate 2002 historical air quality conditions. Emissions calculated during March 2002 were applied to January, May, and July 2002 to evaluate seasonal-influences on impacts from fires. Impacts were observed to decrease from January to July, most likely due to increased instability and vertical mixing. Additionally, an increased number of thunderstorms during summer months reduce impacts by increasing ventilation and pollution rainout.

Since managers can choose in which season to burn, evaluating the optimal burning season to mitigate emissions and impacts is crucial. The two major southeastern seasonal impacts are the change in atmospheric dispersion and fuel conditions. Korontzi et al. (2003) found seasonal emission factors, for African savanna fires, correlate linearly 
with fuel moisture content. Emissions factors for products of incomplete combustion were higher when fuels were greener. During summer months in the southeast, the growing season, fuel moisture contents are higher compared to winter. Tian et al. (2008) do not incorporate the influence of fuel moisture content on emissions, but point out higher fuel moisture contents lead to less fuel consumption and increased incomplete combustion. Since emissions depend on the amount of fuel consumed and amount of pollutants produced, Tian et al. (2008) point out emissions could either increase or decrease; therefore, seasonal influences on emissions from southeastern prescribed fires must be quantified to answer these questions.

Whereas previous studies have evaluated emissions from prescribed fire, this study will focus on effects of seasonal-related variations and of turbulence generation on emissions and concentration impacts utilizing in situ data. 


\section{Methodology}

In this study, effects of seasonal-related variations and turbulence generation on emissions and impacts from prescribed fires were evaluated. High frequency in situ data were obtained from three summer (July 2008) and three winter (January 2009) fires within the active burn perimeter using a $10 \mathrm{~m}$ instrumented flux tower at the Joseph $\mathrm{W}$. Jones Ecological Research Center at Ichauway, Georgia. Permits were obtained from the GFC prior to each burn, and the Ichauway burn crew allowed us to monitor air quality and meteorology during each burn.

Data obtained using the Moderate Resolution Imaging Spectroradiometer (MODIS) suite have recently been used to estimate biomass burning emissions; however, no fires during this experiment were detected by MODIS although fire sizes were orders of magnitude larger than the minimum needed for detection. Most prescribed fires in Southeast long-leaf pine (Pinus palustris) forests consume understorey fuels (e.g., grass, live shrubs, and needles) with little to no tree scorch, and are not easily detected by remote sensing techniques; thus, in situ measurements are utilized to quantify turbulence, which cannot be ascertained by space-borne instruments, and seasonal influences on emissions from prescribed fire.

\section{a. Instrumentation}

Three wind components (u, v, and w) and temperature were sampled at $10 \mathrm{~Hz}$ using a 3D ultrasonic anemometer (R. M. Young 81000) and type e fine-wire thermocouples (Omega, Inc.), respectively. Data have been effectively collected from prescribed fires using sonic anemometers and represent a practical method, given 
inherent errors, to observe atmospheric motions on small time scales (Clements et al. 2006, 2007). Tower configuration followed that used by Clements et al. $(2006,2007)$ where the sonic anemometry and gas analyzers are mounted on a cross arm pointed towards the upwind direction of the tower (Fig. 1).

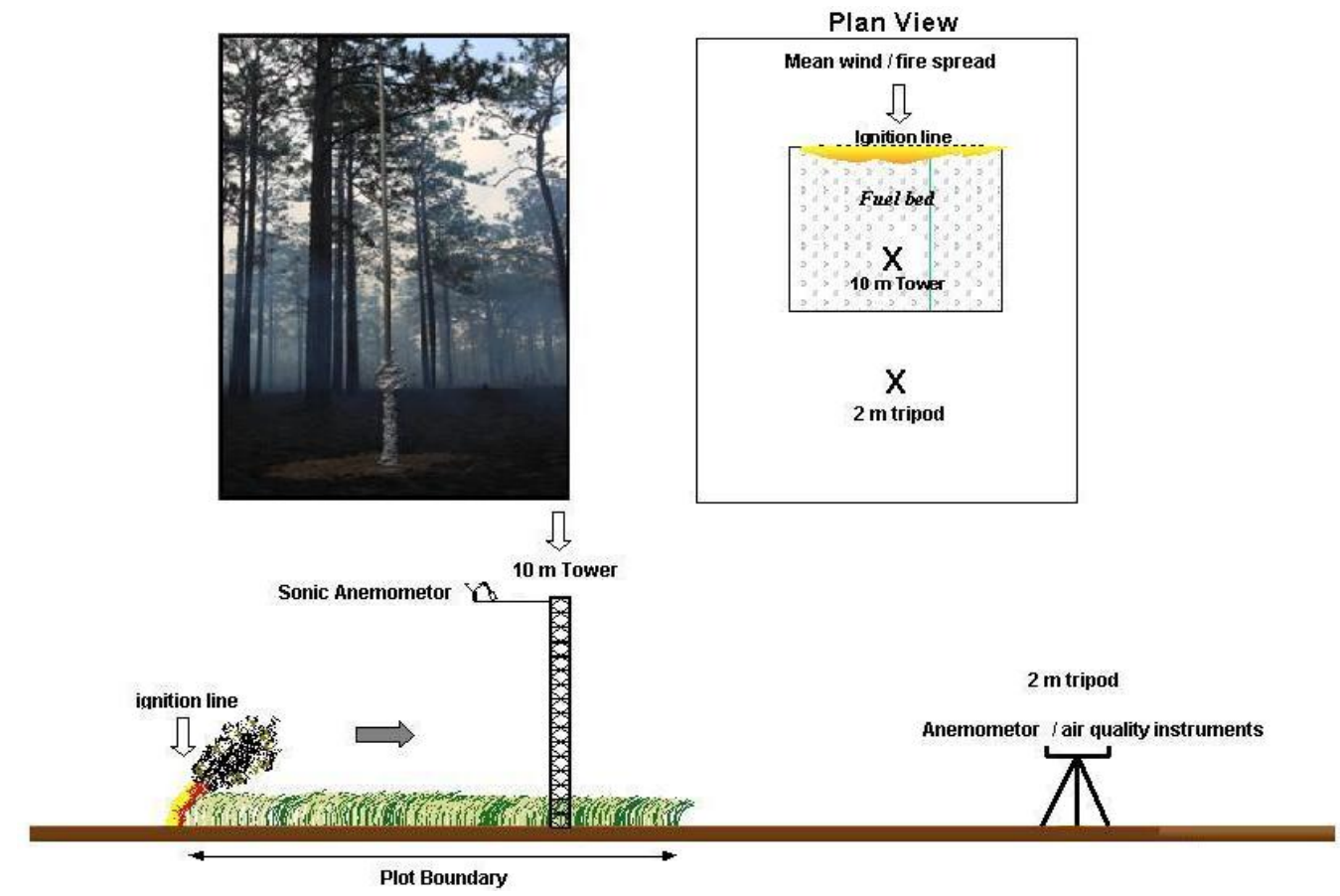

Fig. 1. Schematic drawing of tower configuration and experimental design. A photograph of the interior $10 \mathrm{~m}$ tower following the first burn on 15 July 2008 is shown in the upper left.

Linking emissions to turbulence required use of quick-response air quality sensors. All interior-tower (hereafter referred to as tower) instruments were placed $10 \mathrm{~m}$ AGL. Concentrations of $\mathrm{PM}_{2.5}$ were made with the DUSTTRAK (model 8520, TSI) aerosol monitor. Prior to each burn, the DUSTTRAK was calibrated and fitted with a cyclone impactor to screen out large particles $(>2.5 \mu \mathrm{m})$. The DUSTTRAK converts 
scattered light into mass concentrations every $1 \mathrm{~s}$; however, scattered light is dependent on particle size and is most dramatic for particles with diameters less than $0.25 \mu \mathrm{m}$. In addition, count median diameters of particles in fresh smoke ( $<4$ hours) from biomass burning are typically in the $0.1-0.16 \mu \mathrm{m}$ range (Reid et al. 2005). As a consequence, DUSTTRAK derived concentrations may have some degree of error.

Carbon dioxide was sampled using a robust, open-path infrared sensor (Vaisala, Inc. GMP343 probe). The Vaisala probe has a wide temperature operating range and temporal resolution of $5 \mathrm{~s}$. Carbon monoxide was sampled with the Onset HOBO H11001 logger (hereafter referred to as $\mathrm{HOBO}$ ). The HOBO has three operating channels, each of which having unique degrees of resolution and accuracy. Channel 1 covers CO concentrations from $0.2-124.3 \mathrm{ppm}$ with $0.5 \mathrm{ppm}$ resolution, while Channel 2 operates from $1-497.1 \mathrm{ppm}$ with $2 \mathrm{ppm}$ resolution. The $\mathrm{HOBO}$ operated in both channels allowing for a wider dynamic range without sacrificing resolution. Relatively small number of data fell outside the highest quality range (channel 1), and data from channel 2 were substituted in these instances. Channel $1 \mathrm{HOBO}$-accuracy is typically within \pm 4.5 ppm and there may be an additional error that increases as temperatures increase above $20{ }^{\circ} \mathrm{C}$. Although $\mathrm{HOBO}$ data most likely contain an absolute error, the HOBO performed well and was able to provide high-frequency measurements. The response time of the instrument was much better than indicated in the instrument manual and is most likely on the order of about $1 \mathrm{~min}$. 
A R. M. Young 05103-5 wind monitor was also installed $10 \mathrm{~m}$ AGL on the tower. This provided wind speed and direction measurements used to verify R. M. Young 81000 ultrasonic anemometer data.

During the three winter burns an additional air quality sensor was tower-mounted: a Magee Scientific Aethalometer (microAeth AE51). The AE51 is small and lightweight (250 g) and provided BC concentration measurements every $1 \mathrm{~s}$. Measurement range, resolution, and precision are $0-1 \mathrm{mg} \mathrm{BC} \mathrm{m}^{-3}$ for 15 min sampling period at $50 \mathrm{~mL} \mathrm{~min}{ }^{-1}$ flow rate, $0.001 \mu \mathrm{g} \mathrm{m}^{-3}$, and $\pm 0.100 \mu \mathrm{g} \mathrm{m}^{-3}$ for 1 min averages at $150 \mathrm{~mL} \mathrm{~min}^{-1}$ flow rate, respectively.

The downwind receptor site consisted of a $2 \mathrm{~m}$ tripod, and was placed directly downwind of each burn-unit (hereafter referred to as unit) to assess plume particle concentrations and meteorological conditions. On the tripod, a Campbell Scientific, Inc. temperature and relative humidity probe (CS215), and R. M. Young 05103-5 anemometer were deployed to assess meteorological conditions, while HOBO (H11-001), DUSTTRAK (model 8520, TSI), and Magee Scientific Aethalometor instruments evaluated air quality. A cyclone impactor was installed on the Aetholometor inlet to screen out particles greater than $2.5 \mu \mathrm{m}$ to evaluate $\mathrm{BC}_{2.5}$ concentrations. Prior to, during, and after each prescribed fire, atmospheric profiles were obtained using the Graw, Inc. DFM-06 radiosonde system. This provided a high vertical resolution dataset of boundary layer and lower tropospheric meteorological structure that determines local dispersion, plume transport, and plume heights. 


\section{b. Burn Implementation}

Three summer burns were conducted between 15 - 17 July 2008, and represented typical burning conditions for southeastern growing season fires (Fig. 2). Three winter fires, representing winter burn conditions, were performed from 12 - 14 January 2009 (Fig. 3). The fuel during summer consisted of more live-green vegetation indicative of greater moisture content than winter vegetation. Data were collected from over 1300 acres of fire consumption during ideal burning conditions at the Joseph W. Jones Ecological Research Center at Ichauway, Georgia (Fig. 4).

Fuel loadings of pine needles, grass fuels and shrub biomass were measured pre and post burn in all units. Consumption was estimated through clipping and weighing pre and post burn samples (Table 1). 


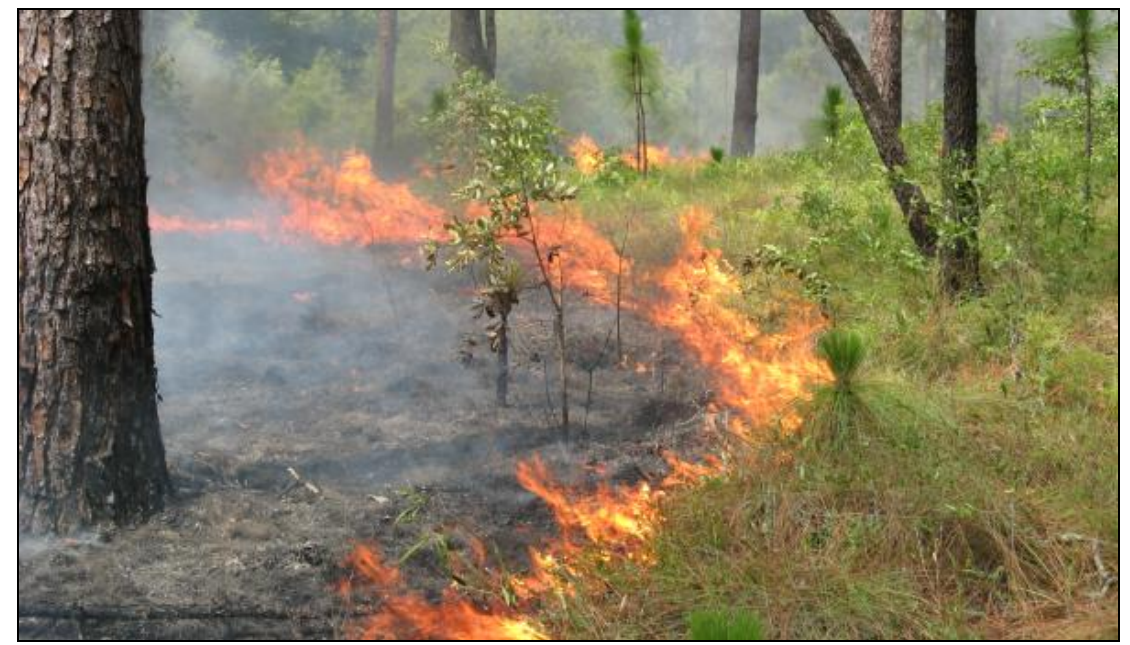

Fig. 2. Photograph of moist wiregrass fuel and backing fire front on 16 July 20081045 EST.

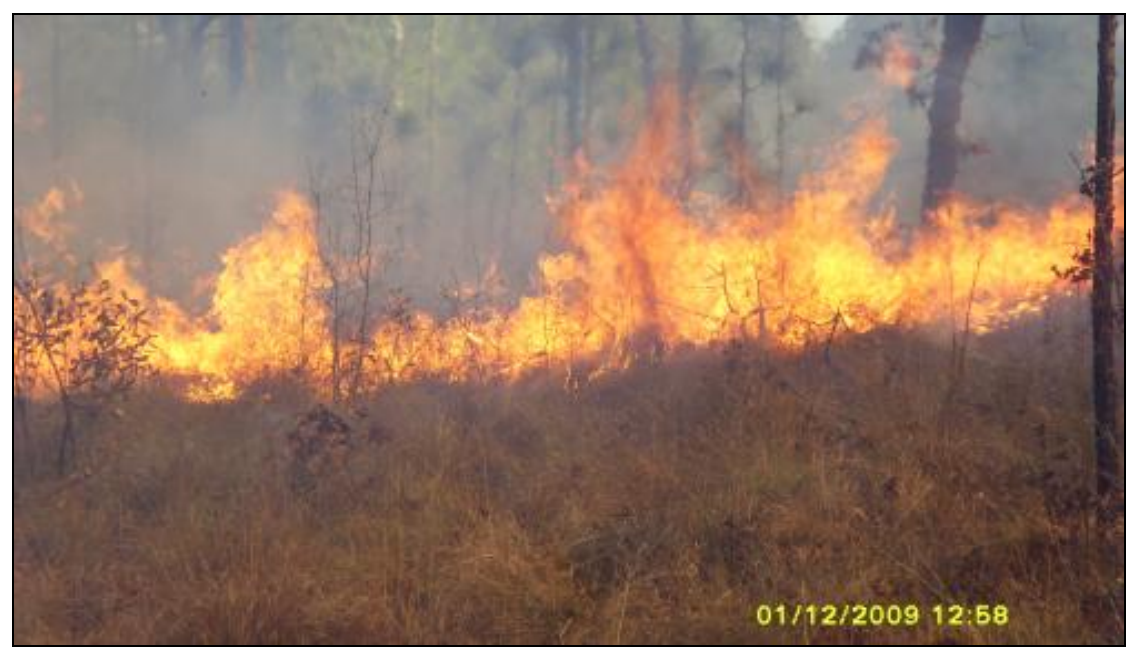

Fig. 3. Photograph of dry wiregrass fuel and fire front on 12 January 20091258 EST. 


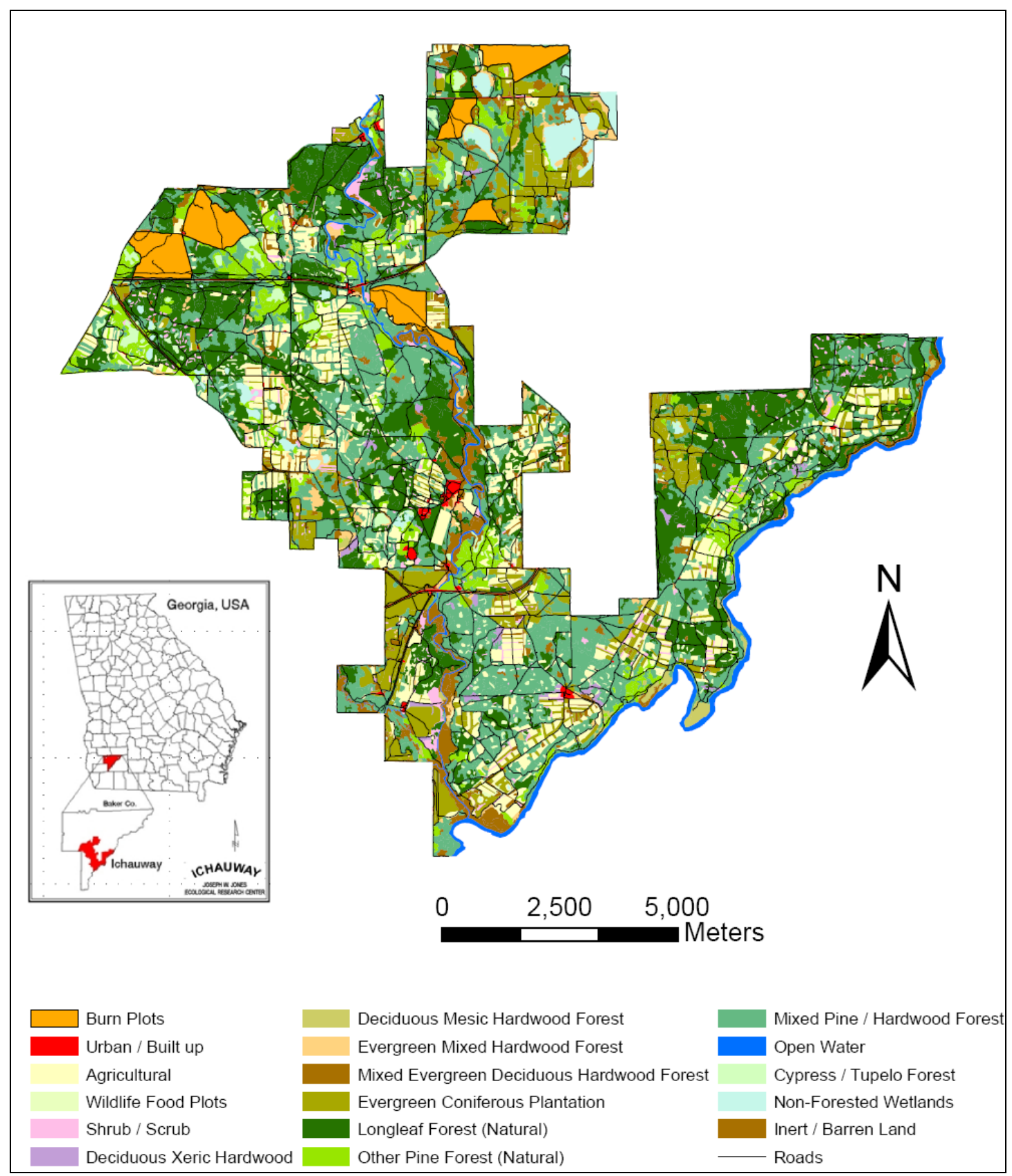

Fig. 4. Joseph W. Jones Ecological Research Center at Ichauway, Georgia land-cover map. Units considered in this study are presented in the orange fill. 
Table 1. Select fuel and fire characteristics of 2008 and 2009 experimental burns.

\begin{tabular}{cccc}
\hline Burn Date & Unit Size (acres) & Loading (tons/acre) & $\begin{array}{c}\text { Consumption } \\
\text { (tons/acre) }\end{array}$ \\
\hline $7 / 15 / 2008$ & 218 & 3.15 & 2.02 \\
$7 / 16 / 2008$ & 105 & 3.36 & 2.19 \\
$7 / 17 / 2008$ & 110 & 2.61 & 1.31 \\
$1 / 12 / 2009$ & 260 & 2.72 & 0.85 \\
$1 / 13 / 2009$ & 261 & 3.11 & 1.81 \\
$1 / 14 / 2009$ & 257 & 3.60 & 1.90 \\
\hline
\end{tabular}

A handheld GPS unit was used to obtain instrument coordinates and ESRIArcGIS software was utilized to visualize these locations. Experimental designs and instrument locations for data collected during three summer fires on the 15,16 , and 17 July 2008 are shown in Fig. 5a, b, and c, respectively. Experimental designs for data collected during three winter fires on the 12, 13, and 14 January 2009 are shown in Fig. $5 \mathrm{~d}$, e, and f, respectively. 


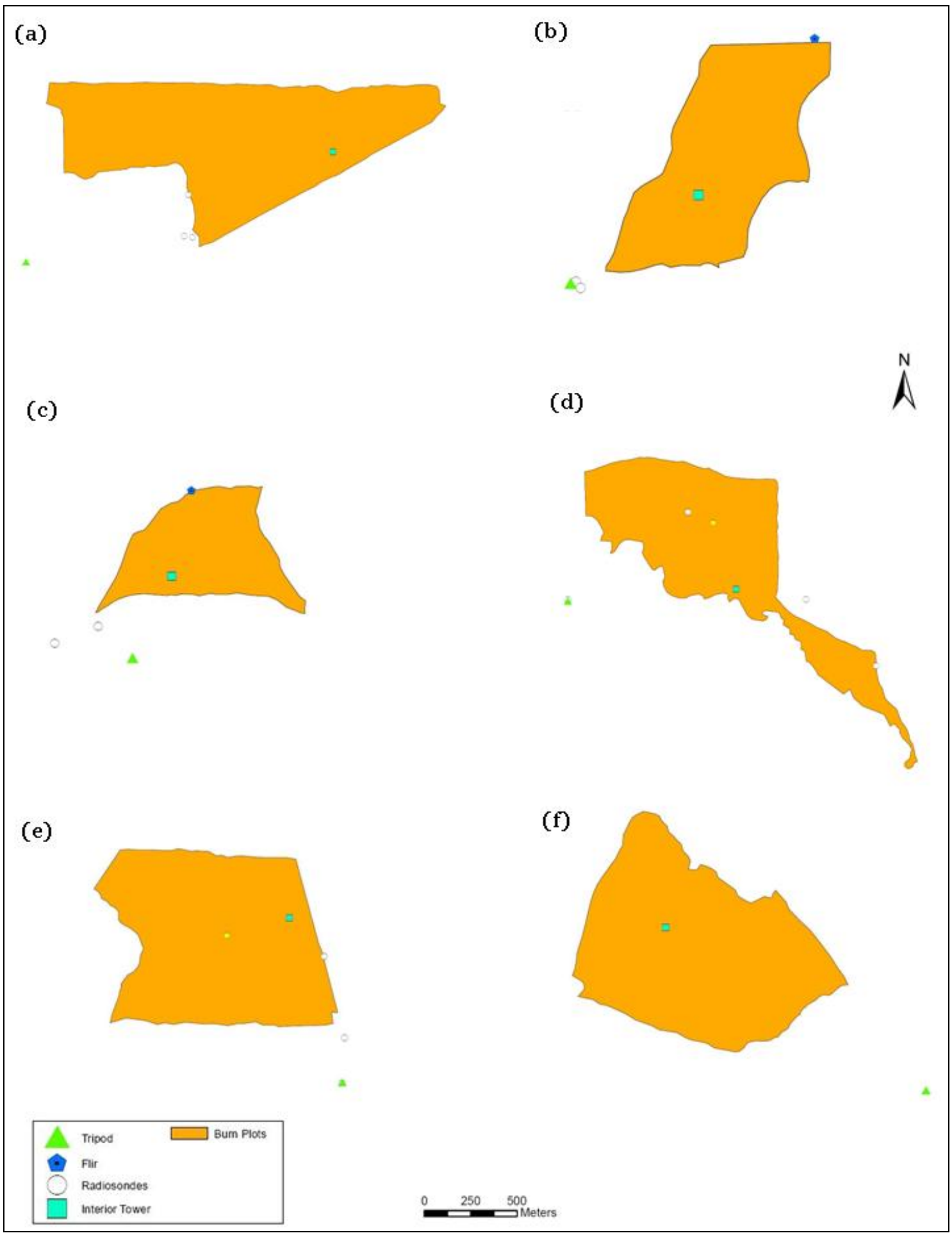

Fig. 5. Experimental designs and instrument locations for data collected during three summer fires on the 15 (a), 16 (b), and 17 (c) July 2008, and during three winter fires on the 12 (d), 13 (e), and 14 (f) January 2009. 
Each burn was implemented in a systematic fashion. Burn crews first evaluated the prevailing wind direction and proceeded to ignite the unit along the downwind edge. A backing fire was initiated and slowly progressed into the wind. After a substantial blackline had developed, the crew moved upwind, approximately $50 \mathrm{~m}$, and ignited a line perpendicular to the wind direction. This created a short-lived head fire that propagates with the wind towards previously consumed fuels. For these burns, in situ data were collected at the tower, placed directly in the fuel bed, as a head fire propagates towards, under, and past the tower. A small area around the tower was cleared of fuel to prevent instrument damage. Adequate time was allowed to pass before the fire crew ignited further upwind allowing data collection during the smoldering stage. Once fire is set further upwind, the tower becomes a downwind receptor, and subsequent data collected represents a mixture from both flaming and smoldering combustion.

Prior to ignition, the two $\mathrm{m}$ tripod was placed directly downwind $(150-900 \mathrm{~m})$ of the unit (Table 2). It proved difficult to maintain an equivalent distance downwind for all burns as a truck was required to transport equipment. This limited possible tripod location choices, as the tripod needed to be placed near established-passable roads. During each burn, trucks were prohibited from driving upwind and near the tripod as this would contaminate the particulate data. 
Table 2. Distance along mean wind direction observed during the burn duration from the most downwind edge of the unit to the tripod.

\begin{tabular}{cc}
\hline Date & Distance downwind $(\mathbf{m})$ \\
\hline $7 / 15 / 2008$ & 880 \\
$7 / 16 / 2008$ & 150 \\
$7 / 17 / 2008$ & 230 \\
$1 / 12 / 2009$ & 300 \\
$1 / 13 / 2009$ & 400 \\
$1 / 14 / 2009$ & 700 \\
\hline
\end{tabular}

\section{c. Data Processing}

Data were collected on numerous data loggers. Prior to each burn, all data logger clocks were synchronized as close to US official Eastern Standard Time (EST) as possible. Data were downloaded and stored following each burn for processing. If a data logger clock was not properly aligned to EST during an experiment, the data were synchronized during processing.

Ultrasonic anemometers were manually leveled in the horizontal and vertical plane; however, Dyer (1981) points out small alignment errors can cause large momentum flux errors due to cross contamination of velocities. To correct possible errors due to alignment issues, the $10 \mathrm{~Hz} \mathrm{u}, \mathrm{v}$, and w wind components were tilt-corrected using a planar fit technique described in detail by Wilczak et al. (2001). 
High-frequency turbulent measurements are subject to short-duration, largeamplitude fluctuations, defined as spikes. Spikes result from natural phenomenon or instrument noise and error. A quality control procedure is required to flag and remove data spikes (Brock 1985; Lee et al. 2004). Spikes are defined as points larger than four times the Standard Deviation (SD) of the time series. Lee et al. (2004) recommends processing high-frequency turbulence time series two to three times to flag and remove spikes. Usually, each point is tested against four times the SD of the time series. This approach proved inadequate for turbulence data gathered during a fire front passage, as fire generates turbulence significantly above background levels; thus, an algorithm was developed specifically for this dataset.

The algorithm calculates the SD of two min segment (1 200 points) and tests each point within the segment. Points greater than four times the segment-SD are characterized as spikes. A thorough visual and mathematical inspection is conducted to ensure points flagged by the algorithm are most likely instrument noise. Spikes are replaced with the mean value of the ten points preceding and following. The process is conducted three times to ensure erroneous spikes are removed.

Turbulent components of the flow were calculated by

$$
\begin{gathered}
u^{\prime}=U-\bar{U} \\
v^{\prime}=V-\bar{V} \\
w^{\prime}=W-\bar{W},
\end{gathered}
$$


where $\mathrm{u}^{\prime}, \mathrm{v}^{\prime}, \mathrm{w}^{\prime}$ are turbulent components of the flow, $\bar{U}, \bar{V}, \bar{W}$ are 30 min mean velocities, and U, V, W are tilt-corrected-despiked instantaneous velocities (Stull 1988). Variances were calculated using turbulent components and fluxes were calculated from one min averaged covariances (Clements et al. 2006, 2007).

Turbulent Kinetic Energy (TKE) is defined as the mean kinetic energy of eddies in turbulent flow per unit mass, and is given by

$$
T K E=\frac{1}{2}\left(\overline{u^{\prime 2}}+\overline{v^{\prime 2}}+\overline{w^{\prime 2}}\right)
$$

where $\overline{u^{\prime 2}}, \overline{v^{\prime 2}}$, and $\overline{w^{\prime 2}}$ represent one min mean velocity variances. A one min TKE time series was produced for each burn to evaluate turbulent energy production and if a relationship between TKE generation and emissions exists.

\section{d. Emissions}

Tower concentration data of $\mathrm{PM}_{2.5}, \mathrm{CO}_{2}$, and $\mathrm{CO}$ were averaged to one min. Data collected during the flaming and smoldering stage of the fire were separated to evaluate the difference in emissions from flaming and smoldering combustion (Table 3), where the data separation for all burns from the flaming and smoldering stage is shown Fig. 6 . 
Table 3. Start and end times (EST) of flaming and smoldering stage emissions for all burns.

\begin{tabular}{ccccc}
\hline & \multicolumn{2}{c}{ Flaming Stage } & \multicolumn{2}{c}{ Smoldering Stage } \\
\hline Date & Start & End & Start & End \\
\hline $7 / 15 / 2008$ & 1241 & 1244 & 1245 & 1254 \\
$7 / 16 / 2008$ & 1043 & 1053 & 1054 & 1112 \\
$7 / 17 / 2008$ & 908 & 914 & 915 & 940 \\
$1 / 12 / 2009$ & 1226 & 1228 & 1233 & 1238 \\
$1 / 13 / 2009$ & 1220 & 1223 & 1224 & 1234 \\
$1 / 14 / 2009$ & 1359 & 1405 & 1400 & 1414 \\
\hline
\end{tabular}



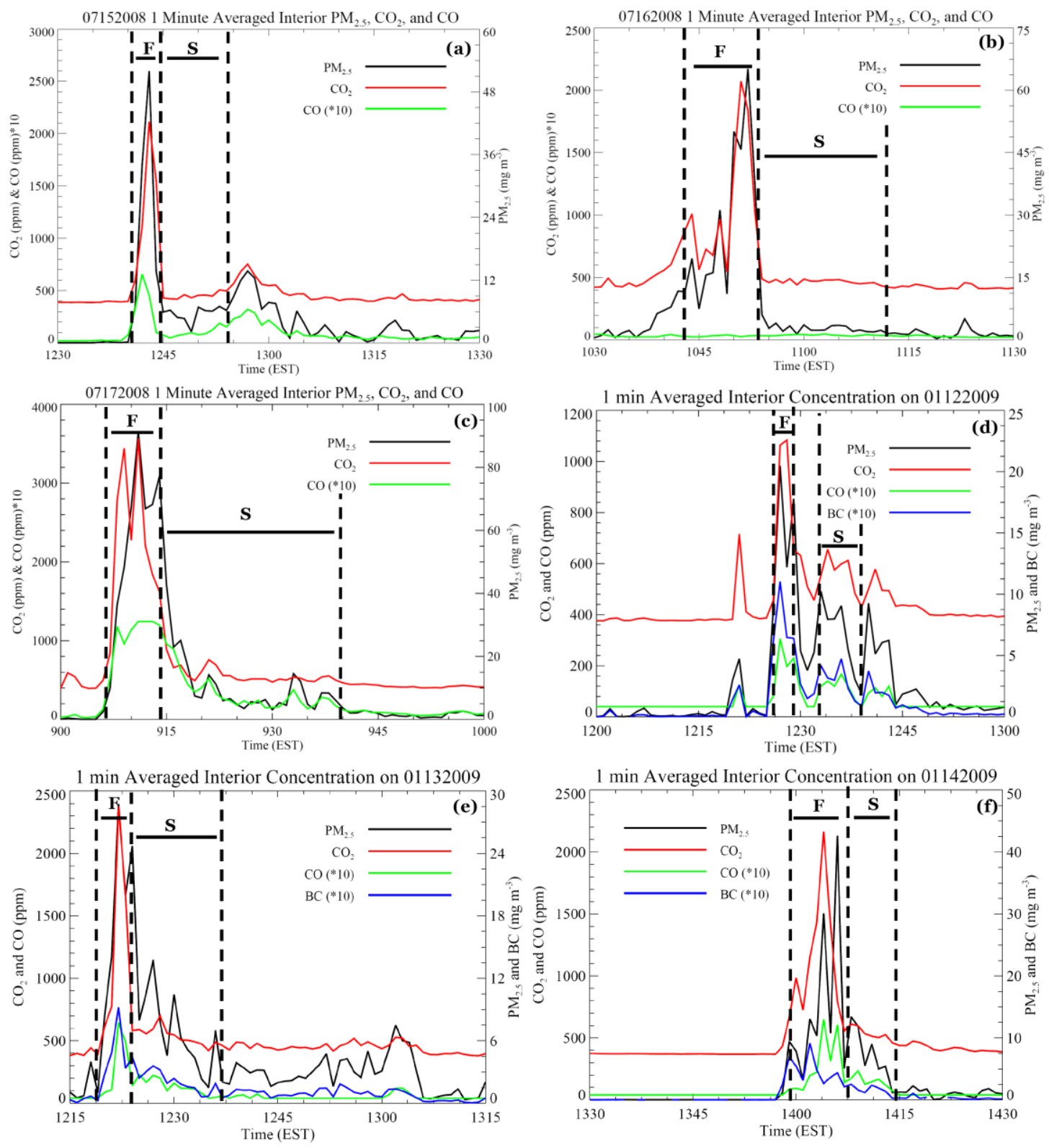

Fig. 6. One min average concentration data on the 15 (a), 16 (b), and 17 (c) July 2008, and on the 12 (d), 13 (e), and 14 (f) January 2009. The dashed lines indicate where the data were separated from flaming stage emissions $(\mathrm{F})$, and smoldering stage emissions

$(\mathrm{S})$. 
To characterize emissions from each fire, in situ data were used to calculate Emission Factors $(\mathrm{EFs})$ during the flaming $\left(\mathrm{EF}_{\mathrm{f}}\right)$ and smoldering stage $\left(\mathrm{EF}_{\mathrm{s}}\right)$. This calculation (Andreae and Merlet 2001) is given by

$$
E F_{x} \cong \frac{\left[\Delta C_{x}\right]}{\sum\left(\left[\Delta C_{C O_{2}}\right]+\left[\Delta C_{C O}\right]+\left\{\left[\Delta C_{C O_{2}}\right]+\left[\Delta C_{C O}\right]\right\}^{* 0.025)}\right.}[C]_{b},
$$

where $\Delta \mathrm{C}_{\mathrm{x}}$ is the concentration in the plume minus the ambient concentration for species $\mathrm{x}\left(\mathrm{g} \mathrm{m}^{-3}\right),[\mathrm{C}]_{\mathrm{b}}$ is the carbon content of the fuel ( $\mathrm{g}$ carbon $/ \mathrm{kg}$ fuel consumed), and $\left\{\left[\Delta \mathrm{C}_{\mathrm{CO} 2}\right]+\left[\Delta \mathrm{C}_{\mathrm{CO}}\right]\right\} * 0.025$ is a conservative factor representing non- $\mathrm{CO}_{2}$ and $\mathrm{CO}$ carbon emissions [e.g., hydrocarbons $\left(\mathrm{CH}_{4}\right)$, elemental and black carbon (Andreae and Merlet 2001; Ward and Hardy 1990)]. The mean pollutant concentrations observed before the fire were used to characterize ambient concentrations.

Since the fuel was determined to consist of $50 \%$ carbon by weight, the carbon content of the fuel $\left([\mathrm{C}]_{\mathrm{b}}\right)$ used was 0.5 . Instantaneous fuel consumption was calculated by

$$
W_{v}=\frac{\sum C_{n}}{[C]_{b}}
$$

where $\mathrm{W}_{\mathrm{v}}$ is the amount of fuel consumed $\left(\mathrm{g} \mathrm{m}^{-3}\right), \mathrm{C}$ the carbon fraction of emissions, and $\mathrm{n}$ represents the various species emitted containing carbon (Hardy et al. 1996). 
Calculation of the instantaneous fuel consumption was required to evaluate the effective $\mathrm{EF}\left(\mathrm{EF}_{\mathrm{t}}\right)$, which represents emissions during the fire duration (i.e., total fire). This was achieved using a weighted averaged procedure given by

$$
E F_{t_{j}}=\frac{\overline{E F_{f_{j}}} * \sum W_{f}+\overline{E F_{s_{j}}} * \sum W_{s}}{\sum W_{f}+\sum W_{s}},
$$

where $\overline{E F_{f}}$ is the mean EF during the flaming stage, $\overline{E F_{s}}$ the mean EF during smoldering, $\Sigma \mathrm{W}_{\mathrm{f}}$ fuel consumed during flaming, $\Sigma \mathrm{W}_{\mathrm{s}}$ fuel consumed during smoldering, and $\mathrm{j}$ is the species evaluated (Hardy et al. 1996).

The mean $\mathrm{EFs}_{\mathrm{f}}, \mathrm{EFs}_{\mathrm{s}}$, and $\mathrm{EFs}_{\mathrm{t}}$ for each burn were evaluated. To evaluate the precision and uncertainty of the means, the Standard Error (SE) of the means was calculated. The SE depends on the sample size, $\mathrm{N}$, and the standard deviation of the sample, and decreases with increasing N. Since the EFs were found to be autocorrelated, the number of independent observations is fewer than $\mathrm{N}$. The autocorrelations were found to be first-order (dependence on a time lag of one only) such that the effective sample size, $\mathrm{N}^{\prime}$, can be calculated by

$$
N^{\prime}=N \frac{\left(1-r_{1}\right)}{\left(1+r_{1}\right)},
$$


where $r_{1}$ is the first-order autocorrelation coefficient (WMO 1966). Accounting for autocorrelation, the SE is then calculated by

$$
S E=\frac{\sigma}{\sqrt{N^{\prime}}},
$$

where $\sigma$ is the standard deviation of the sample. A schematic diagram is presented in Fig. 7, which shows the process used to derive the EFs.

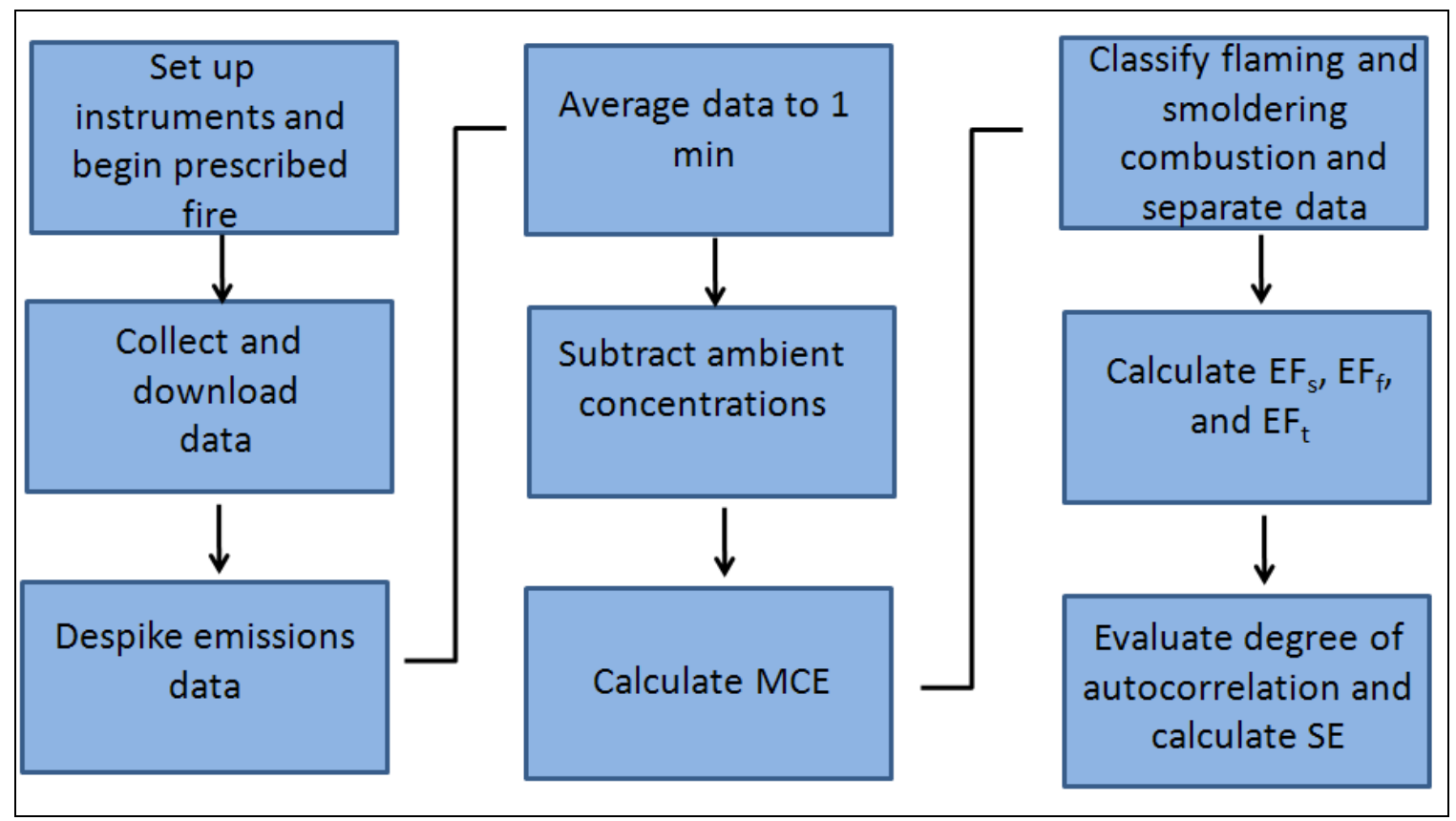

Fig. 7. Schematic diagram of the process used to evaluate the EFs for each prescribed burn. 


\section{Results}

\section{a. Modified Combustion Efficiency}

The instantaneous Modified Combustion Efficiency (MCE) for each case was evaluated by

$$
M C E \equiv \frac{\Delta C_{\mathrm{CO}_{2}}}{\Delta C_{\mathrm{CO}_{2}}+\Delta C_{\mathrm{CO}}} * 100 \%
$$

a measure of fire efficiency (Ward and Radke 1993). The MCEs were evaluated during smoldering $\left(\mathrm{MCE}_{\mathrm{s}}\right)$, flaming $\left(\mathrm{MCE}_{\mathrm{f}}\right)\left(\right.$ Fig. 8), and for the effective fire $\left(\mathrm{MCE}_{\mathrm{t}}\right)($ Table 4). The MCEs observed during the winter were much less variable than MCEs observed during summer. Less efficient combustion produces relatively more products of incomplete combustion. The summer mean $\mathrm{MCE}_{\mathrm{t}}$ was $94.4 \pm 0.7 \%$ and the winter mean $\mathrm{MCE}_{\mathrm{t}}$ was $97.1 \pm 0.7 \%$. The difference between the summer and winter mean $\mathrm{MCE}_{\mathrm{t}}$ was found to be statistically significant to the $95 \%$ confidence interval and suggests winter fires were more efficient in oxidizing the carbon contained in the fuel such that increased emissions of $\mathrm{CO}_{2}$ and decreased emissions of $\mathrm{CO}$ and $\mathrm{PM}_{2.5}$ should be observed compared to summer. 


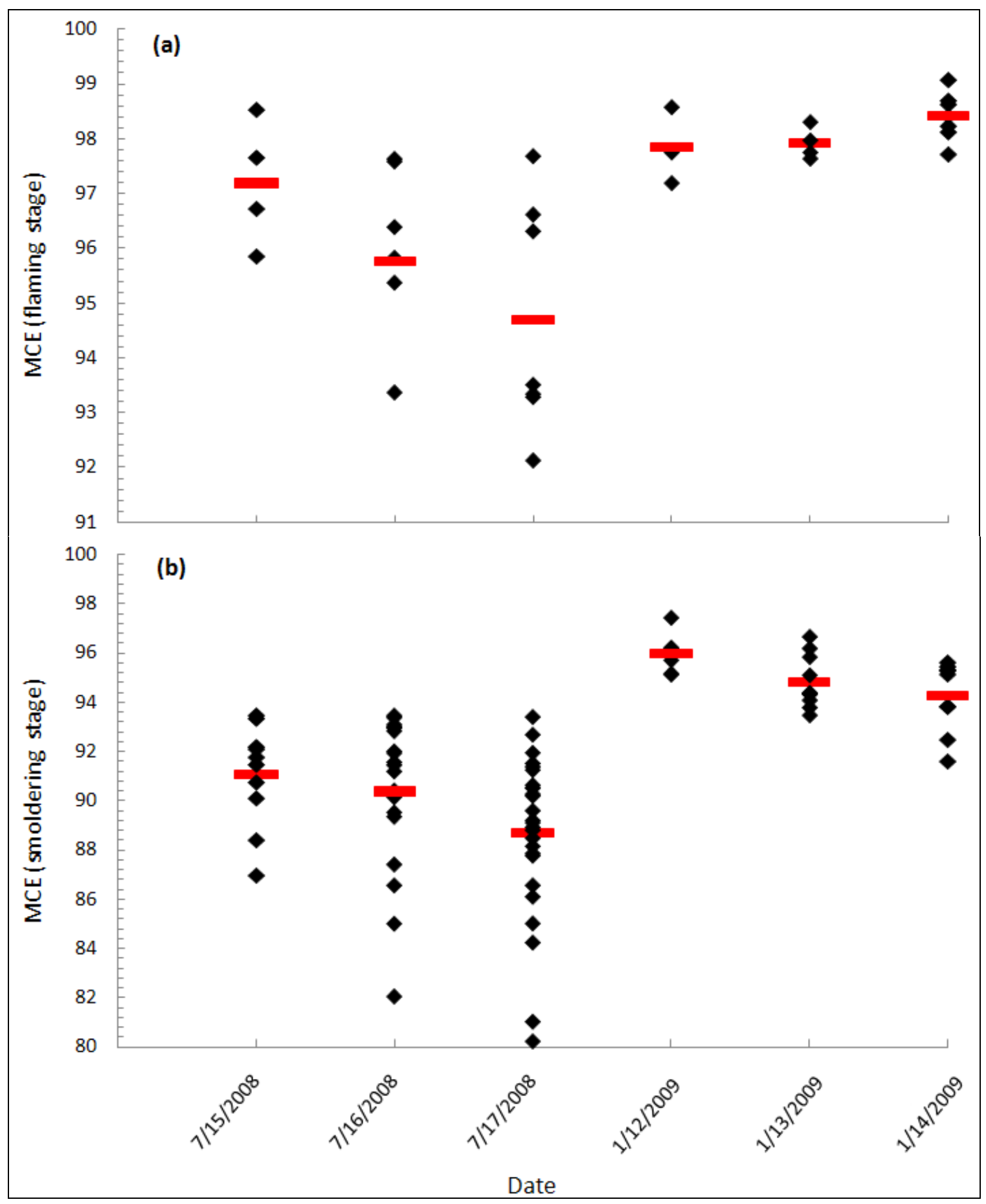

Fig. 8. Flaming (a) and smoldering (b) MCEs during all burns. The red line indicates the mean of the calculated MCEs. 
Table 4. Summer and winter Modified Combustion Efficiency (MCE). MCE*

\begin{tabular}{cccc}
\hline Date & MCE $_{\mathbf{f}}$ & MCE $_{\mathbf{s}}$ & $\mathbf{M C E}_{\mathbf{t}}$ \\
\hline $7 / 15 / 2008$ & $97.2 \pm 0.9$ & $91.1 \pm 1.0$ & $96.3 \pm 0.9$ \\
$7 / 16 / 2008$ & $95.8 \pm 0.7$ & $90.4 \pm 1.1$ & $94.9 \pm 0.7$ \\
$7 / 17 / 2008$ & $94.7 \pm 1.4$ & $88.7 \pm 1.1$ & $93.2 \pm 1.3$ \\
Summer & $\mathbf{9 5 . 7} \pm \mathbf{0 . 7}$ & $\mathbf{8 9 . 7} \pm \mathbf{0 . 7}$ & $\mathbf{9 4 . 4} \pm \mathbf{0 . 7}$ \\
$1 / 12 / 2009$ & $97.8 \pm 0.7$ & $96.0 \pm 0.6$ & $97.0 \pm 0.7$ \\
$1 / 13 / 2009$ & $97.9 \pm 0.3$ & $94.8 \pm 0.7$ & $96.8 \pm 0.4$ \\
$1 / 14 / 2009$ & $98.4 \pm 0.3$ & $94.3 \pm 0.9$ & $97.4 \pm 0.4$ \\
Winter & $\mathbf{9 8 . 1} \pm \mathbf{0 . 3}$ & $\mathbf{9 4 . 9} \pm \mathbf{0 . 4}$ & $\mathbf{9 7 . 1} \pm \mathbf{0 . 3}$ \\
\hline
\end{tabular}

* Values are means \pm one SE

\section{b. Emissions}

One min averaged tower $\mathrm{PM}_{2.5}, \mathrm{CO}_{2}, \mathrm{CO}$, and $\mathrm{BC}$ concentrations, tripod $\mathrm{PM}_{2.5}$, $\mathrm{CO}$, and $\mathrm{BC}_{2.5}$ concentrations, and wind speed and direction measured during the fire front passage on the 15, 16, and 17 July 2008 are presented in Figs. 9, 10, and 11, respectively. The fire front passage is clearly seen in all tower time series as concentration of all species sharply increases. Data obtained during this brief period represent the flaming stage of combustion when MCEs are largest. Data were also obtained during the smoldering stage when MCE decreases. The segregation of data 
between flaming and smoldering stages was confirmed using temperature, TKE, and MCE observed at the tower.

Similarly, one min averaged tower $\mathrm{PM}_{2.5}, \mathrm{CO}_{2}, \mathrm{CO}$, and $\mathrm{BC}$ concentrations measured during fire front passage on 12, 13, and 14 January 2009 are presented in Figs. 12,13 , and 14, respectively.
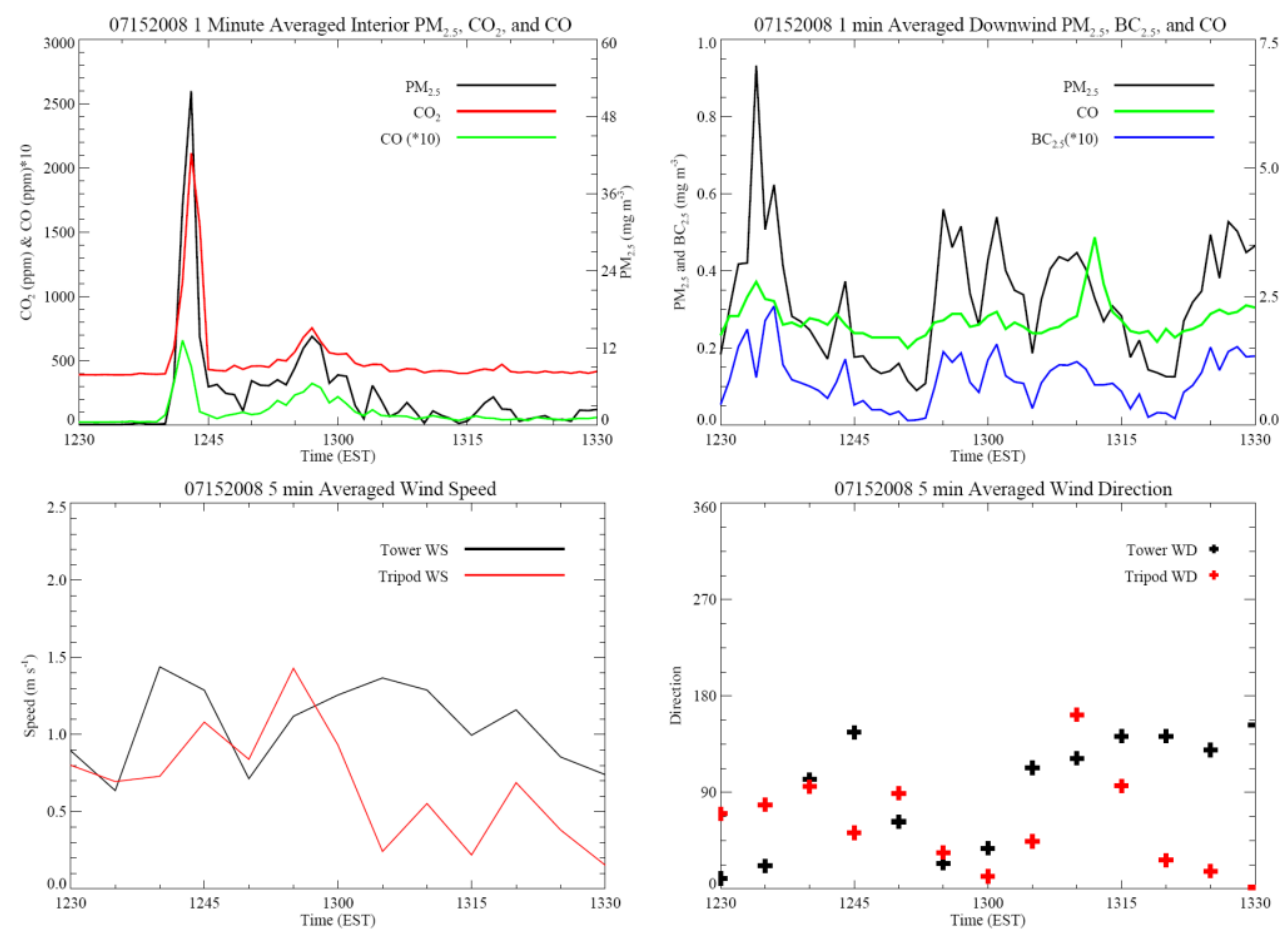

Fig. 9. One min averaged tower $\mathrm{PM}_{2.5}, \mathrm{CO}_{2}, \mathrm{CO}$, and $\mathrm{BC}$ concentrations, tripod $\mathrm{PM}_{2.5}$, $\mathrm{CO}$, and $\mathrm{BC}_{2.5}$ concentrations, and tower and tripod wind speed and direction measured during hour when fire front moved passed tower on 15 July 2008. 

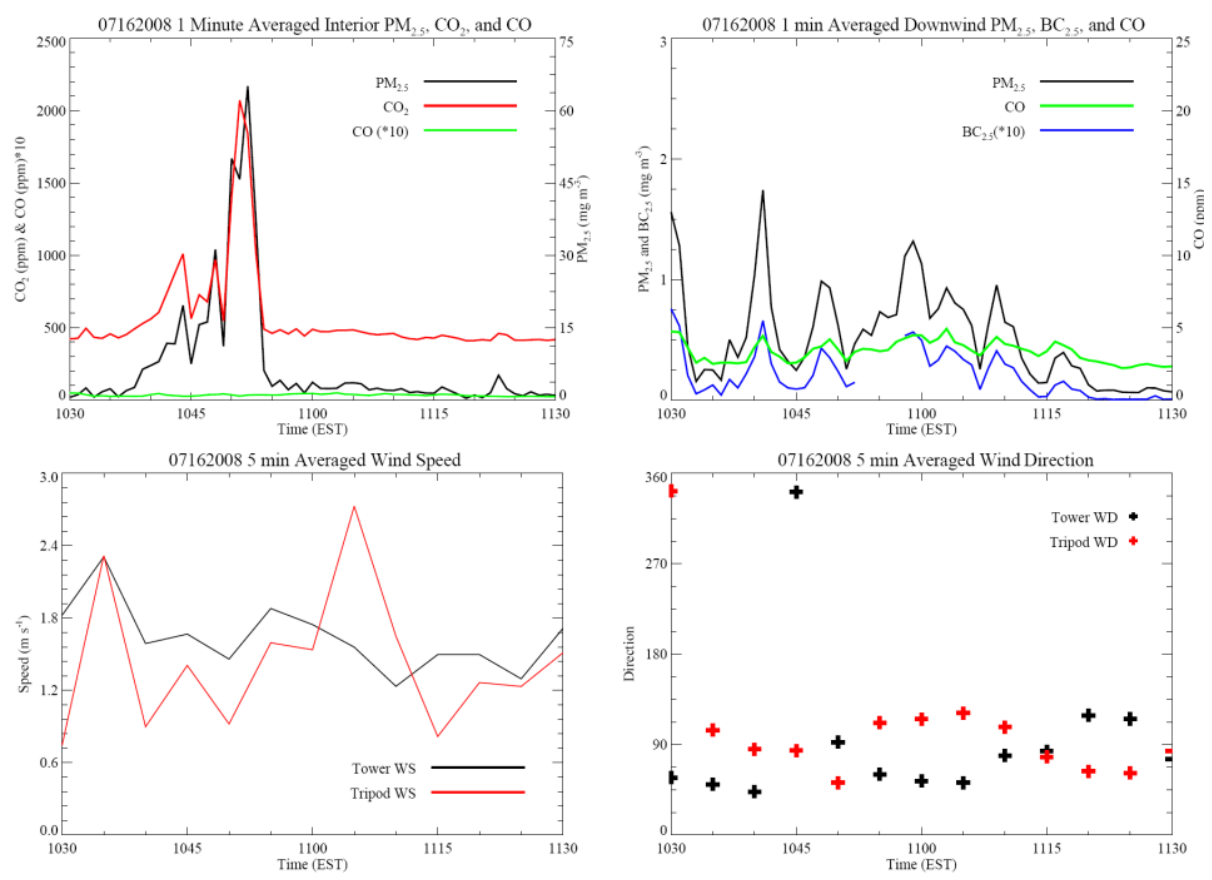

Fig. 10. One min averaged tower $\mathrm{PM}_{2.5}, \mathrm{CO}_{2}, \mathrm{CO}$, and $\mathrm{BC}$ concentrations, tripod $\mathrm{PM}_{2.5}$, $\mathrm{CO}$, and $\mathrm{BC}_{2.5}$ concentrations, and tower and tripod wind speed and direction measured during hour when fire front moved passed the tower on 16 July 2008.
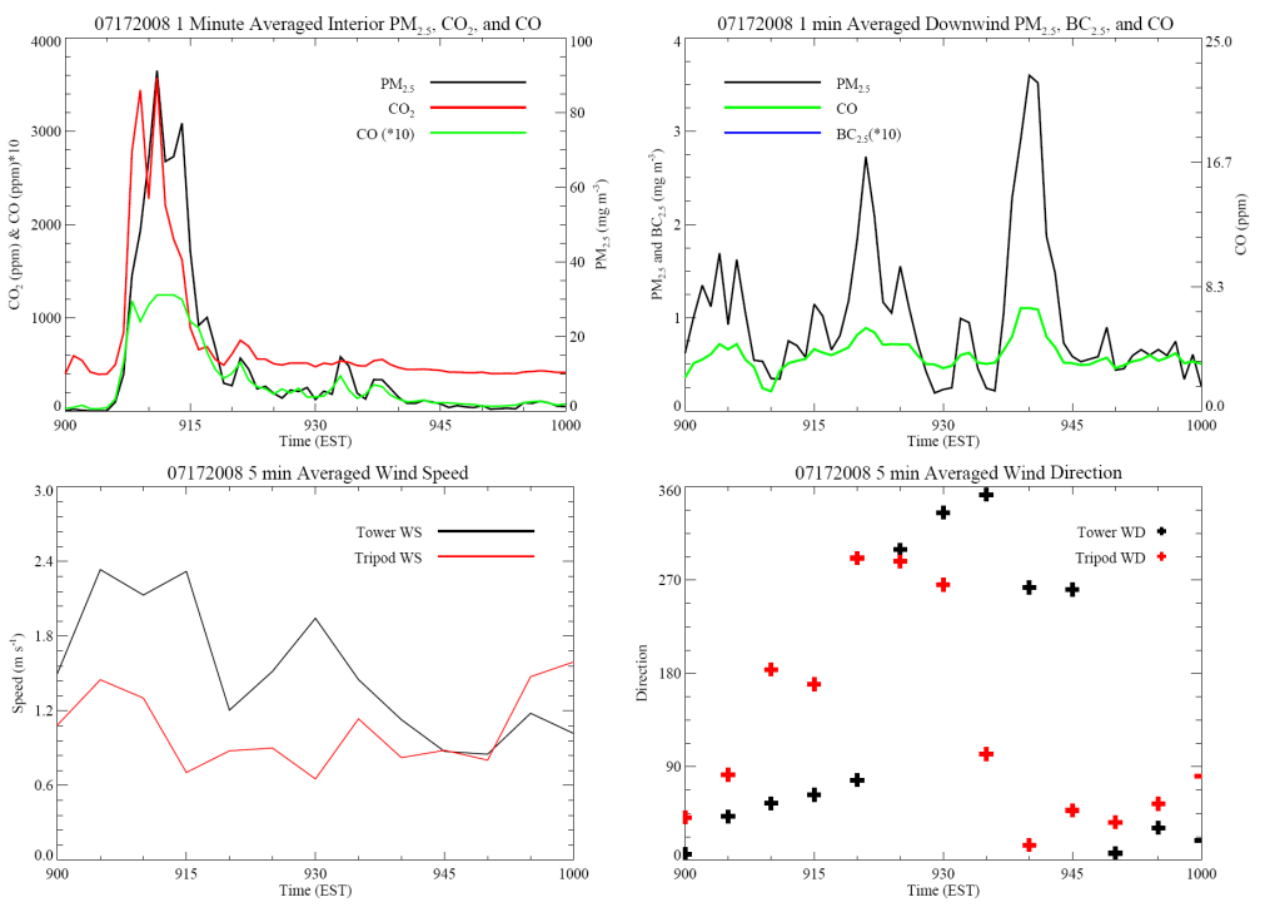

Fig. 11. One min averaged tower $\mathrm{PM}_{2.5}, \mathrm{CO}_{2}, \mathrm{CO}$, and $\mathrm{BC}$ concentrations, tripod $\mathrm{PM}_{2.5}$, $\mathrm{CO}$, and $\mathrm{BC}_{2.5}$ concentrations, and tower and tripod wind speed and direction measured during hour when fire front moved passed the tower on 17 July 2008. 

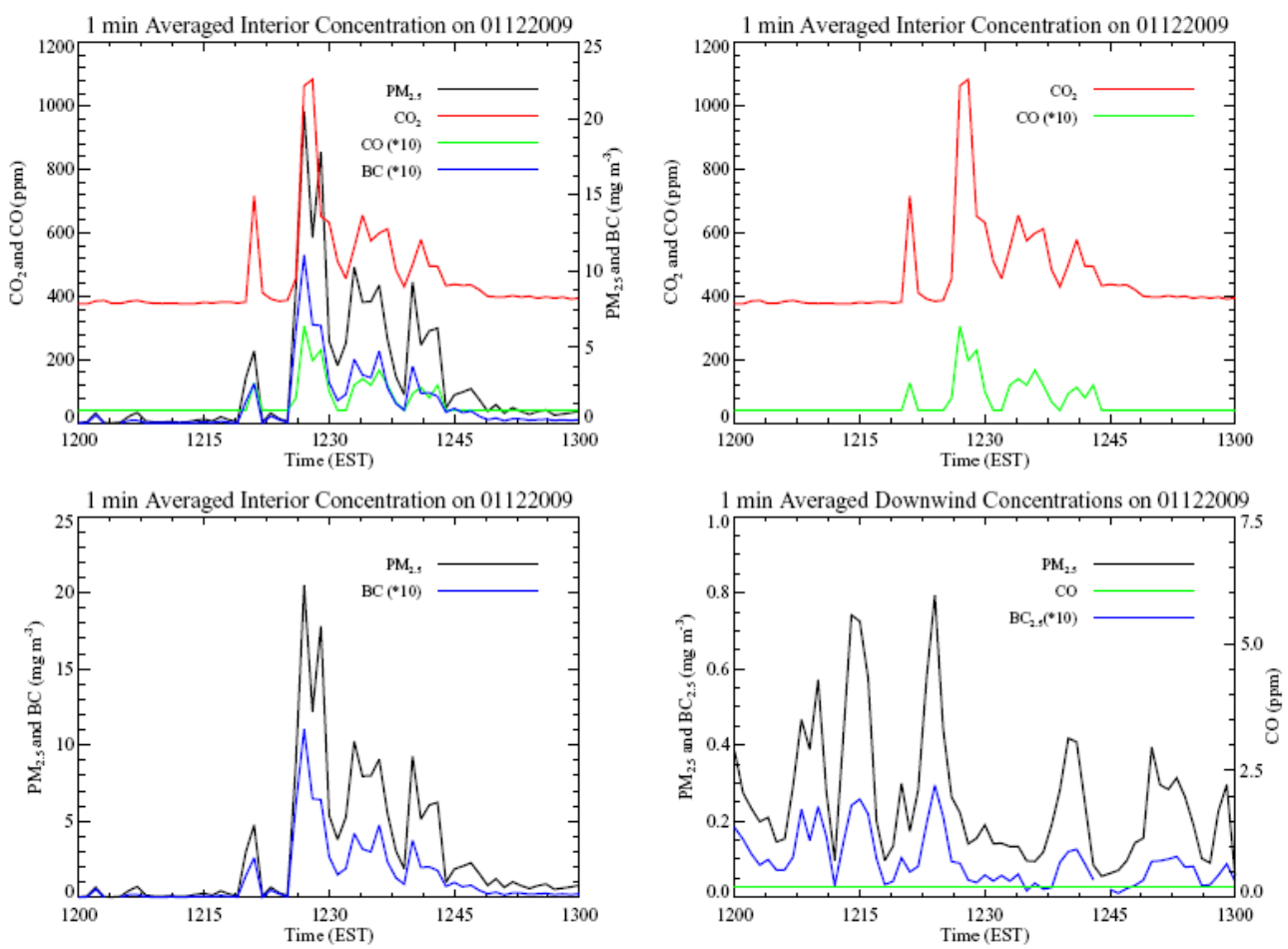

Fig. 12. One min averaged tower $\mathrm{PM}_{2.5}, \mathrm{CO}_{2}, \mathrm{CO}$, and $\mathrm{BC}$ concentrations measured during hour when fire front moved passed the tower on 12 January 2009.
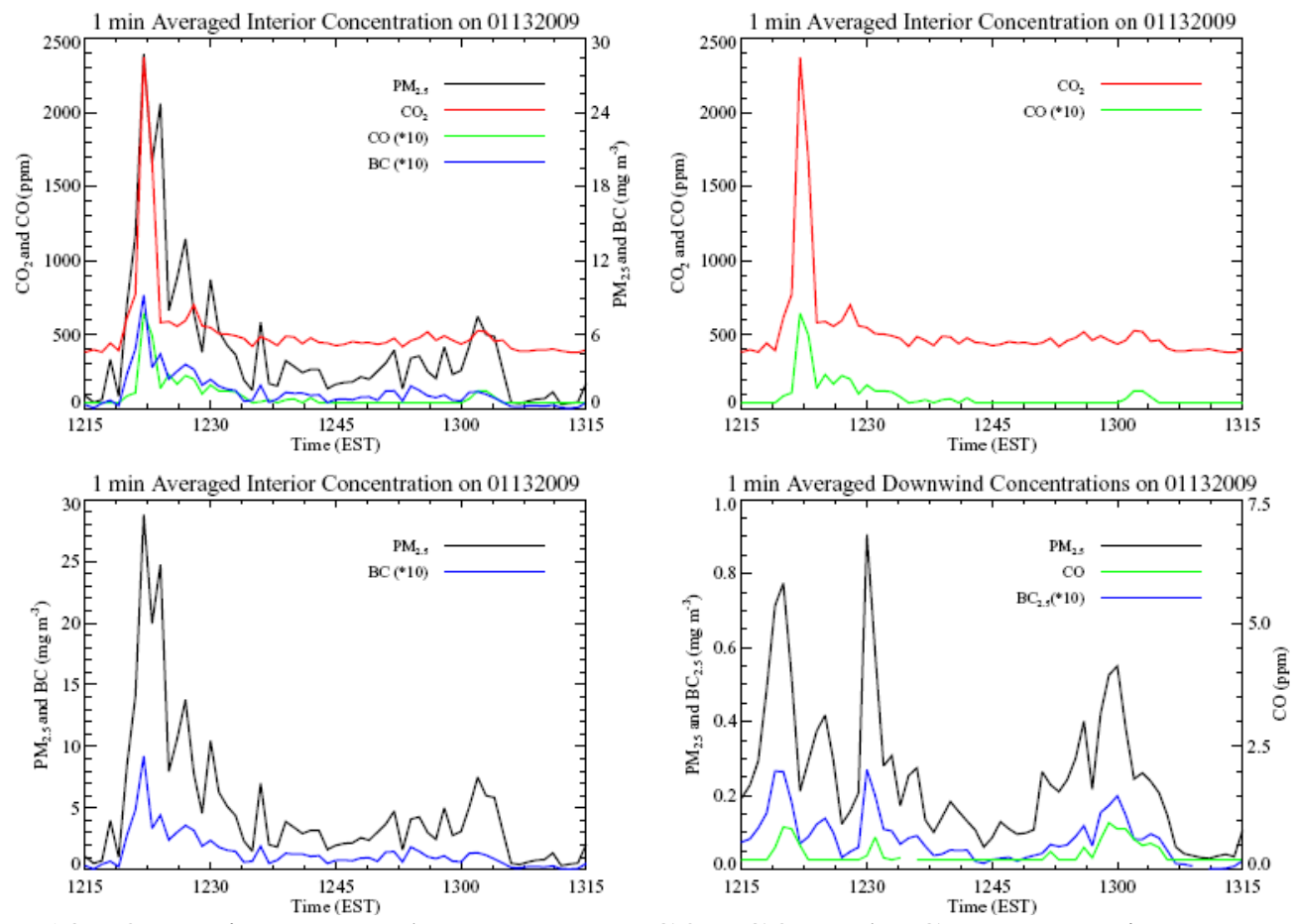

Fig. 13. One min averaged tower $\mathrm{PM}_{2.5}, \mathrm{CO}_{2}, \mathrm{CO}$, and $\mathrm{BC}$ concentrations measured during hour when fire front moved passed the tower on 13 January 2009. 

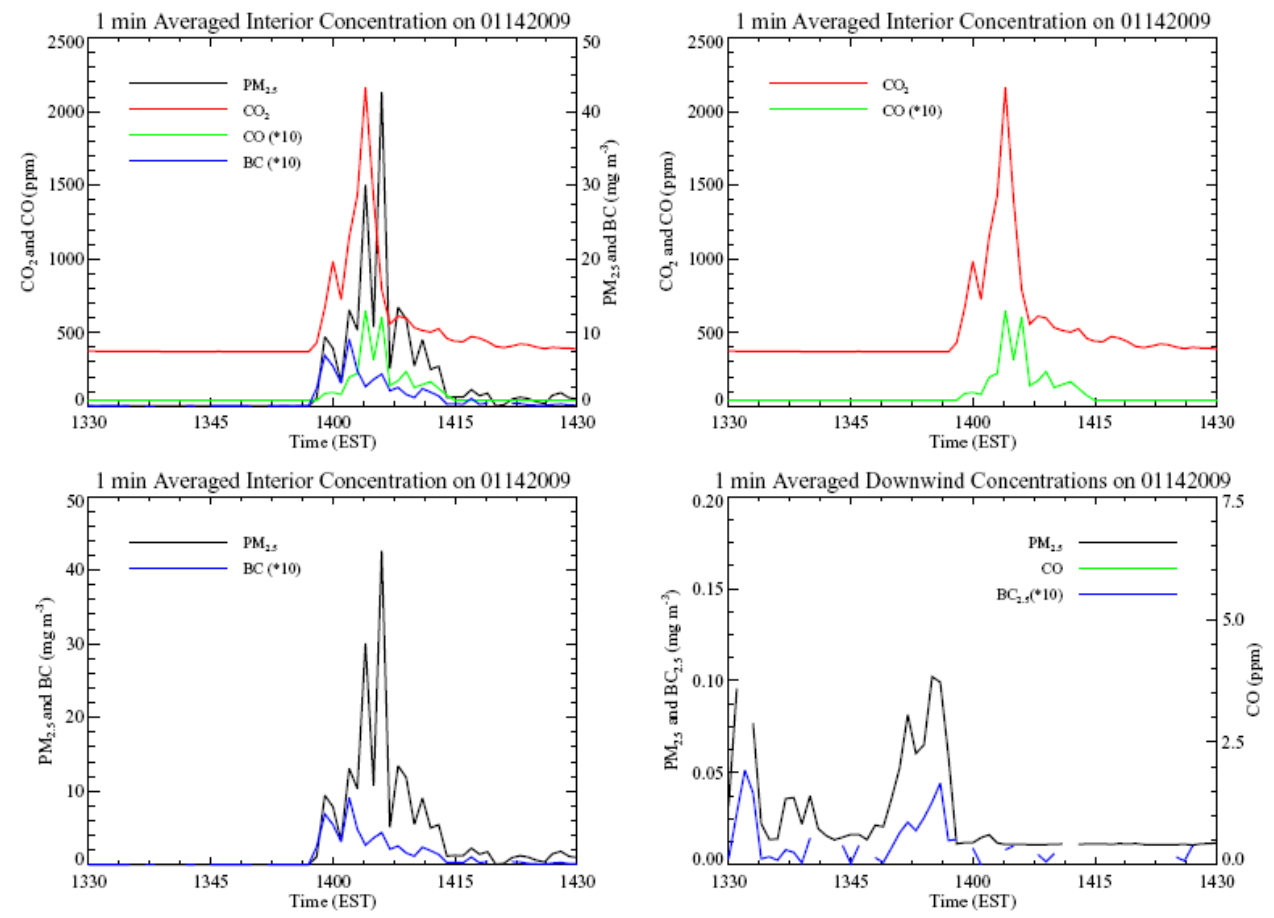

Fig. 14. One min averaged tower $\mathrm{PM}_{2.5}, \mathrm{CO}_{2}, \mathrm{CO}$, and $\mathrm{BC}$ concentrations measured during hour when fire front moved passed the tower on 14 January 2009.

Utilizing the in situ tower concentration data, $\mathrm{EFs}$ for $\mathrm{PM}_{2.5}, \mathrm{CO}, \mathrm{CO}_{2}$, and $\mathrm{BC}$ (winter only) were determined. A visual inspection of each unit revealed a nearly homogenous fuel bed; thus, EFs derived from tower data are valid across the whole unit. These EFs are applicable for homogenous wiregrass longleaf-pine fuel with a FRI of approximately two yr. The EFs are presented in units of $g$ of pollutant emitted per kg fuel consumed. To evaluate emissions from a prescribed burn falling within these burn parameters, one simply needs to estimate or calculate fuel consumption and then apply an EF. Tower and tripod maximum observed concentrations for each burn are presented in Table 5. 
Table 5. Maximum tower $(10 \mathrm{~m})$ and tripod $(2 \mathrm{~m})$ concentrations measured during summer and winter burns.

\begin{tabular}{cccccccc}
\hline & \multicolumn{9}{c}{ Interior } & & \multicolumn{3}{c}{ Downwind } \\
\hline Date & $\mathbf{P M}_{2.5}$ & $\mathbf{C O 2}$ & $\mathbf{C O}$ & $\mathbf{B C}$ & $\mathbf{P M}_{2.5}$ & $\mathbf{B C}_{\mathbf{2 . 5}}$ & $\mathbf{C O}$ \\
& $\left(\mathrm{mg} \mathrm{m}^{-3}\right)$ & $(\mathrm{ppm})$ & $(\mathrm{ppm})$ & $\left(\mathrm{mg} \mathrm{m}^{-3}\right)$ & $\left(\mathrm{mg} \mathrm{m}^{-3}\right)$ & $\left(\mathrm{mg} \mathrm{m}^{-3}\right)$ & $(\mathrm{ppm})$ \\
\hline $7 / 15 / 2008$ & 52.0 & 2115 & 65.8 & $* *$ & 0.93 & 0.031 & 3.65 \\
$7 / 16 / 2008$ & 65.1 & 2072 & 21.0 & $* *$ & 2.24 & 0.100 & 6.16 \\
$7 / 17 / 2008$ & 91.3 & 3567 & 124.3 & $* *$ & 3.60 & $*$ & 6.89 \\
$1 / 12 / 2009$ & 20.5 & 1084 & 30.6 & 1.10 & 0.79 & 0.029 & 1.06 \\
$1 / 13 / 2009$ & 28.8 & 2373 & 64.4 & 0.92 & 0.91 & 0.032 & 0.99 \\
$1 / 14 / 2009$ & 42.6 & 2165 & 65.0 & 0.91 & 0.30 & 0.009 & $*$ \\
\hline
\end{tabular}

* Instrument error

** Not measured

Summer and winter derived $\mathrm{PM}_{2.5}$ EFs during flaming and smoldering combustion are shown in Fig. 15, and the mean EFs during flaming, smoldering, and for the total effective-fire are presented in Table 6. As expected, the $\mathrm{EFs}_{\mathrm{f}}$ for each burn were lower than $\mathrm{EFs}_{\mathrm{s}}$. Due to increased MCEs, the $\mathrm{PM}_{2.5} \mathrm{EFs}_{\mathrm{t}}$ for all winter fires were lower than summer fires; however, the surface concentration impact downwind from winter fires may be greater than summer fires due to increased atmospheric stability.

Summer and winter derived CO EFs during flaming and smoldering combustion are shown in Fig. 16, and the mean EFs during flaming, smoldering, and for the total effective-fire are presented in Table 7. Results are similar to EFs derived for $\mathrm{PM}_{2.5}$, as 
$\mathrm{CO}$ is also a product of incomplete combustion. Less $\mathrm{CO}$ was emitted in dryer fuel conditions of winter than during more moist fuel conditions of summer. Burning under dryer conditions can result in a reduction of about half, as seen in the winter versus summer mean $\mathrm{EFs}_{\mathrm{t}}$. Summer and winter derived $\mathrm{CO}_{2} \mathrm{EFs}$ during flaming and smoldering combustion are shown in Fig. 17, and the mean EFs during flaming, smoldering, and for the total effective-fire are presented in Table $8 . \mathrm{More}^{\mathrm{CO}_{2}}$ was emitted during all winter fires due to increased MCEs. 


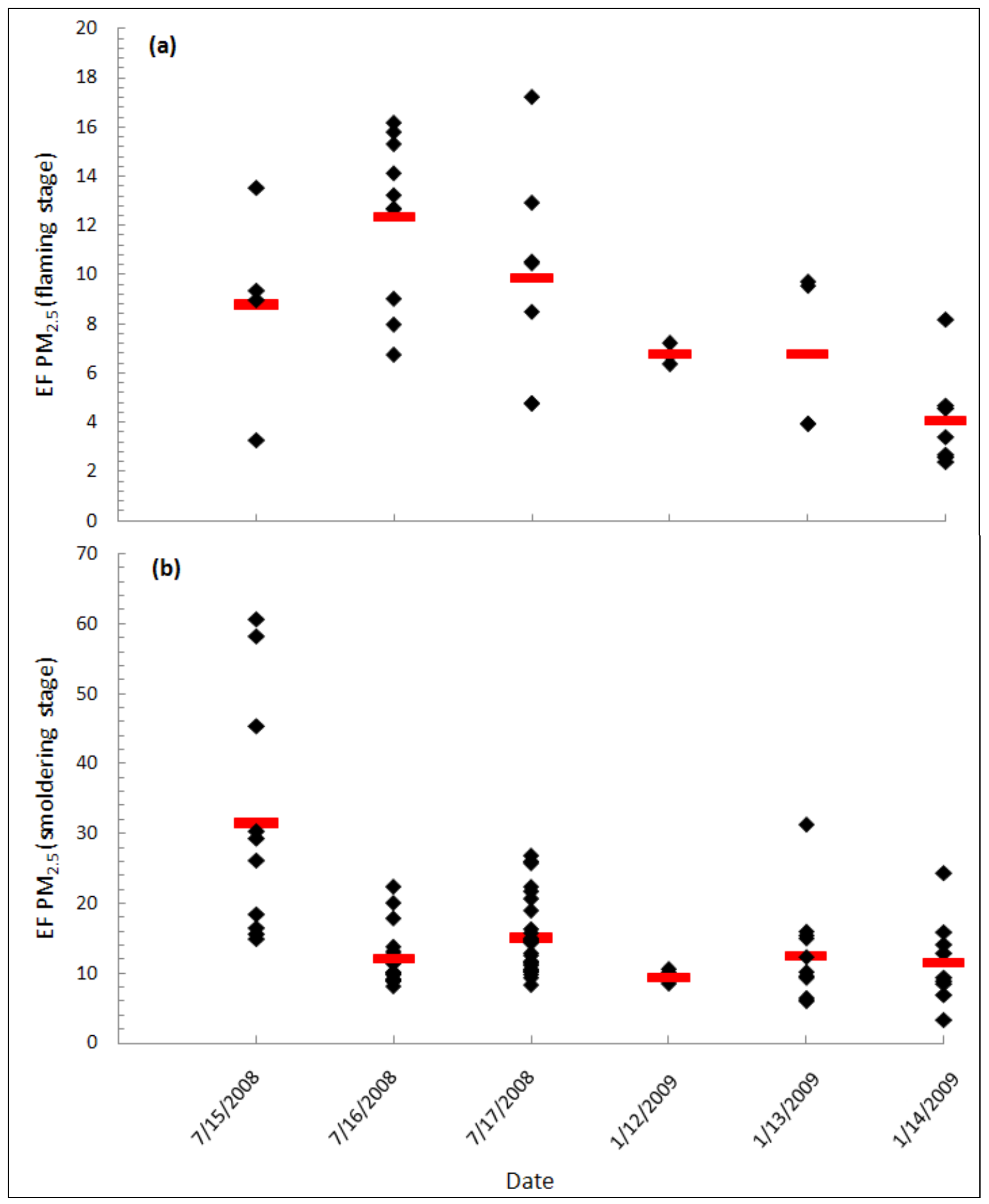

Fig. 15. Flaming (a) and smoldering (b) $\mathrm{PM}_{2.5}$ EFs during all burns. The red line indicates the mean of the calculated EFs. 
Table 6. Summer and winter derived $\mathrm{PM}_{2.5}$ EFs.

\begin{tabular}{cccc}
\hline \multicolumn{4}{c}{$\mathbf{P M}_{\mathbf{2 . 5}} \mathbf{E F s}^{*}\left[\mathbf{g ~ k g}^{-1}\right]$} \\
\hline Date & $\mathbf{E F}_{\mathbf{f}}$ & $\mathbf{E F}_{\mathbf{s}}$ & $\mathbf{E F}_{\mathbf{t}}$ \\
\hline $7 / 15 / 2008$ & $8.8 \pm 3.6$ & $31.5 \pm 9.2$ & $12.1 \pm 4.4$ \\
$7 / 16 / 2008$ & $12.4 \pm 1.6$ & $11.8 \pm 1.3$ & $11.9 \pm 1.5$ \\
$7 / 17 / 2008$ & $9.9 \pm 3.4$ & $15.1 \pm 2.2$ & $11.1 \pm 3.2$ \\
Summer & $\mathbf{1 0 . 8} \pm \mathbf{1 . 7}$ & $\mathbf{1 7 . 0} \pm \mathbf{2 . 9}$ & $\mathbf{1 2 . 1} \pm \mathbf{2 . 0}$ \\
$1 / 12 / 2009$ & $6.8 \pm 0.5$ & $9.4 \pm 0.6$ & $7.9 \pm 0.5$ \\
$1 / 13 / 2009$ & $6.8 \pm 1.9$ & $12.5 \pm 2.6$ & $8.8 \pm 2.2$ \\
$1 / 14 / 2009$ & $4.1 \pm 0.8$ & $11.6 \pm 2.2$ & $9.6 \pm 1.1$ \\
Winter & $\mathbf{5 . 4}$ & $\mathbf{1 1 . 5} \pm \mathbf{1 . 3}$ & $\mathbf{7 . 3} \pm \mathbf{1 . 3}$ \\
\hline
\end{tabular}

* Values are means \pm one SE 


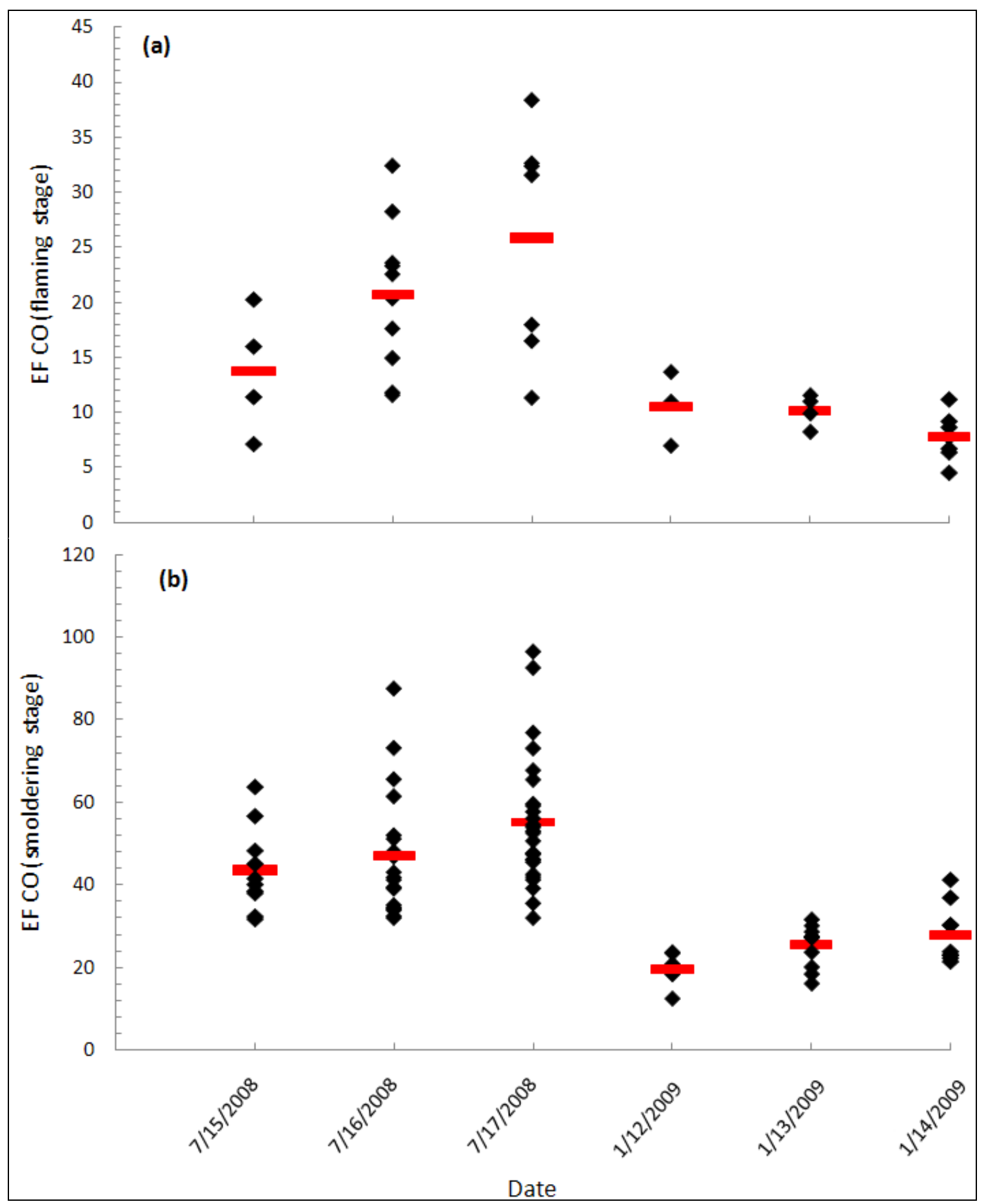

Fig. 16. Flaming (a) and smoldering (b) CO EFs during all burns. The red line indicates the mean of the calculated EFs. 
Table 7. Summer and winter derived CO EFs.

\begin{tabular}{cccc}
\hline \multicolumn{3}{c}{$\mathbf{C O ~ E F}^{*}\left[\mathbf{g ~ k g}^{-\mathbf{1}}\right]$} & \\
\hline Date & $\mathbf{E F}_{\mathbf{f}}$ & $\mathbf{E F}_{\mathbf{s}}$ & $\mathbf{E F}_{\mathbf{t}}$ \\
\hline $7 / 15 / 2008$ & $13.7 \pm 4.4$ & $43.6 \pm 5.0$ & $18.1 \pm 4.5$ \\
$7 / 16 / 2008$ & $20.7 \pm 3.3$ & $46.7 \pm 5.4$ & $41.2 \pm 3.6$ \\
$7 / 17 / 2008$ & $25.9 \pm 6.7$ & $55.3 \pm 5.3$ & $33.1 \pm 6.5$ \\
Summer & $\mathbf{2 1 . 1} \pm \mathbf{3 . 3}$ & $\mathbf{5 0 . 3} \pm \mathbf{3 . 6}$ & $\mathbf{2 7 . 2} \pm \mathbf{3 . 3}$ \\
$1 / 12 / 2009$ & $10.5 \pm 3.4$ & $19.6 \pm 3.0$ & $14.4 \pm 3.2$ \\
$1 / 13 / 2009$ & $10.1 \pm 1.6$ & $25.4 \pm 3.3$ & $15.4 \pm 2.2$ \\
\hline $1 / 14 / 2009$ & $7.8 \pm 1.4$ & $27.9 \pm 4.2$ & $22.6 \pm 2.1$ \\
Winter & $\mathbf{9 . 0} \pm \mathbf{1 . 4}$ & $\mathbf{2 4 . 9} \pm \mathbf{2 . 2}$ & $\mathbf{1 4 . 0} \pm \mathbf{1 . 7}$ \\
\hline Values are means \pm one SE & &
\end{tabular}




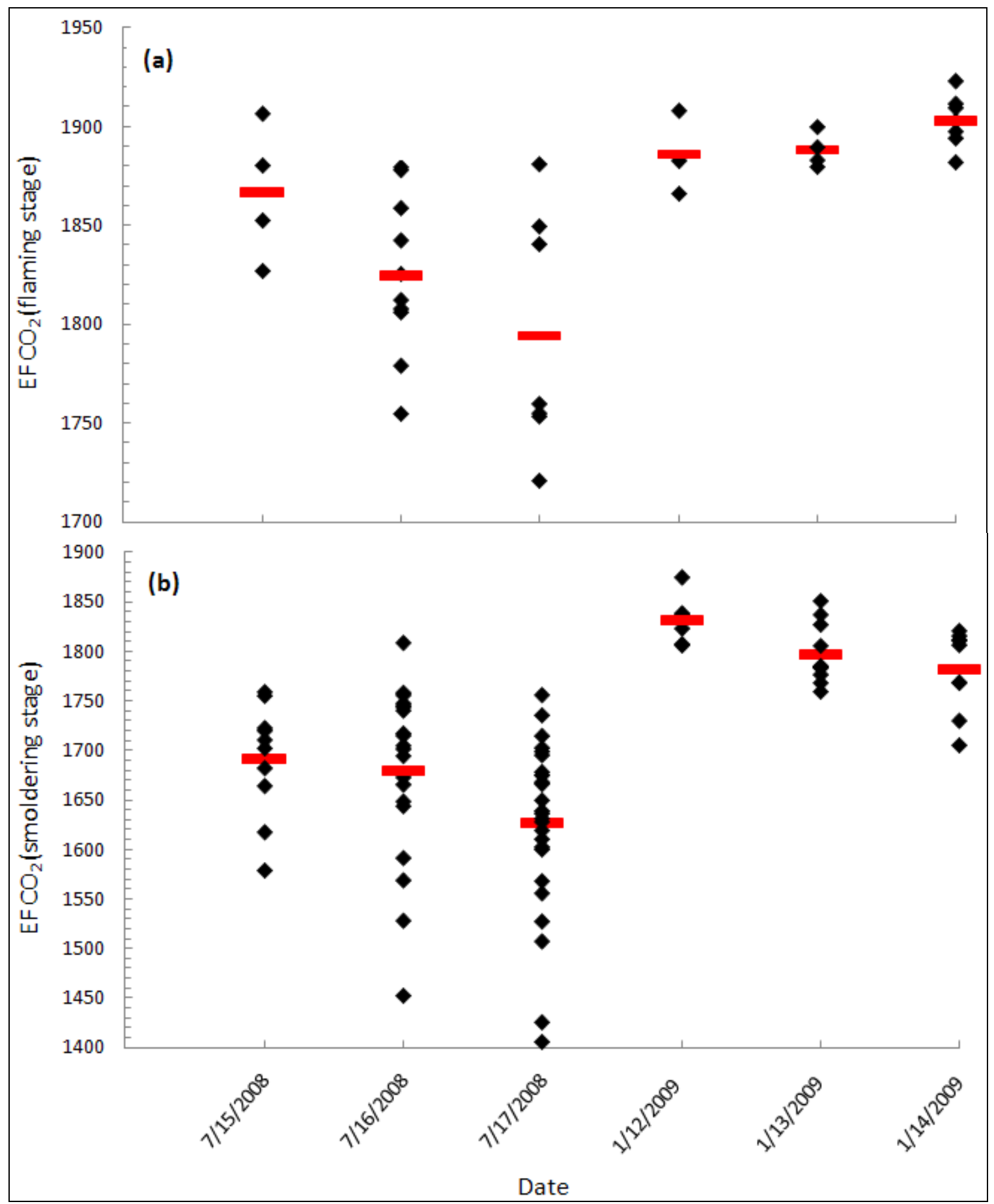

Fig. 17. Flaming (a) and smoldering (b) $\mathrm{CO}_{2}$ EFs during all burns. The red line indicates the mean of the calculated EFs. 
Table 8. Summer and winter derived $\mathrm{CO}_{2}$ EFs.

\begin{tabular}{cccc}
\hline \multicolumn{4}{c}{$\mathbf{E F s ~ \mathbf { C O } _ { 2 } * \mathbf { g ~ k g } ^ { - 1 } ]}$} \\
\hline Date & $\mathbf{E F}_{\mathbf{f}}$ & $\mathbf{E F}_{\mathbf{s}}$ & $\mathbf{E F}_{\mathbf{t}}$ \\
\hline $7 / 15 / 2008$ & $1867 \pm 27$ & $1691 \pm 28$ & $1841 \pm 27$ \\
$7 / 16 / 2008$ & $1825 \pm 20$ & $1675 \pm 30$ & $1706 \pm 22$ \\
$7 / 17 / 2008$ & $1794 \pm 40$ & $1626 \pm 30$ & $1753 \pm 39$ \\
Summer & $\mathbf{1 8 2 2} \pm \mathbf{2 0}$ & $\mathbf{1 6 5 4} \pm \mathbf{2 0}$ & $\mathbf{1 7 8 7} \pm \mathbf{2 0}$ \\
$1 / 12 / 2009$ & $1886 \pm 21$ & $1831 \pm 18$ & $1862 \pm 20$ \\
$1 / 13 / 2009$ & $1888 \pm 10$ & $1796 \pm 20$ & $1856 \pm 13$ \\
$1 / 14 / 2009$ & $1903 \pm 9$ & $1781 \pm 25$ & $1814 \pm 13$ \\
Winter & $\mathbf{1 8 9 5} \pm \mathbf{9}$ & $\mathbf{1 7 9 9} \pm \mathbf{1 3}$ & $\mathbf{1 8 6 5} \pm \mathbf{1 0}$ \\
\hline
\end{tabular}

* Values are means \pm one SE

Winter derived BC EFs are presented in Table 9. Unfortunately, the microAethalometer could not be secured in time for the summer burns. Burning in winter produced about $0.28 \pm 0.05 \mathrm{~g}$ of $\mathrm{BC}$ per $\mathrm{kg}$ of fuel consumed. It is very reasonable to suspect $\mathrm{BC}$ EFs during the summer would be greater than winter due to decreased MCEs. 
Table 9. Winter derived BC EFs.

\section{BC EFs* $\left[\mathrm{g} \mathrm{kg}^{-1}\right]$}

\begin{tabular}{cccc}
\hline Date & $\mathbf{E F}_{\mathbf{f}}$ & $\mathbf{E F}_{\mathbf{s}}$ & $\mathbf{E F}_{\mathbf{t}}$ \\
\hline $1 / 12 / 2009$ & $0.40 \pm 0.05$ & $0.40 \pm 0.01$ & $0.40 \pm 0.03$ \\
$1 / 13 / 2009$ & $0.21 \pm 0.07$ & $0.34 \pm 0.04$ & $0.25 \pm 0.06$ \\
$1 / 14 / 2009$ & $0.23 \pm 0.09$ & $0.25 \pm 0.04$ & $0.24 \pm 0.07$ \\
Winter & $\mathbf{0 . 2 6} \pm \mathbf{0 . 0 6}$ & $\mathbf{0 . 3 2} \pm \mathbf{0 . 0 3}$ & $\mathbf{0 . 2 8} \pm \mathbf{0 . 0 5}$ \\
\hline
\end{tabular}

* Values are means \pm one SE

Direct $\mathrm{EFs}$ for $\mathrm{BC}_{2.5}$ could not be ascertained from measurements as the aethalometer could not be installed on the tower due to instrument size and weight; however, $\mathrm{BC}_{2.5}$ EFs were estimated using tripod $\mathrm{BC}_{2.5}$ and $\mathrm{PM}_{2.5}$ data, and $\mathrm{PM}_{2.5}$ measurements from the tower. Due to the proximity of the source location to the tripod we can assume the concentration ratio of $\mathrm{BC}_{2.5}$ to $\mathrm{PM}_{2.5}$ does not change during plume transport by a substantial amount. The mean $\mathrm{BC}_{2.5} / \mathrm{PM}_{2.5}$ observed at the tripod during each burn was evaluated and used to estimate $\mathrm{BC}_{2.5}$ concentrations at the tower. Results are presented in Table 10. The statistical significance of the mean $\mathrm{BC}_{2.5} / \mathrm{PM}_{2.5}$ to the 95 $\%$ confidence interval was tested using 1.96 times the SE of the means. For all burns, the mean $\mathrm{BC}_{2.5} / \mathrm{PM}_{2.5}$ was found to be statistically significant to the $95 \%$ confidence interval, which indicates the variability of the $\mathrm{BC}_{2.5} / \mathrm{PM}_{2.5}$ is within an acceptable range to estimate $\mathrm{BC}_{2.5}$ tower concentrations. Tower concentrations of $\mathrm{BC}_{2.5}$ are estimated by 
multiplying the mean $\mathrm{BC}_{2.5} / \mathrm{PM}_{2.5}$ and tower $\mathrm{PM}_{2.5}$ concentrations. From these estimated $\mathrm{BC}_{2.5}$ tower concentrations, $\mathrm{BC}_{2.5} \mathrm{EFs}$ are calculated (Table 11). Since $\mathrm{BC}_{2.5}$ EFs were not directly derived, the values presented are means only. The $\mathrm{BC}_{2.5} / \mathrm{PM}_{2.5}$ observed during this experiment agree with results from Lee et al. (2005), where the $\mathrm{BC}_{2.5} / \mathrm{PM}_{2.5}$ was found to be $\sim 0.04$ from similar prescribed fires in Georgia.

Table 10. Summer and winter $\mathrm{BC}_{2.5} / \mathrm{PM}_{2.5}$.

\begin{tabular}{cccc}
\hline Date & $\mathbf{B C}_{2.5} / \mathbf{P M}_{2.5}{ }^{\mathbf{a}}$ & $\mathbf{B C}_{2.5} / \mathbf{P M}_{2.5}(\mathbf{s t d} \mathbf{~ d e v})^{\mathbf{b}}$ & $\mathbf{B C}_{2.5} / \mathbf{P M}_{2.5} \mathbf{( S E}^{\mathbf{c}}$ \\
\hline $7 / 15 / 2008$ & 0.032 & 0.014 & 0.000 \\
$7 / 16 / 2008$ & 0.040 & 0.015 & 0.001 \\
$7 / 17 / 2008$ & $*$ & $*$ & $*$ \\
$1 / 12 / 2009$ & 0.037 & 0.014 & 0.001 \\
$1 / 13 / 2009$ & 0.033 & 0.010 & 0.001 \\
$1 / 14 / 2009$ & 0.026 & 0.010 & 0.001 \\
\hline * Data were not collected & &
\end{tabular}

a. Values are arithmetic means computed at the downwind tripod during the burn

b. Values presented are one standard deviation

c. Values presented are one SE 
Table 11. Summer and winter derived $\mathrm{BC}_{2.5}$ EFs.

\begin{tabular}{cccc}
\hline \multicolumn{4}{c}{$\mathbf{B C}_{2.5} \mathbf{E F s}^{*}\left[\mathbf{g ~ k g}^{-1}\right]$} \\
$\mathbf{E F}_{\mathbf{f}}$ & $\mathbf{E F}_{\mathrm{s}}$ & $\mathbf{E F}_{\mathbf{t}}$ \\
\hline $7 / 15 / 2008$ & 0.28 & 1.01 & 0.39 \\
$7 / 16 / 2008$ & 0.50 & 0.47 & 0.48 \\
$7 / 17 / 2008$ & $* *$ & $* *$ & $* *$ \\
Summer & $\mathbf{0 . 4 4}$ & $\mathbf{0 . 6 7}$ & $\mathbf{0 . 4 7}$ \\
$1 / 12 / 2009$ & 0.25 & 0.35 & 0.29 \\
$1 / 13 / 2009$ & 0.22 & 0.41 & 0.29 \\
$1 / 14 / 2009$ & 0.11 & 0.30 & 0.17 \\
Winter & $\mathbf{0 . 1 7}$ & $\mathbf{0 . 3 6}$ & $\mathbf{0 . 2 3}$ \\
\hline
\end{tabular}

\footnotetext{
* Values are means

** Data were not collected
}

From laboratory experiments, McMeeking et al. (2009) found the MCE for the combustion of longleaf pine fuel was $94.4 \pm 2.3 \%$. This agrees with results from this study where the summer mean $\mathrm{MCE}_{\mathrm{t}}$ was $94.4 \pm 0.7 \%$ and the winter mean $\mathrm{MCE}_{\mathrm{t}}$ was $97.1 \pm 0.7 \%$. McMeeking et al. (2009) found the $\mathrm{PM}_{2.5} \mathrm{EF}_{\mathrm{t}}$ to be $38.3 \pm 13.6 \mathrm{~g} \mathrm{~kg}^{-1}$, which is much larger than the $\mathrm{EFs}_{\mathrm{t}}$ found during this experiment. Andreae and Merlet (2001) compiled and integrated all available literature and produced EFs for species emitted from various types of biomass burning. From data obtained from savanna and grassland, tropical forest, and extratropical forest burns, the $\mathrm{PM}_{2.5} \mathrm{EF}_{\mathrm{t}}$ was found to be 
$5.4 \pm 1.5,9.1 \pm 1.5$, and $13.0 \pm 7.0 \mathrm{~g} \mathrm{~kg}^{-1}$, respectively. The $\mathrm{PM}_{2.5} \mathrm{EFs}_{\mathrm{t}}$ observed during summer and winter experiment burns fall within the range published by Andreae and Merlet (2001) for extratropical forest.

A statistical analysis was performed for quality control, parameter prediction ability, and to measure the association of the relationship between variables. Table 12 presents the Pearson 2-tailed correlations between MCE, instantaneous fuel consumption, and one min averaged concentrations of $\mathrm{CO}_{2}, \mathrm{CO}$, and $\mathrm{PM}_{2.5}$ for the 15 July 2008 prescribed burn. All correlations for this case were found to be significantly significant to the $95 \%$ confidence interval.

The predictive power of $\mathrm{MCE}$ for the $\mathrm{PM}_{2.5} \mathrm{EF}_{\mathrm{t}}$ for all burns was evaluated. A MCE- $\mathrm{PM}_{2.5} \mathrm{EF}_{\mathrm{t}}$ scatter plot for the 15 July 2008 burn is shown in Fig. 18, and linear and exponential regressions models were produced. The linear regression model is given by

$$
\begin{gathered}
P M_{2.5} E F_{t}=410.1-4.15(M C E) \\
R^{2}=0.61 \quad p=0.001,
\end{gathered}
$$

and is statistically significant to the $99 \%$ confidence interval. The MCE has the ability to capture the variance in the $\mathrm{PM}_{2.5} \mathrm{EF}_{\mathrm{t}}$, as seen in its reasonable $\mathrm{R}^{2}$ value. The exponential regression model for this burn is given by

$$
\begin{gathered}
P M_{2.5} E F_{t}=2.38 \times 10^{9} e^{(-0.201 \bullet M C E)} \\
R^{2}=0.73 \quad p=0.000
\end{gathered}
$$


and is statistically significant to the $99 \%$ confidence interval. The MCE has the ability to capture the variance in the $\mathrm{EF}_{\mathrm{t}}$, as seen in its reasonable $\mathrm{R}^{2}$ value. Utilizing these equations could enable one to estimate the emissions from a prescribed burn in similar fuel types and under similar conditions from a MCE calculation alone.

Table 12. Pearson correlation coefficients between MCE, instantaneous fuel consumption (Fuel C) and one min averaged concentrations of $\mathrm{CO}_{2}, \mathrm{CO}$, and $\mathrm{PM}_{2.5}$ for burn on 15 July 2008.

\begin{tabular}{cccccc}
\hline & MCE & $\mathbf{C O}_{2}$ & $\mathbf{C O}$ & $\mathbf{P M}_{2.5}$ & Fuel C \\
\hline $\mathrm{MCE}$ & 1 & $0.76^{*}$ & $0.67^{*}$ & $0.58^{* *}$ & $0.64^{* *}$ \\
$\mathrm{CO}_{2}$ & $0.76^{*}$ & 1 & $0.91^{*}$ & $0.87^{*}$ & $0.92^{*}$ \\
$\mathrm{CO}$ & $0.67^{*}$ & $0.91^{*}$ & 1 & $0.97^{*}$ & $0.97^{*}$ \\
$\mathrm{PM}_{2.5}$ & $0.58^{* *}$ & $0.87^{*}$ & $0.97^{*}$ & 1 & $0.99 *$ \\
Fuel C & $0.64^{* *}$ & $0.92^{*}$ & $0.97^{*}$ & $0.99^{*}$ & 1 \\
\hline
\end{tabular}

* Correlation is statistically significant to the $99 \%$ confidence interval

** Correlation is statistically significant to the $95 \%$ confidence interval

A MCE-PM $2.5 \mathrm{EF}_{\mathrm{t}}$ scatter plot for the 12 January 2009 burn is shown in Fig. 19, and linear and exponential regressions models were produced. The linear regression model is given by

$$
\begin{gathered}
P M_{2.5} E F_{t}=165.1-1.613(M C E) \\
R^{2}=0.55 \quad p=0.002,
\end{gathered}
$$


and is statistically significant to the $99 \%$ confidence interval. The exponential regression model for this burn is given by

$$
\begin{gathered}
P M_{2.5} E F_{t}=1.965 \times 10^{7} e^{(-0.151 \bullet M C E)} \\
R^{2}=0.57 \quad p=0.001,
\end{gathered}
$$

and is statistically significant to the $99 \%$ confidence interval. In both cases an exponential regression provided the best fit for the data. Caution should be taken when estimating emissions from the exponential regressions when MCEs are small because the y-intercept values are unrealistic, and when MCEs approach $100 \%$ because, in theory, the EFs for products of incomplete combustion should go to zero. 


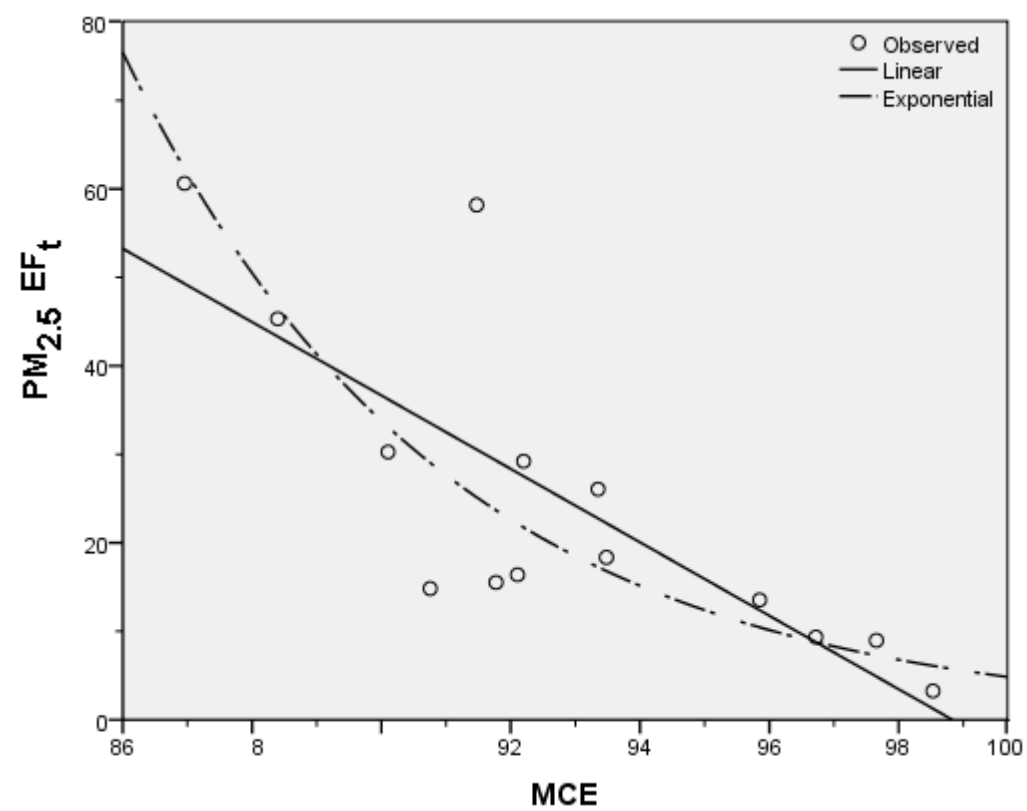

Fig. 18. Scatter plot of $\mathrm{PM}_{2.5} \mathrm{EF}_{\mathrm{t}}$ versus MCE for the 15 July 2008 burn. The solid line shows the linear regression while the dashed line shows the exponential regression.

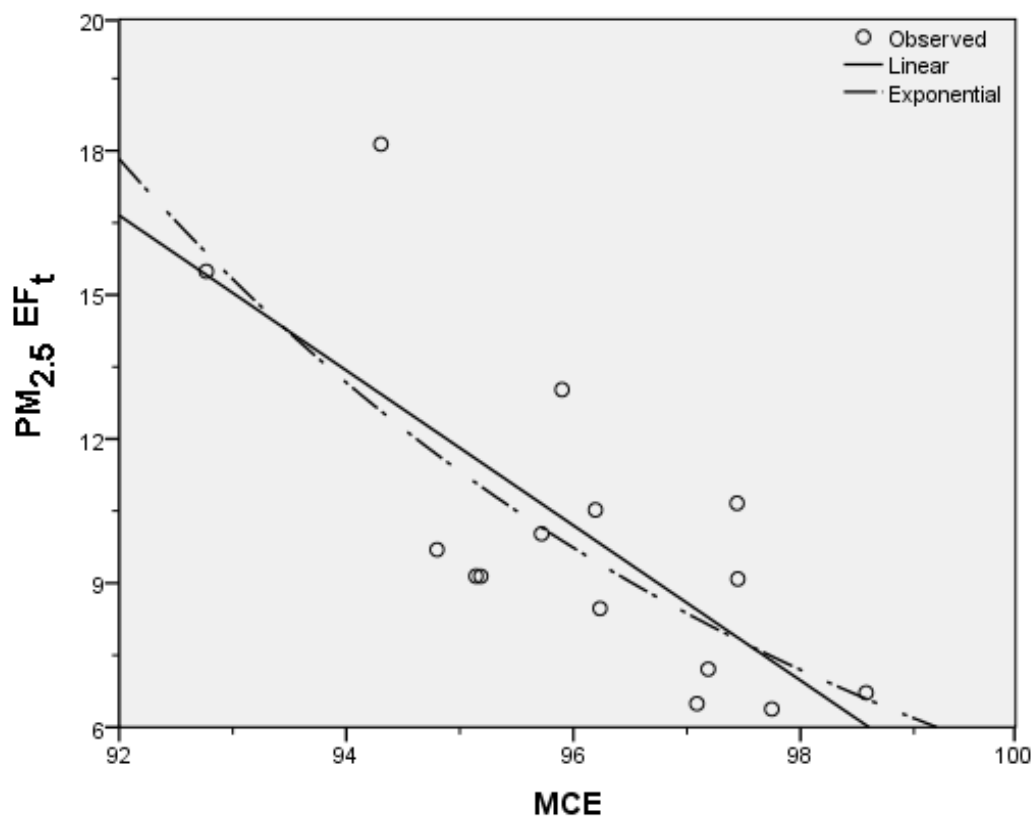

Fig. 19. Scatter plot of $\mathrm{PM}_{2.5} \mathrm{EF}_{\mathrm{t}}$ versus MCE for the 12 January 2009 burn. The solid line shows the linear regression while the dashed line shows the exponential regression. 
The two statistical examples above represent only one summer and one winter burn. All summer collected and derived data were combined and statistically tested to evaluate the variability between the three summer burns. Table 13 presents the correlations between MCE, instantaneous fuel consumption, and one min averaged concentrations of $\mathrm{CO}_{2}, \mathrm{CO}$, and $\mathrm{PM}_{2.5}$ for the combined summer data. The correlation of the combined data is smaller than for any individual burn; however, all correlations were found to be statistically significant except for the MCE-CO correlation. Differences in fuel moisture and fuel loading between burns may explain the enhanced variability in the combined data.

A MCE-PM $2.5 \mathrm{EF}_{\mathrm{t}}$ scatter plot for all summer burn data is presented in Fig. 20, and linear and exponential regressions models were produced. The linear regression model is given by

$$
\begin{gathered}
P M_{2.5} E F_{t}=95.9-0.883(M C E) \\
R^{2}=0.12 \quad p=0.002,
\end{gathered}
$$

and is statistically significant to the $99 \%$ confidence interval, while the exponential regression model is given by

$$
\begin{array}{r}
P M_{2.5} E F_{t}=2900 e^{(-0.059 \bullet M C E)} \\
R^{2}=0.21 \quad p=0.000
\end{array}
$$

and is statistically significant to the $99 \%$ confidence interval. 
Table 13. Pearson correlation coefficients between MCE, instantaneous fuel consumption (Fuel $\mathrm{C}$ ) and one min averaged concentrations of $\mathrm{CO}_{2}, \mathrm{CO}$, and $\mathrm{PM}_{2.5}$ for all summer burn data combined.

\begin{tabular}{cccccc}
\hline & MCE & $\mathbf{C O}_{2}$ & CO & PM $_{2.5}$ & Fuel C \\
\hline MCE & 1 & $0.52^{*}$ & 0.20 & $0.39^{*}$ & $0.51^{*}$ \\
$\mathrm{CO}_{2}$ & $0.52^{*}$ & 1 & $0.83^{*}$ & $0.87^{*}$ & $0.99^{*}$ \\
$\mathrm{CO}$ & 0.20 & $0.83^{*}$ & 1 & $0.92^{*}$ & $0.85^{*}$ \\
$\mathrm{PM}_{2.5}$ & $0.39 *$ & $0.87^{*}$ & $0.92^{*}$ & 1 & $0.89^{*}$ \\
Fuel C & $0.51^{*}$ & $0.99^{*}$ & $0.85^{*}$ & $0.89^{*}$ & 1 \\
\hline
\end{tabular}

* Correlation is statistically significant to the $99 \%$ confidence interval

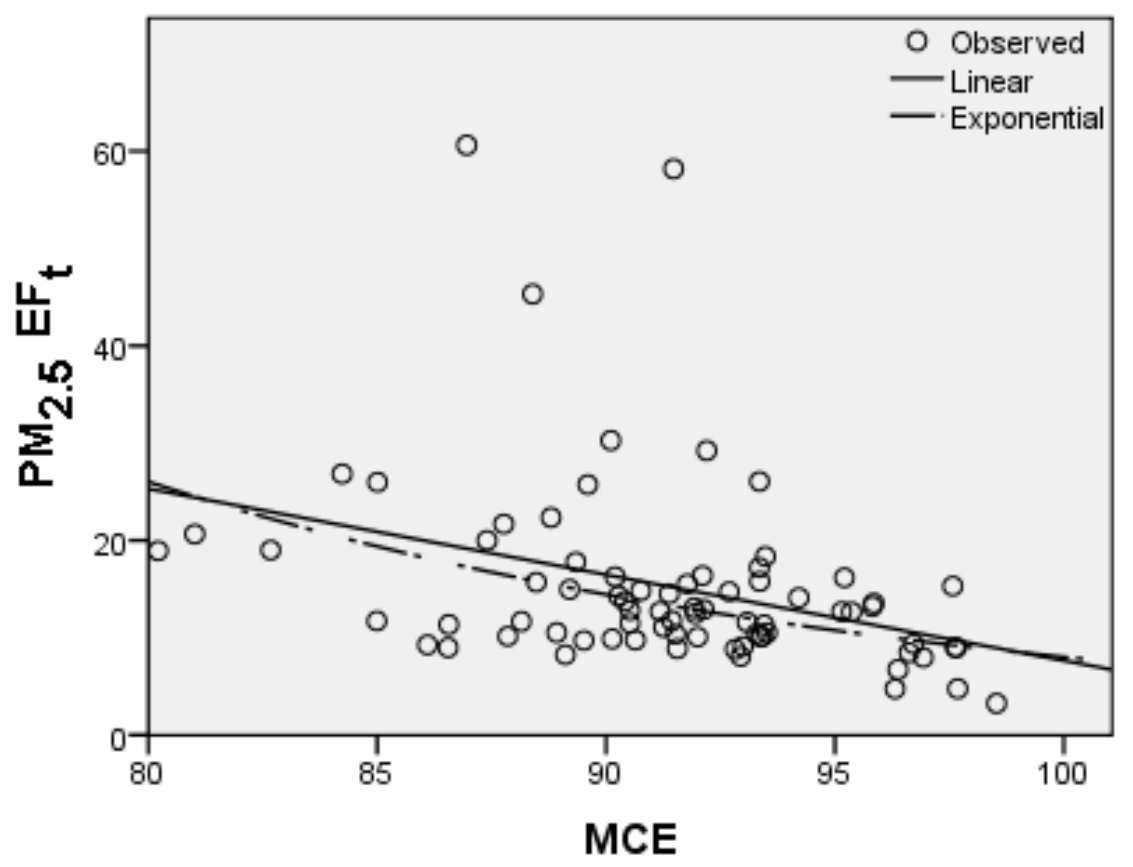

Fig. 20. Scatter plot of $\mathrm{PM}_{2.5} \mathrm{EF}_{\mathrm{t}}$ versus $\mathrm{MCE}$ for all summer burn data. The solid line shows the linear regression, while the dashed line shows the exponential regression. 
All winter collected and derived data were combined and statistically tested to evaluate the variability between the three winter burns. Table 14 presents the correlations between MCE, TKE, and one min averaged concentrations of $\mathrm{CO}_{2}, \mathrm{CO}, \mathrm{BC}$, and $\mathrm{PM}_{2.5}$ for the combined data.

A MCE-PM $2.5 \mathrm{EF}_{\mathrm{t}}$ scatter plot for all winter burn data is presented in Fig. 21, and linear and exponential regressions models were produced. The linear regression model is given by

$$
\begin{gathered}
P M_{2.5} E F_{t}=178.3-1.76(M C E) \\
R^{2}=0.34 \quad p=0.000,
\end{gathered}
$$

and is statistically significant to the $99 \%$ confidence interval. The exponential regression model for the combined data is given by

$$
\begin{gathered}
P M_{2.5} E F_{t}=3.2 \times 10^{9} e^{(-0.206 \bullet M C E)} \\
R^{2}=0.45 \quad p=0.000,
\end{gathered}
$$

and is statistically significant to the $99 \%$ confidence interval. 
Table 14. Pearson correlation coefficients between TKE, MCE, and one min averaged concentrations of $\mathrm{CO}_{2}, \mathrm{CO}, \mathrm{PM}_{2.5}$, and $\mathrm{BC}$ for all winter burn data combined.

\begin{tabular}{ccccccc}
\hline & TKE & MCE & $\mathbf{C O}_{2}$ & $\mathbf{C O}$ & $\mathbf{P M}_{2.5}$ & BC \\
\hline $\mathrm{TKE}$ & 1 & $0.51^{*}$ & $0.88^{*}$ & $0.70^{*}$ & $0.60^{*}$ & $0.44^{*}$ \\
$\mathrm{MCE}$ & $0.51^{*}$ & 1 & $0.54^{*}$ & -0.01 & 0.02 & $0.57^{*}$ \\
$\mathrm{CO}_{2}$ & $0.88^{*}$ & $0.54^{*}$ & 1 & $0.79 *$ & $0.60^{*}$ & $0.53^{*}$ \\
$\mathrm{CO}$ & $0.70^{*}$ & -0.01 & $0.79^{*}$ & 1 & $0.85^{*}$ & $0.32^{* *}$ \\
$\mathrm{PM}{ }_{2.5}$ & $0.60^{*}$ & 0.02 & $0.60^{*}$ & $0.85^{*}$ & 1 & $0.48^{*}$ \\
$\mathrm{BC}$ & $0.44^{*}$ & $0.57^{*}$ & $0.53^{*}$ & $0.32^{* *}$ & $0.48^{*}$ & 1 \\
\hline
\end{tabular}

* Correlation is statistically significant to the $99 \%$ confidence interval

** Correlation is statistically significant to the $95 \%$ confidence interval

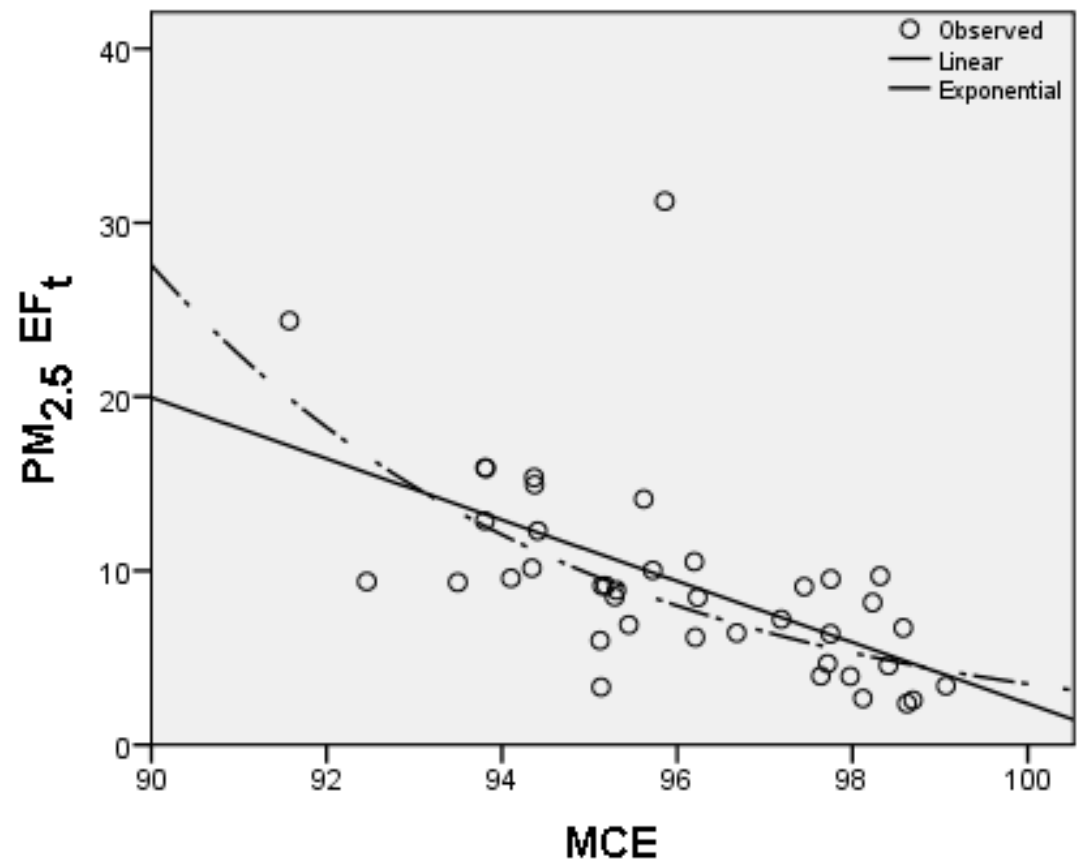

Fig. 21. Scatter plot of PM2.5 EFt versus MCE for all winter burn data. The solid line shows the linear regression, while the dashed line shows the exponential regression. 


\section{c. Observed Fire-Atmosphere Interactions}

The relationship between combustion efficiency and emissions is well understood (Ward and Hardy 1991; Ward et al. 1996; Ward 2001); however, the relationship between MCE, TKE, and emissions is much less known. A statistical analysis was performed to test the relationship between turbulence generation, TKE, and other measured quantities. The correlations between TKE and all variables, notably MCE, are statistically significant to the $99 \%$ confidence interval, thus suggesting turbulence generation, fire efficiency, and emissions from fires, in this experiment, are related. For all combined data a TKE-MCE scatter plot was produced (Fig. 22), and a linear regression model was produced. The linear regression model is given by

$$
\begin{gathered}
M C E=94.9+0.61(T K E) \\
R^{2}=0.26 \quad p=0.001,
\end{gathered}
$$

and is statistically significant to the $99 \%$ confidence interval. 


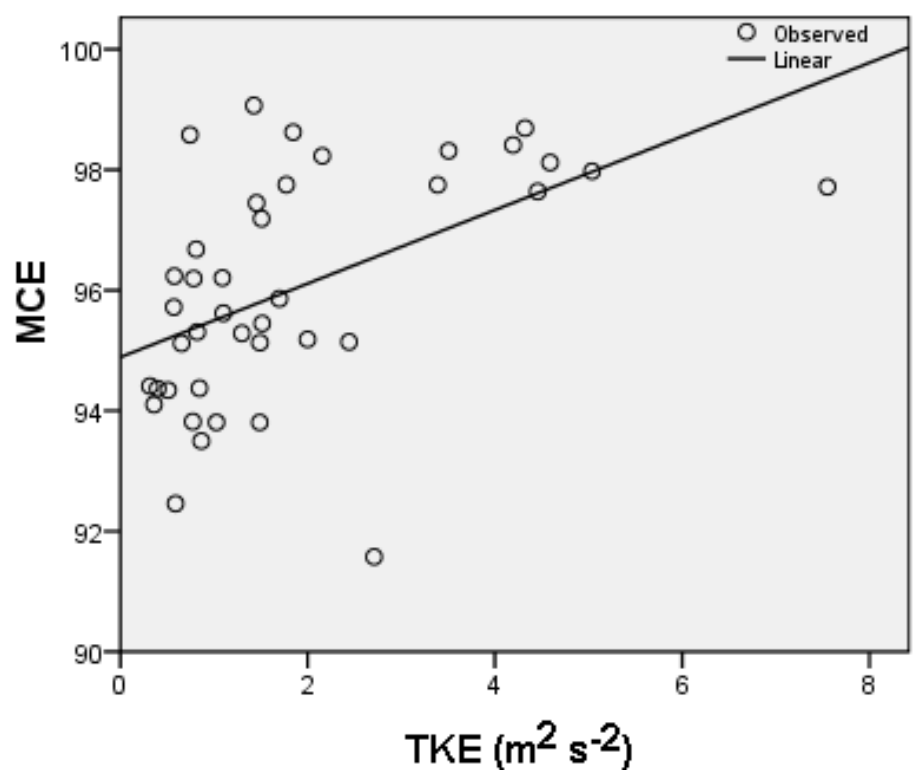

Fig. 22. Scatter plot of MCE versus TKE for all winter burn data, where the solid line shows the linear regression.

Linear regression models for one min averaged tower concentrations of $\mathrm{CO}_{2}(\mathrm{Fig}$. 23a), $\mathrm{CO}$ (Fig. 23b), $\mathrm{PM}_{2.5}$ (Fig. 23c) and BC (Fig. 23d), as a function of TKE, yield $\mathrm{R}^{2}$ values of $0.78,0.50,0.38$, and 0.19 , respectively; thus, TKE is able to explain most of the $\mathrm{CO}_{2}$, and $\mathrm{CO}$ variability. The $\mathrm{CO}_{2}, \mathrm{CO}, \mathrm{PM}_{2.5}$ and $\mathrm{BC}$ linear regressions are given by

$$
\begin{gathered}
C \mathrm{O}_{2}=-77.3+437(T K E) \\
R^{2}=0.78 \quad p=0.000 \\
C O=8.3+7.5(T K E) \\
R^{2}=0.50 \quad p=0.000 \\
P M_{2.5}=5.1+3.1(T K E) \\
R^{2}=0.36 \quad p=0.000
\end{gathered}
$$




$$
\begin{aligned}
B C & =0.233+0.065(T K E) \\
R^{2} & =0.19 \quad p=0.005,
\end{aligned}
$$

respectively, and are statistically significant to the $99 \%$ confidence interval.
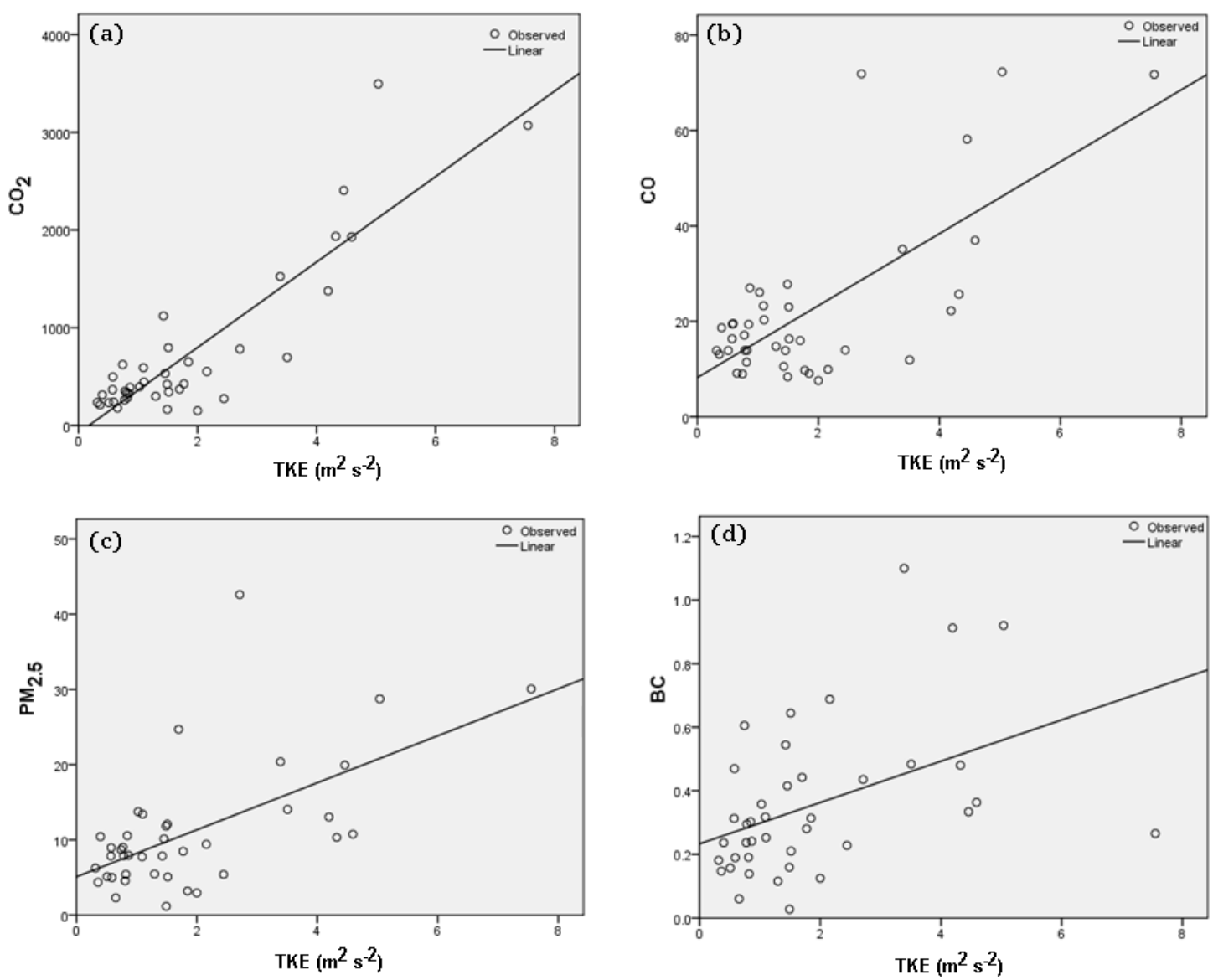

Fig. 23. Scatter plot of tower $\mathrm{CO}_{2}$ (a), $\mathrm{CO}$ (b), $\mathrm{PM}_{2.5}$ (c), and $\mathrm{BC}$ (d) concentrations versus TKE for all winter burn data, where the solid line shows the linear regression. 
The correlation between TKE and $\mathrm{CO}_{2}$ is strongest as represented by a large $\mathrm{R}^{2}$ value. As seen in Fig. 23a, $\mathrm{CO}_{2}$ concentrations increase when more turbulence is present. Enhanced turbulence generation may enable more oxygen entrainment into oxygen deficient regions allowing for increased carbon oxidization. On the other hand, complete combustion liberates more heat than incomplete combustion, which creates turbulence due to enhanced buoyancy. The impact of turbulence generation on fire efficiency and emissions needs to be more closely examined.

One min averaged TKE and friction velocity during the entire duration of each burn is shown in Fig. 24. The friction velocity is a measure of the vertical flux of horizontal momentum (Stull 1988). Prior to fire front passage, ambient TKE values were generally on the order of $1 \mathrm{~m}^{2} \mathrm{~s}^{-2}$. During fire front passage, TKE values increase well above ambient. After passage, TKE values are generally higher than ambient due to weak convection during smoldering conditions. Since the tower becomes a downwind receptor after passage, subsequent plume impactions, and the turbulence associated with them, causes TKE to increase well above ambient again.

As seen in Fig. 24a, ambient TKE values are observed until about 1240 EST (= 1740 UTC) when TKE values sharply increase. This increase in TKE occurs during the fire front passage and plume impaction of the tower. Before this time, TKE is generated through mechanically generated shear and, to a lesser extent, through buoyancy. Gaps in data, seen in Figs. 24a, b, and c, correspond to the highest temperatures encountered, which caused the sonic anemometer to occasionally fail. As seen in Fig. 24d, e, and f, ambient TKE values are observed until they sharply increase, indicating fire front 
passage and plume impaction. The heat released from the fire, in all cases, generates TKE well above the pre-passage ambient conditions.
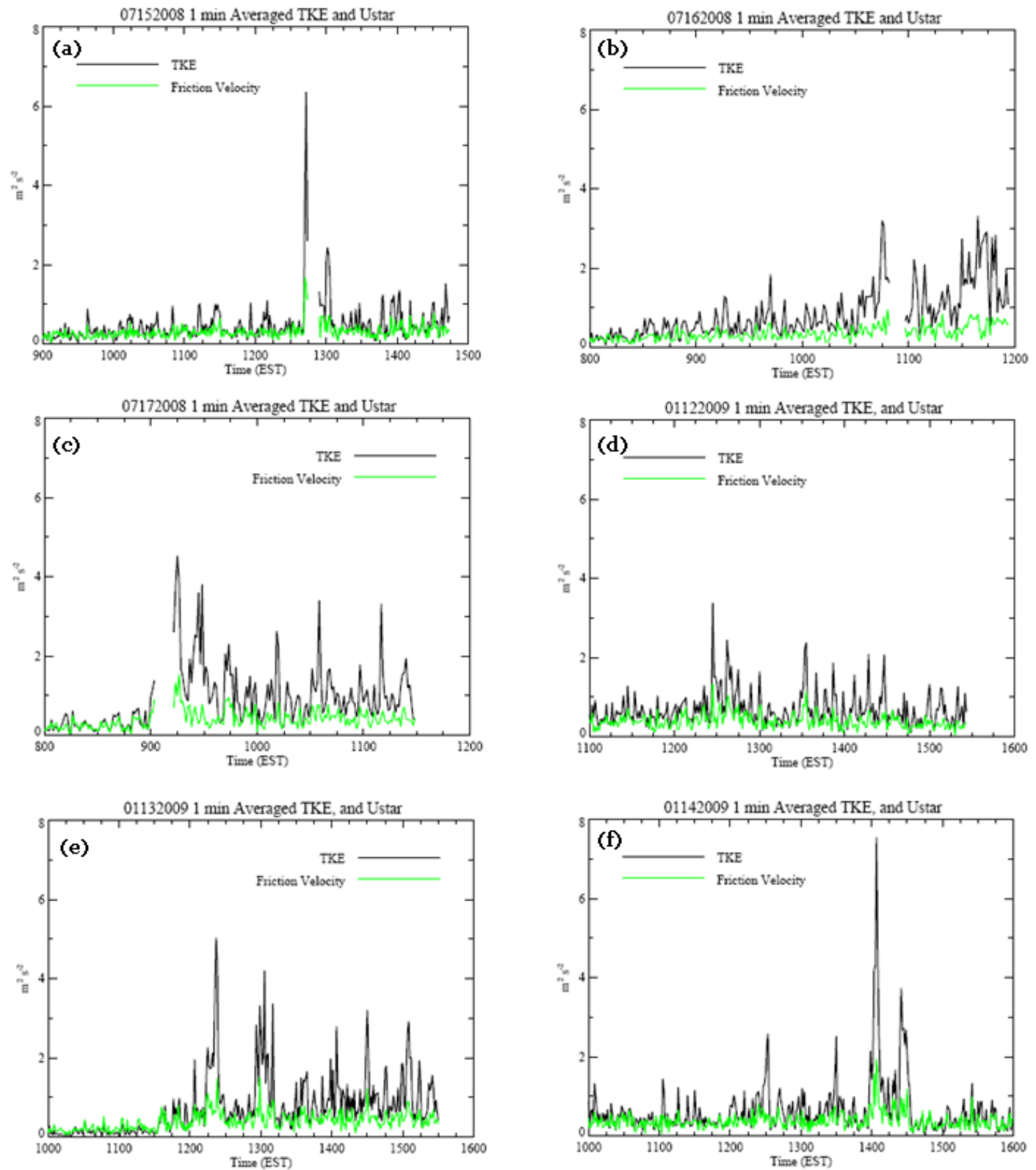

Fig. 24. One min averaged TKE and friction velocity (Ustar) on the 15 (a), 16 (b), and 17 (c) July 2008, and on the 12 (d), 13 (e), and 14 (f) January 2009 during the entire duration of each burn. 
One min averaged TKE, sensible heat flux, and $10 \mathrm{~Hz}$ temperature and $\mathrm{u}, \mathrm{v}$, and w wind components observed at $10 \mathrm{~m}$ during fire front passage at the tower on 15,16 , and 17 July 2008 are presented in Figs. 25, 26, and 27, respectively. The sensible heat flux $\left(\mathrm{KW} \mathrm{m}^{-2}\right)$ is defined as the flux of energy from the surface that does not include phase changes of water.

On 15 July 2008 the plume impacted the tower just after 1240 EST. Sharp increases in TKE (Fig. 25a), u, v, and w wind components (Fig. 25b), sensible heat flux (Fig. 25c), and temperature (Fig. 25d) are clearly observed. The sonic anemometer failed from about 1245 to 1253 EST such that data during this period could not be collected. The thermocouple, placed near the anemometer at $10 \mathrm{~m}$, reveals the maximum temperatures observed in the plume were about $125{ }^{\circ} \mathrm{C}$. Since the thermocouple data did not fail, these data are used to verify when the plume impaction occurred. For this burn the anemometer collected data during the impaction and failed shortly after. In Fig. 25b, as the plume begins to impact the tower (about 1242 EST), a sustained updraft is observed. During this updraft period temperatures (Fig. 25d) start increasing. At approximately 1244 EST the updraft quickly transitions to a downdraft and temperatures return to near-ambient. This suggests that the updraft was observed inside the plume and as the plume propagates beyond the tower a downdraft was observed. Similar results were found by Clements et al. $(2006,2007,2008)$ and seem to suggest the presence of the fire creates a circulation such that a downdraft is observed behind the propagating firefront. 
During the 16 July 2008 burn, the sonic anemometer seemed to fail during the plume impaction (Fig. 26b). As temperatures begin to peak (Fig. 26d) at about 1051 EST, the anemometer failed. Since TKE and sensible heat flux are both derived from 10 $\mathrm{Hz}$ wind components (Fig. 26b), these data are unavailable, thus, the maximum peaks in TKE, sensible heat flux, and the $\mathrm{u}, \mathrm{v}$, and w wind components could not be observed due to instrument failure; however, just before 1045 EST, a very weak plume seems to have impacted the tower as temperature (Fig. 26d) and TKE (Fig. 26a) increase well above ambient. Initially, an updraft is observed, and as the weak plume moves past the tower (about 1045 EST), the updraft transitions to a downdraft.

During the 17 July 2008 burn, the sonic anemometer failed before the plume impaction (Fig. 27b). It remains unknown why the anemometer failed well before temperatures (Fig. 27d) start increasing. Maximum temperatures observed in the plume were about $150{ }^{\circ} \mathrm{C}$. Before the plume completely propagates past the tower the anemometer begins working (912 EST) and reveals an updraft, enhanced wind components (Fig. 27b), and enhanced TKE (Fig. 27a), from about 912 to 915 EST. As temperatures begin to return to ambient a weak downdraft is observed. As the case with the previous burn, maximum TKE and sensible heat flux could not be ascertained due to instrument failure. 

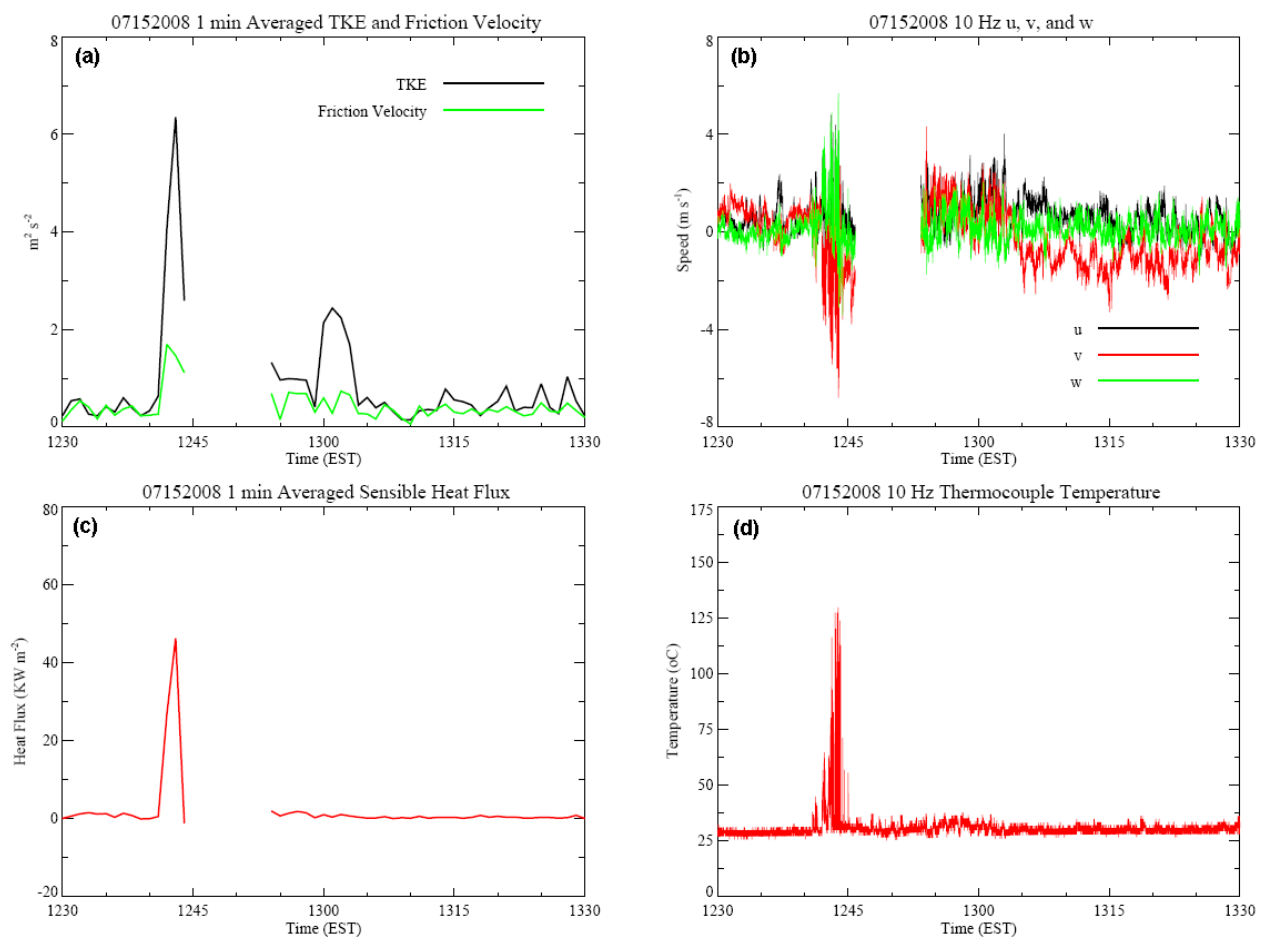

Fig. 25. One min averaged tower TKE, turbulent variances, and vector wind components measured during hour when fire front moved passed the tower on 15 July 2008.
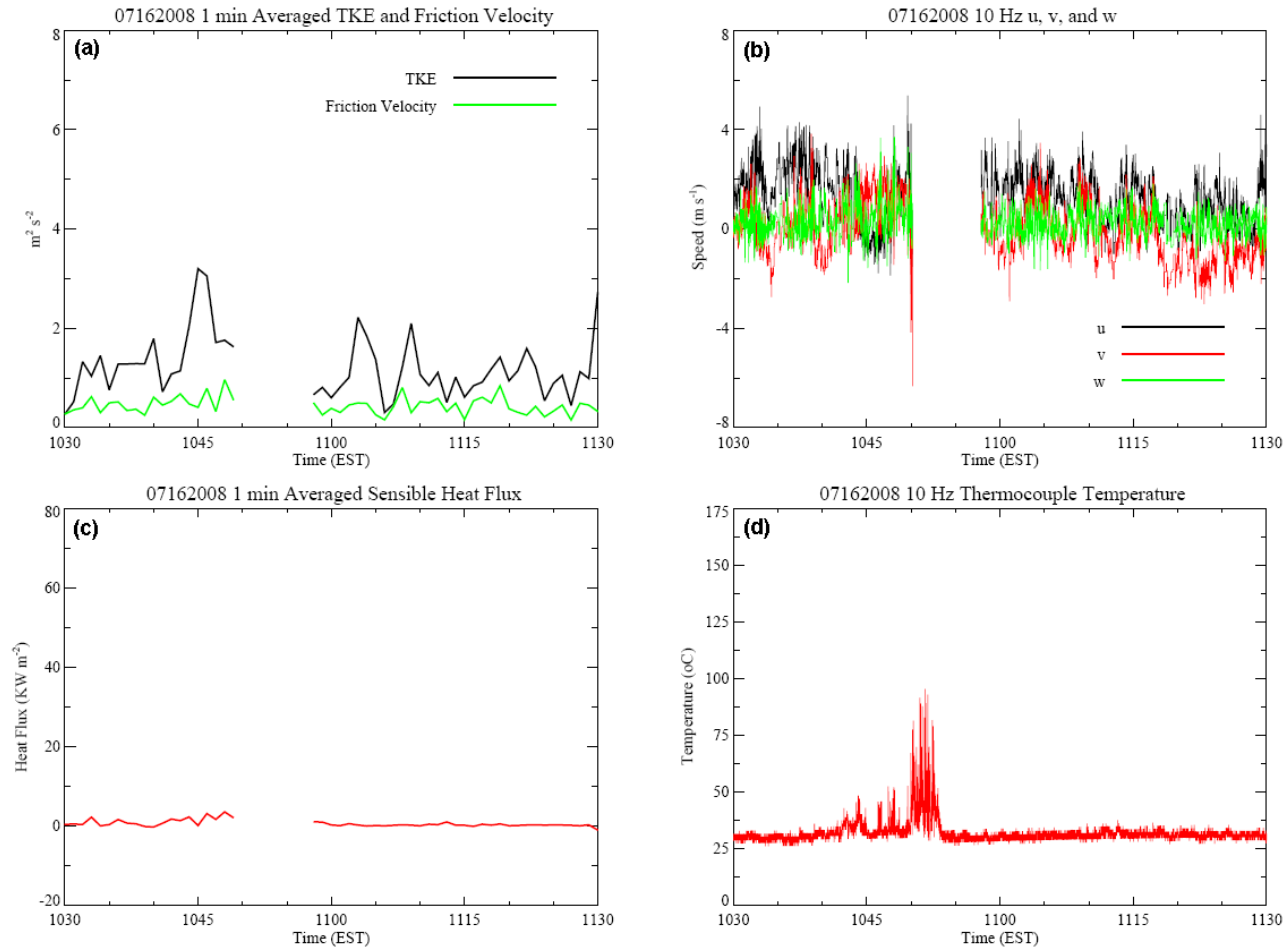

Fig. 26. One min averaged tower TKE, turbulent variances, and vector wind components measured during hour when fire front moved passed the tower on 16 July 2008. 

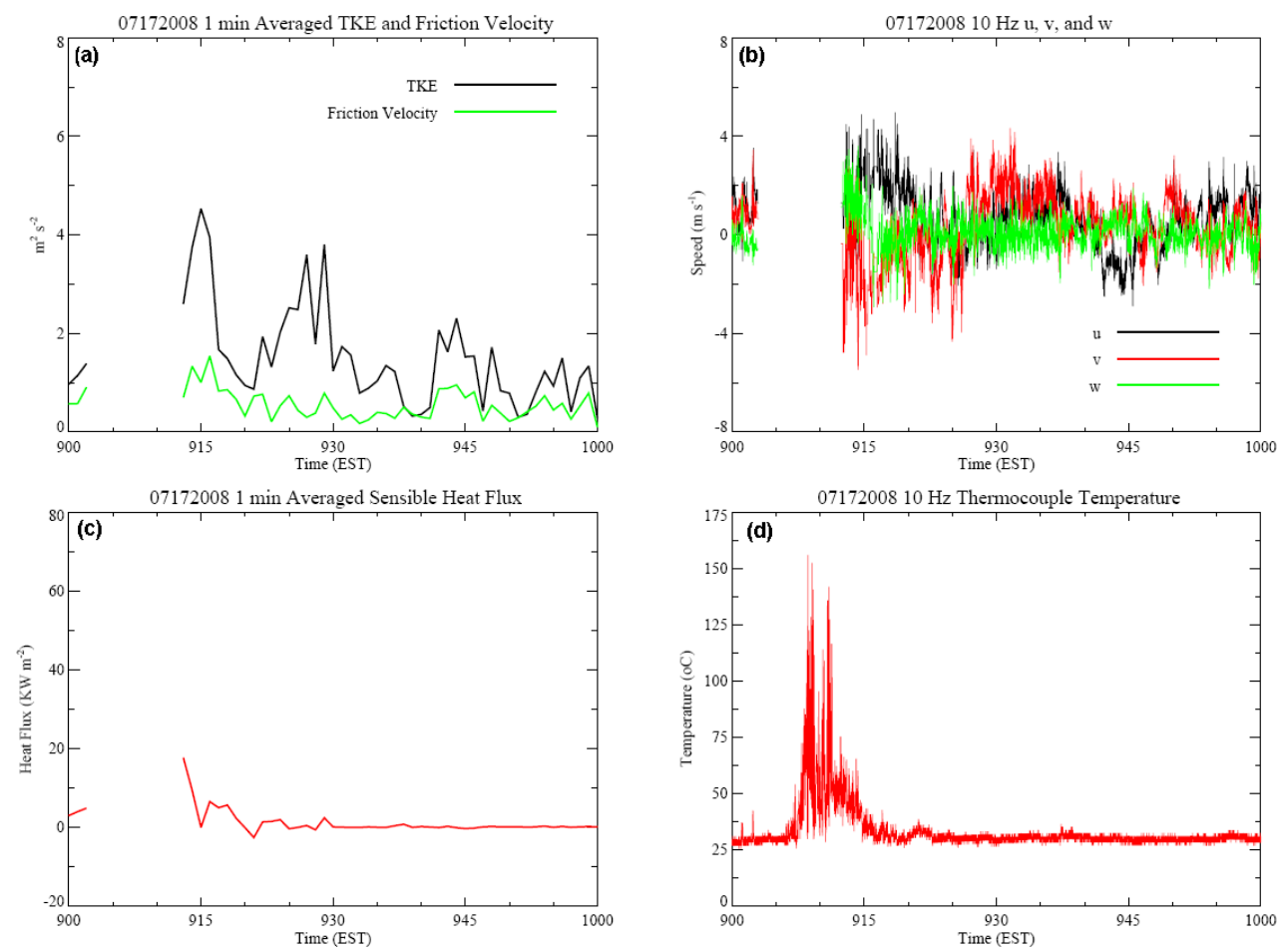

Fig. 27. One min averaged tower TKE, turbulent variances, and vector wind components measured during hour when fire front moved passed the tower on 17 July 2008.

One min averaged TKE, sensible heat flux, $10 \mathrm{~Hz} \mathrm{u}, \mathrm{v}$, and w wind components, and $1 \mathrm{~Hz}$ thermocouple temperature observed at 10 and $2 \mathrm{~m}$ during fire front passage at the tower on 12, 13, and 14 January 2009 are presented in Figs. 28, 29, and 30, respectively. During the winter burns the sonic anemometer did not fail allowing for complete data collecting during plume impaction.

The plume on the 12 January 2009 prescribed fire impacted the tower just after 1220 EST. Sensible heat flux (Fig. 28c), TKE (Fig. 28a), and u, v, and w wind components (Fig. 28b), increase well above ambient from about 1220 to 1223 EST during the impaction. Temperature was measured at $10 \mathrm{~m}$ and $2 \mathrm{~m}$ (Fig. 28d). The $10 \mathrm{~m}$ 
temperature is collected at the same level as the sonic anemometer data. This reveals that the plume and increased temperatures are first observed at $10 \mathrm{~m}$, since the wind causes the plume to bend as it rises. The fire front moves directly under the tower around 1230 as revealed in the $2 \mathrm{~m}$ temperature (Fig. 28d). Smoke from combustion directly under the tower does not impact the tower as the wind advects the smoke downwind before it can rise $10 \mathrm{~m}$, thus, the data collected as the plume impacts the instruments placed at $10 \mathrm{~m}$, occurs from combustion some distance directly upwind of the tower. Similar results were found by Clements et al. (2006, 2007).

The plume impaction at $10 \mathrm{~m}$ was associated by an updraft and was followed by a downdraft (Fig. 28b). The downdraft occurs as TKE (Fig. 28a), sensible heat flux (Fig. 28c), and $10 \mathrm{~m}$ temperature (Fig. 28d) return to near-ambient levels. The maximum temperature and sensible heat flux values observed were about $50{ }^{\circ} \mathrm{C}$, and $18 \mathrm{KW} \mathrm{m}$, respectively.

The main plume impaction on the 13 January 2009 burn occurred from about 1220 to 1224 EST. Sensible heat flux (Fig. 29c) increased to about $20 \mathrm{KW} \mathrm{m}^{-2}$, and TKE (Fig. 29a) increased to about $5 \mathrm{~m}^{2} \mathrm{~s}^{-2}$. These maximum values correspond to a maximum $10 \mathrm{~m}$ temperature of almost $100{ }^{\circ} \mathrm{C}$ (Fig. 29d). During the plume impaction an updraft is observed and is followed by a downdraft of about $2 \mathrm{~m} \mathrm{~s}^{-1}$ (Fig. 29b). At approximately 1219 EST, the plume moves past the tower and TKE, sensible heat flux, and temperature return to near-ambient levels. Another sharp increase in TKE (Fig. 29a) is seen at 1255 EST. Coincidentally, there is a distinct wind shift as the $\mathrm{u}$ wind component transitions from positive to negative and the $\mathrm{v}$ component shifts from negative to slightly positive at 
about 1300 EST (Fig. 29b). The wind shift and increased TKE values suggest a secondary plume impacted the tower from upwind flaming and/or smoldering combustion.

The last winter burn on 14 January 2009 was arguably the most intense as the largest TKE and sensible heat flux were recorded. At about 1357 EST 10 m temperatures begin to increase (Fig. 30d). From temperature observations it appears multiple plumes impacted the tower before the main plume impacted the tower at about 1402 EST. There appears to be three major spikes in thermocouple temperature data. The first occurs from about 1338 to $1401 \mathrm{EST}$, the second from about 1403 to $1404 \mathrm{EST}$, and the last and largest from about 1405 to 1408 EST. Prior to 1357 EST the u, v, and w wind components are fairly stable (Fig. 30b) and increase significantly above background values when the plume(s) impact the tower. Updrafts occurred during the three major temperature spikes and were followed by downdrafts. Sensible heat flux (Fig. 30d) and TKE (Fig. 30a) reach maximum values of about $78 \mathrm{KW} \mathrm{m} \mathrm{m}^{-2}$ and $7.7 \mathrm{~m}^{2} \mathrm{~s}^{-2}$ at about 1404 EST, respectively. These peaks coincide with the observed maximum updraft (Fig. 30b) and temperature (Fig. 30d) of about $4 \mathrm{~m} \mathrm{~s}^{-1}$ and $100{ }^{\circ} \mathrm{C}$, respectively. 

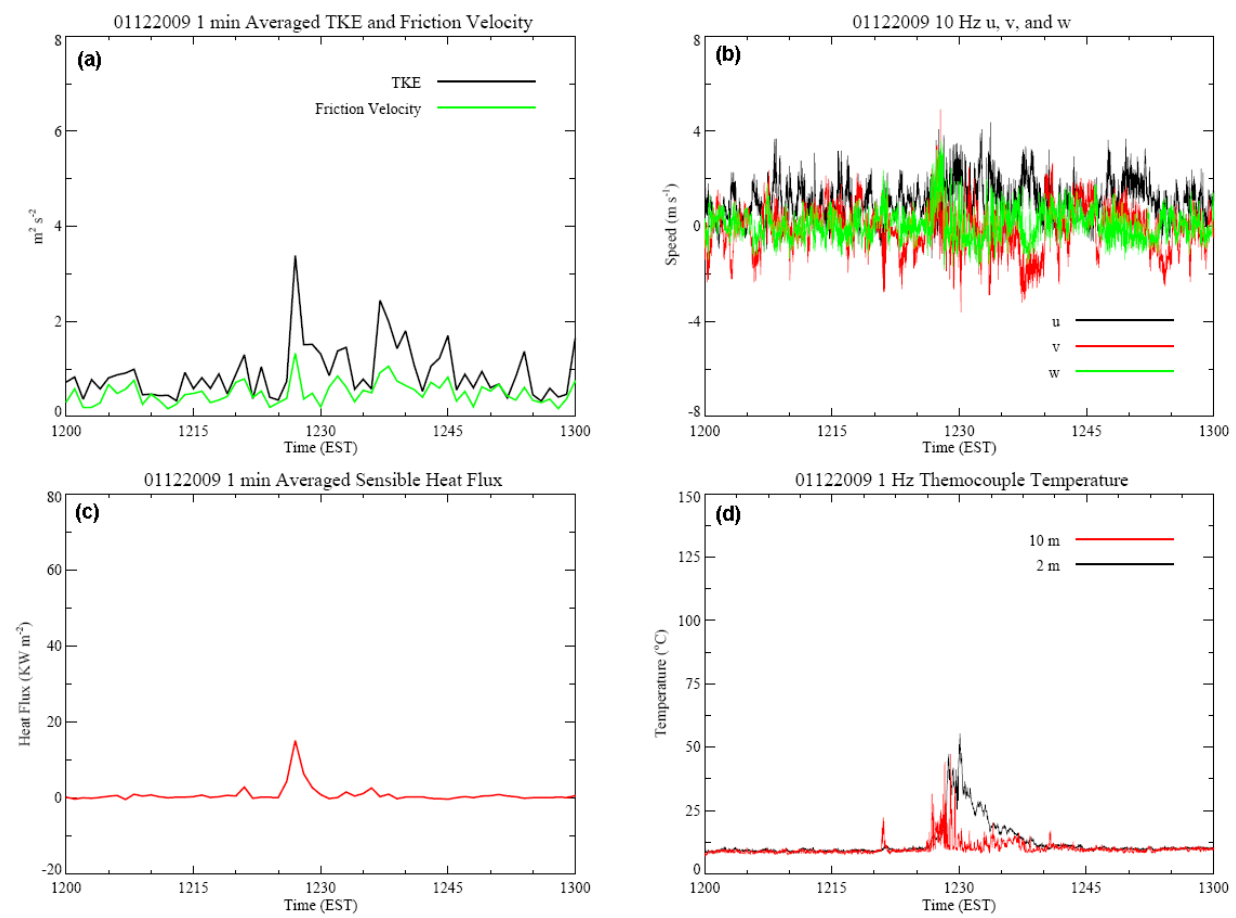

Fig. 28. One min averaged tower TKE, turbulent variances, and vector wind components measured during hour when fire front moved passed the tower on 12 January 2009.
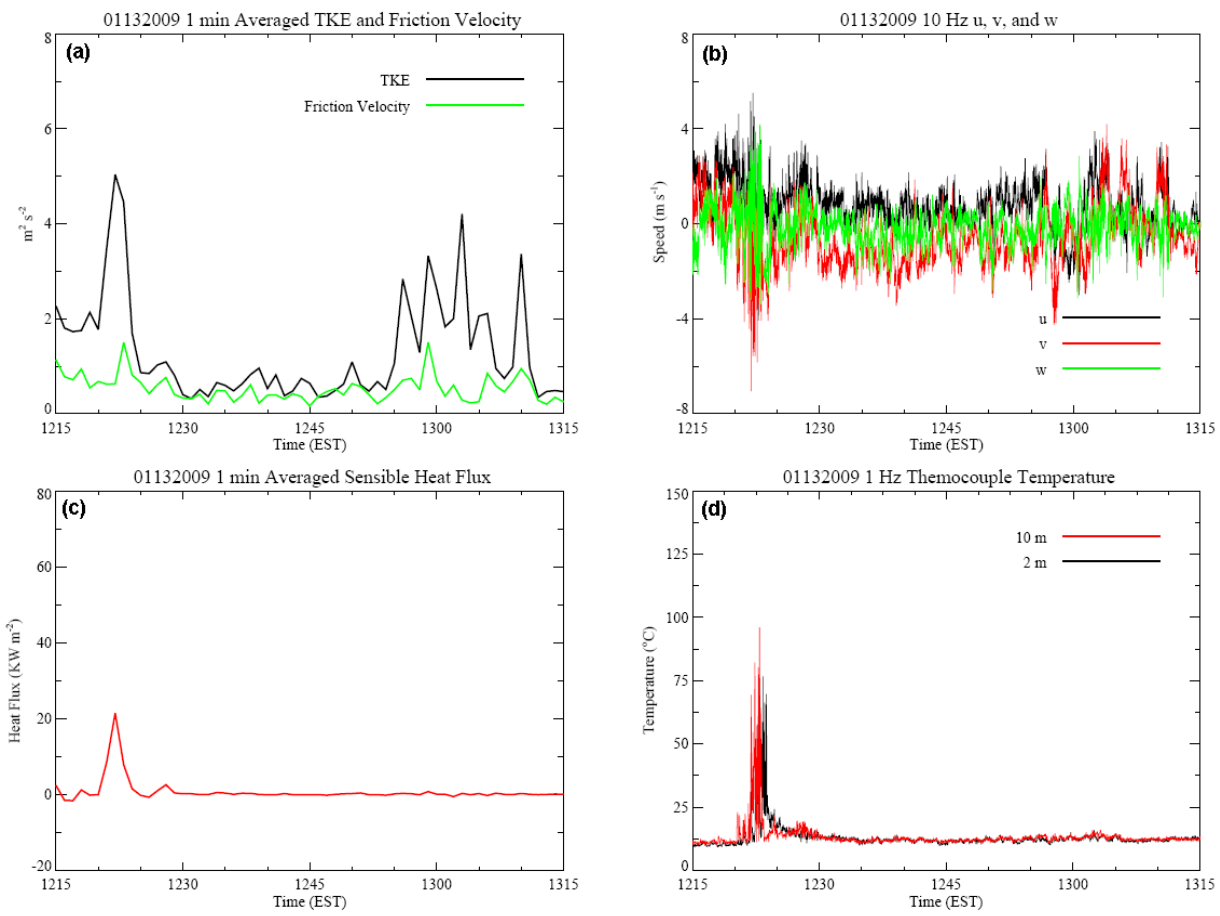

Fig. 29. One min averaged tower TKE, turbulent variances, and vector wind components measured during hour when fire front moved passed the tower on 13 January 2009. 

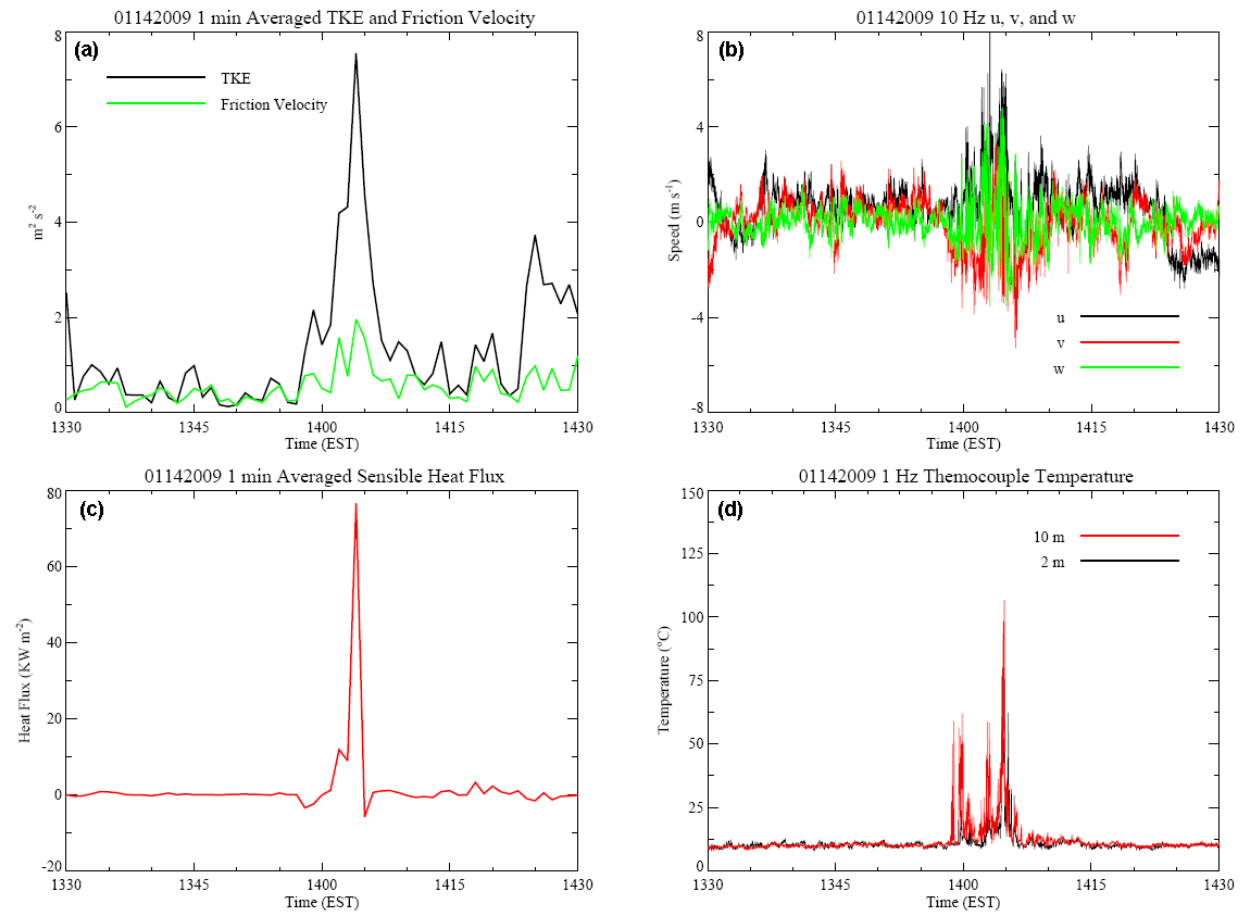

Fig. 30. One min averaged tower TKE, turbulent variances, and vector wind components measured during hour when fire front moved passed the tower on 14 January 2009. 


\section{Dispersion Modeling}

Once the emission characteristics have been determined it is of interest to model the concentration impact of fire on global, regional, and local scales (Wiedinmyer et al. 2006). Numerous methods and models have been used to evaluate the emissions and concentration impacts from fire (e.g., Dennis et al. 2002; Clinton et al. 2006; Roy et al. 2007; Hu et al. 2008; Yongtao et al. 2008)

a. AERMOD

The American Meteorological Society (AMS) - EPA Regulatory Model (AERMOD) was accepted as the preferred short-range regulatory dispersion model on 9 December 2006 (US EPA 2005). The AERMOD modeling system is comprised of the AMS-EPA Meteorological preprocessing model (AERMET), a terrain data preprocessor (AERMAP), and a surface characteristics preprocessor (AERSURFACE) (US EPA 2004a).

Running AERMOD requires basic inputs such as source location(s), receptor locations, and two preprocessed AERMET meteorological data files. One file consists of surface parameters (e.g., roughness length, friction velocity, Bowen ratio), and the other file contains meteorological vertical profiles. AERMOD can simulate multiple point, volume, line, and area source-types. Source emission rates may be varied by hour, month, season, or can be treated as constant throughout the modeling period. Userspecified receptor locations are highly flexible, and can also be placed above the surface (i.e., flagpole receptors). 
The AERMET preprocessor is designed to process National Weather Service (NWS) hourly surface observations, NWS upper air sounding data, and on-site collected data (US EPA 2004b). These data are used to characterize Planetary Boundary Layer (PBL) parameters needed for AERMOD dispersion calculations. The PBL is defined as the region between the surface and the free atmosphere, which is not affected by the surface (Garratt 1992). Sensible and latent heat and momentum fluxes determine PBL evolution and structure. Pollutants are mixed, dispersed, and transported within the PBL, where the depth can be estimated from local-scale surface characteristics. The surface characteristics required by AERMET depend on land-use type (e.g., urban area, forest, grassland) and include the albedo, the Bowen ratio, which is the ratio of sensible to latent heat flux, and the surface roughness length, which is the theoretical height above the ground where the wind speed equals zero.

From meteorological and surface data AERMET calculates the PBL parameters that influence PBL evolution and pollutant dispersion. These parameters include the sensible heat flux, the surface friction velocity, a measure of the vertical transport of horizontal momentum, the Monin-Obukhov length, the height above which convectively driven turbulence dominates over mechanically produced turbulence, the daytime mixed layer height, and nocturnal layer height (US EPA 2004b).

Mixing heights in AERMET are determined by atmospheric stability. If the atmosphere is stable, AERMET computes the mechanical mixing height, which represents the layer formed by mechanically-induced stress, dependent on wind speed and surface characteristics, where pollutants are mixed. During unstable conditions, 
usually during daytime hours when the flux of sensible heat is upwards, AERMET computes both the convective and mechanical mixing heights. Output from AERMET is used to drive the dispersion model, AERMOD.

The AERMOD plume model is steady-state and assumes the horizontal and vertical concentration distributions are Gaussian during stable conditions. During unstable conditions, the distribution in the horizontal is assumed Gaussian while the vertical distribution is treated as a bi-Gaussian probability density function (US EPA 2004c).

Depending on atmospheric stability, AERMOD calculates the dispersion factors, which govern the standard deviations of the lateral and vertical concentration distributions. Dispersion factors are calculated from measures of ambient turbulence and buoyancy.

Although AERMOD is probably not applicable for high-intensity wildfires, as increased turbulence and fumigation may not be captured, AERMOD may be able to reasonably reproduce the observed concentration distribution from low-intensity prescribed fires because prescribed fires are controlled, have smaller flame heights, and liberate much less heat than natural wildfire. Dispersion modeling is currently not required by the EPA for implementing a prescribed fire, but could be used as an important tool for land managers to evaluate the concentration impact downwind. b. Model Setup

Two of the six prescribed fires were modeled with AERMOD. The goal of the simulations is to model the $\mathrm{PM}_{2.5}$ concentrations observed at the downwind tripod during 
the 15 July 2008 and 12 January 2009 prescribed burns. Out of the three burns during the summer and winter these represent the most ideal experiments to model because the wind direction variability was generally low and the tripod was placed in an ideal location downwind.

Surface NWS data from Albany, GA (KABY), and NWS sounding data from Tallahassee, FL (KTLH) were obtained and input to AERMET. The data obtained represent the meteorological conditions for six days starting at 0000 EST two days prior to the simulation. This allows AERMET to compute the growth and decay of the boundary layer and boundary layer parameters for days prior to and after each simulation for comparison. Timeseries of AERMET-derived sensible heat flux, an important parameter used by AERMET to estimate the depth of the PBL, for the July and January simulation are shown in Figs. 31 and 32 respectively.

Wind direction and speed, temperature, and $\mathrm{RH}$ obtained at the tripod were utilized as on-site data. The tripod was in operation during the duration of each burn, thus employing these on-site data assures a more representative calculation of PBL parameters in the model domain. One min averaged wind speed and direction measured at the tripod during the duration of the burn on 15 July 2008 and 12 January 2009 are shown in Figs. 33 and 34, respectively. During both burns the prevailing winds were mainly north-easterly. All tripod meteorological data were averaged to one hour to be read by AERMET. The log-law was used to estimate $10 \mathrm{~m}$ wind speeds from $2 \mathrm{~m}$ tripod measurements (Arya 1999). 
The AERSURFACE algorithm was applied to obtain realistic surface characteristic values of albedo, Bowen ratio, and surface roughness length. Given the location of the tripod, AERSURFACE reads in a $30 \mathrm{~m}$ resolution Georgia land cover dataset from the US Geological Survey (USGS) and computes the seasonal surface characteristic values for a specified area (US EPA 2008). The area chosen was the 90 deg-wide segment of a circle with a $1 \mathrm{~km}$ radius that encapsulates the tripod and the burn unit. The AERSURFACE-derived surface roughness lengths for the summer and winter simulations were 0.287 and 0.254 , respectively. These values agree with Hicks et al. (1975) who found the surface roughness length of a pine forest to be 0.32. With NWS surface, profile, on-site, and surface characteristic data, AERMET was run and successfully produced meteorological input files for AERMOD. 


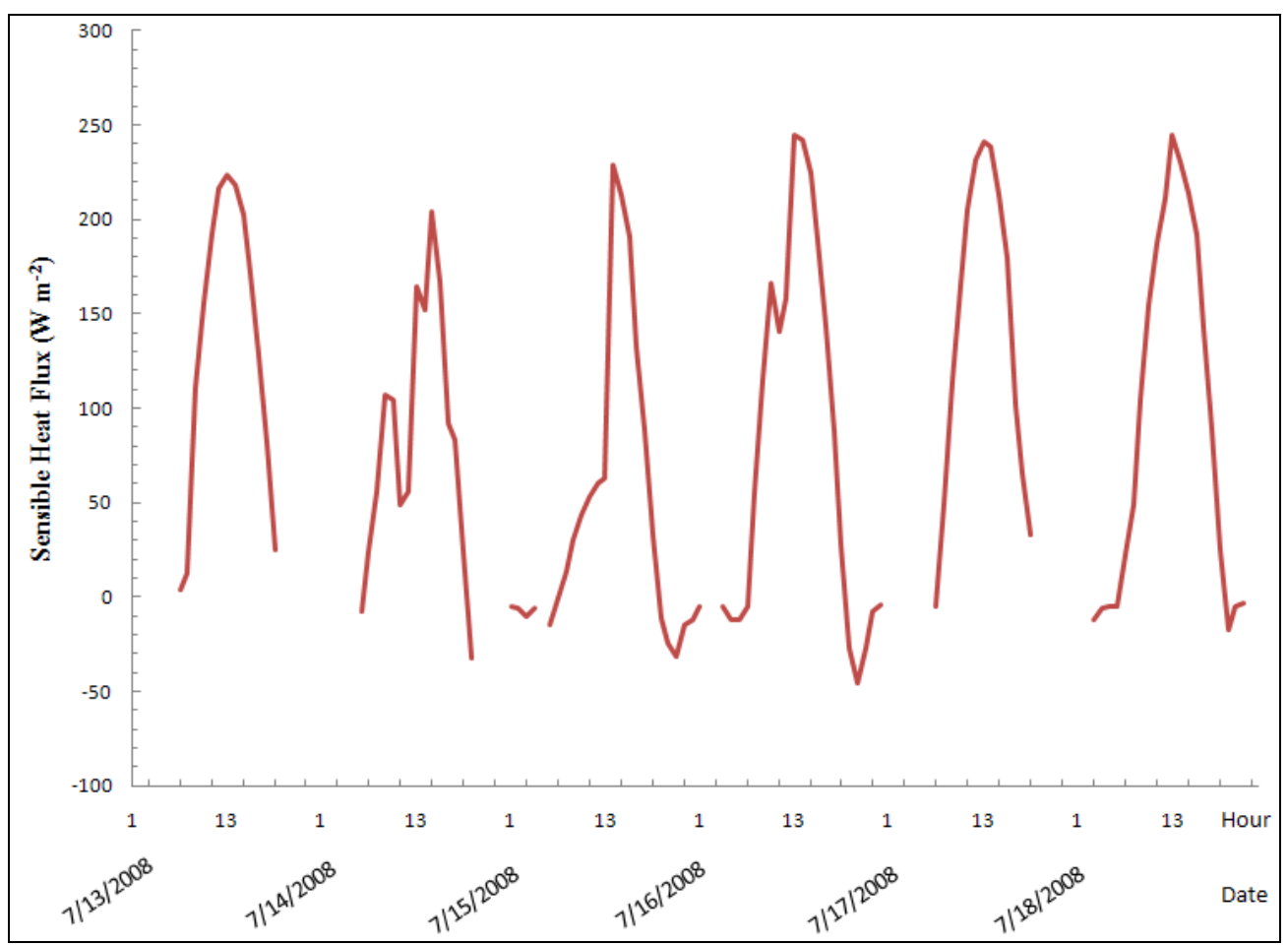

Fig. 31. Timeseries of AERMET derived sensible heat flux from 13 to 18 July 2008.

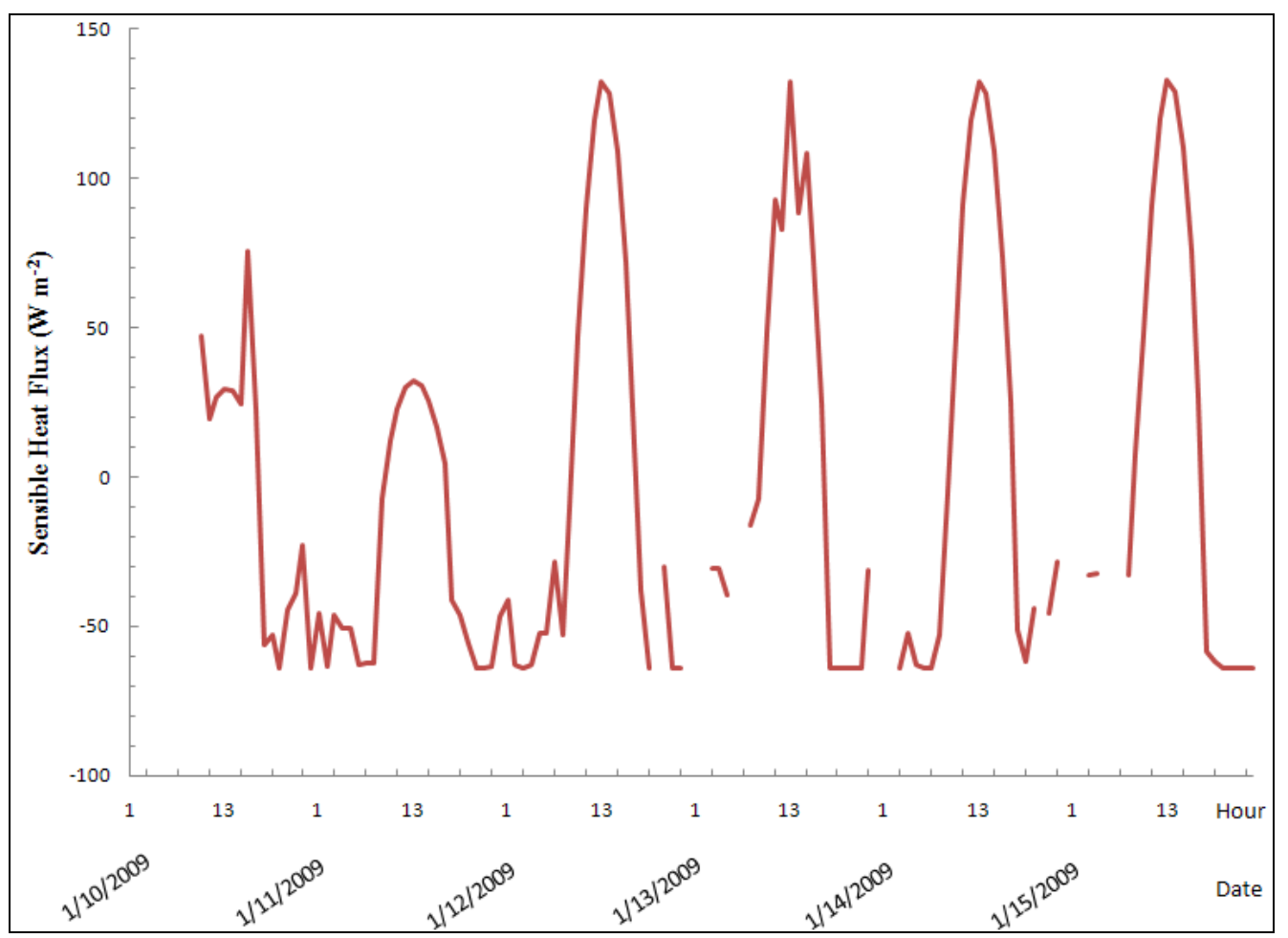

Fig. 32. Timeseries of AERMET derived sensible heat flux from 10 to 15 January 2009. 


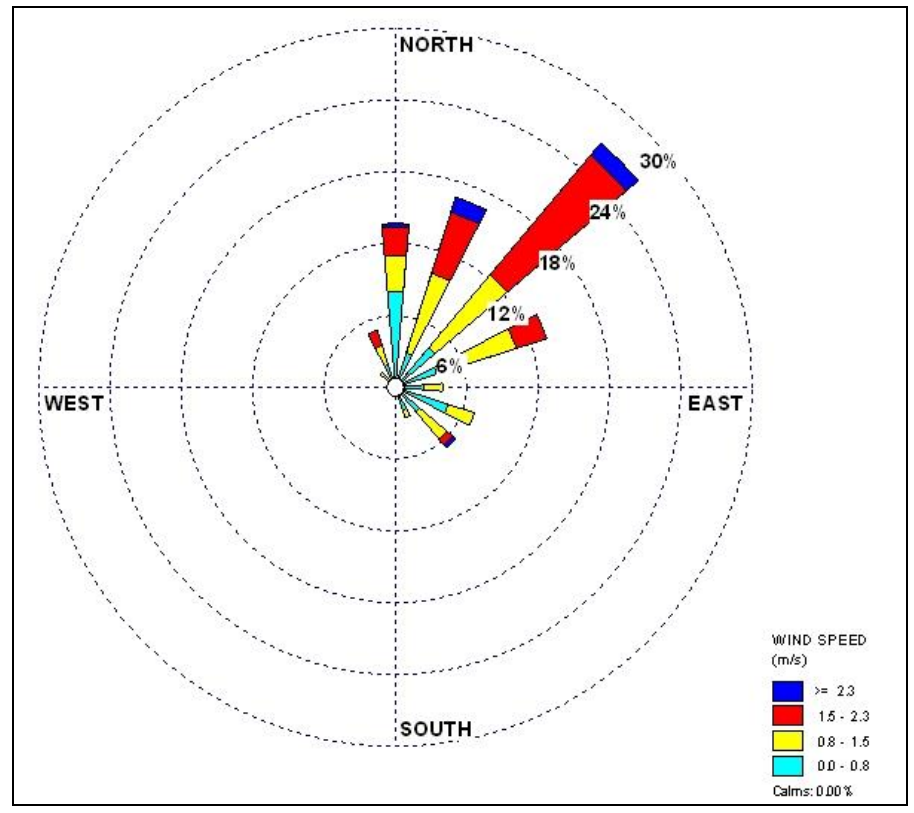

Fig. 33. Wind speed and direction (averaged to $1 \mathrm{~min}$ ) measured at the tripod during the duration of the burn on 15 July 2008.

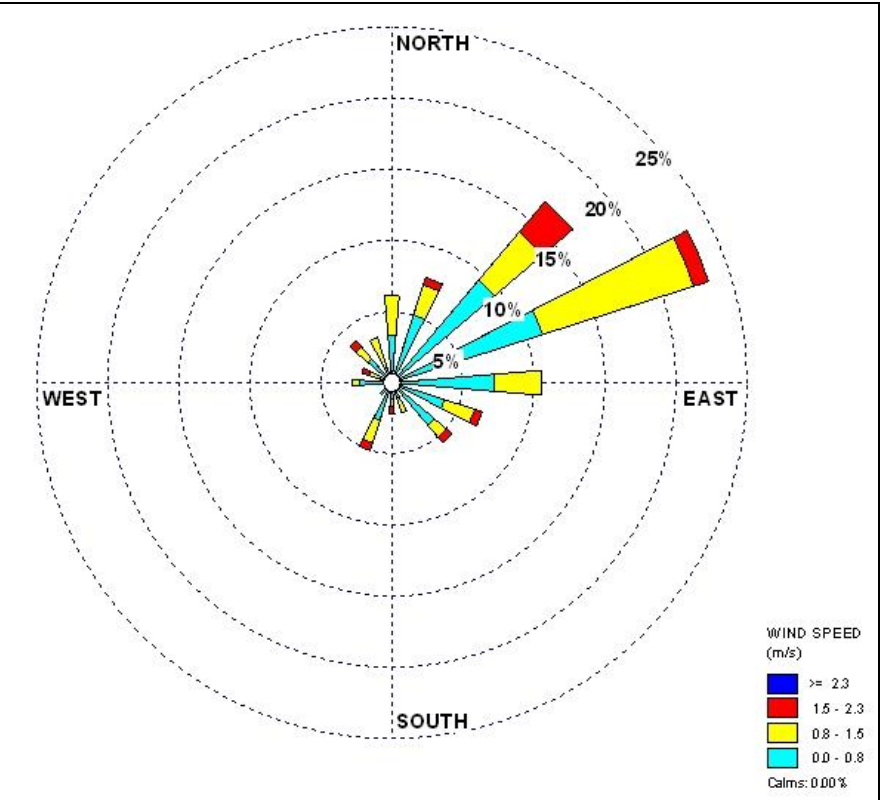

Fig. 34. Wind speed and direction (averaged to $1 \mathrm{~min}$ ) measured at the tripod during the duration of the burn on 12 January 2009. 
The AERMOD simulations were conducted over the duration of the prescribed burns to ascertain the period and hourly averaged $\mathrm{PM}_{2.5}$ concentration distributions. The burn duration was well documented with numerous data loggers and in field manuals. The tripod location was recorded with a GPS unit and is represented in the model by a 2 m flagpole receptor, the height of the $\mathrm{PM}_{2.5}$ inlet.

Since the unit was burned from the most downwind edge to the most upwind edge, numerous area sources were created in the simulations to replicate this burning pattern. Although the exact location and time of ignition is uncertain, the unit was ignited from the most downwind to the most upwind side; thus, instead of modeling the emissions from the burns as one area source over the burn-duration, numerous area sources were utilized in the runs.

The location of the units, and the area sources derived from the unit locations, were determined from GIS data and Google Earth Pro software. The first hour of each burn required the development of a blackline, using a slow-propagating backing fire; accordingly, the first hour represents the smallest area source. The total remaining area of the units were divided by the remaining hours of each burn to obtain the average acreage burned per hour (Table 15). The location of the area sources, representing the area burned from hr 1 to $\mathrm{N}$, are placed upwind of the previous source and do not overlap. The edge of each area source was assumed to be oriented perpendicular to the mean wind direction. 
Table 15. AERMOD burn unit section number and size delineation for the 15 July 2008 and 12 January 2009 prescribed fires.

\begin{tabular}{cccc}
\hline & \multicolumn{1}{l}{$\mathbf{7 / 1 5 / 2 0 0 8}$} & \multicolumn{1}{l}{$\mathbf{1 2 / 2 0 0 9}$} \\
\hline Section & Size (acres) & Section & Size (acres) \\
\hline 1 & 23 & 1 & 49 \\
2 & 47 & 2 & 75 \\
3 & 47 & 3 & 75 \\
4 & 47 & 4 & 47 \\
5 & 47 & & \\
\hline
\end{tabular}

The burn on 15 July 2008 took five hours to complete. The tripod collected data for an additional hour, following the conclusion of flaming, during smoldering. The unit was divided into five sections (Fig. 35), and was simulated by initiating (i.e., "turning on") the units from one to five. The 12 January 2009 burn took four hours to complete, and was divided into four sections (Fig. 36). The burn crew was initially not going to ignite the area to the southeast, but due to time, they were able to burn this area last; therefore, the fire was simulated by initiating units one to three over the first three hours, and the unit four, to the southeast, was initiated during the last hour of the burn. 


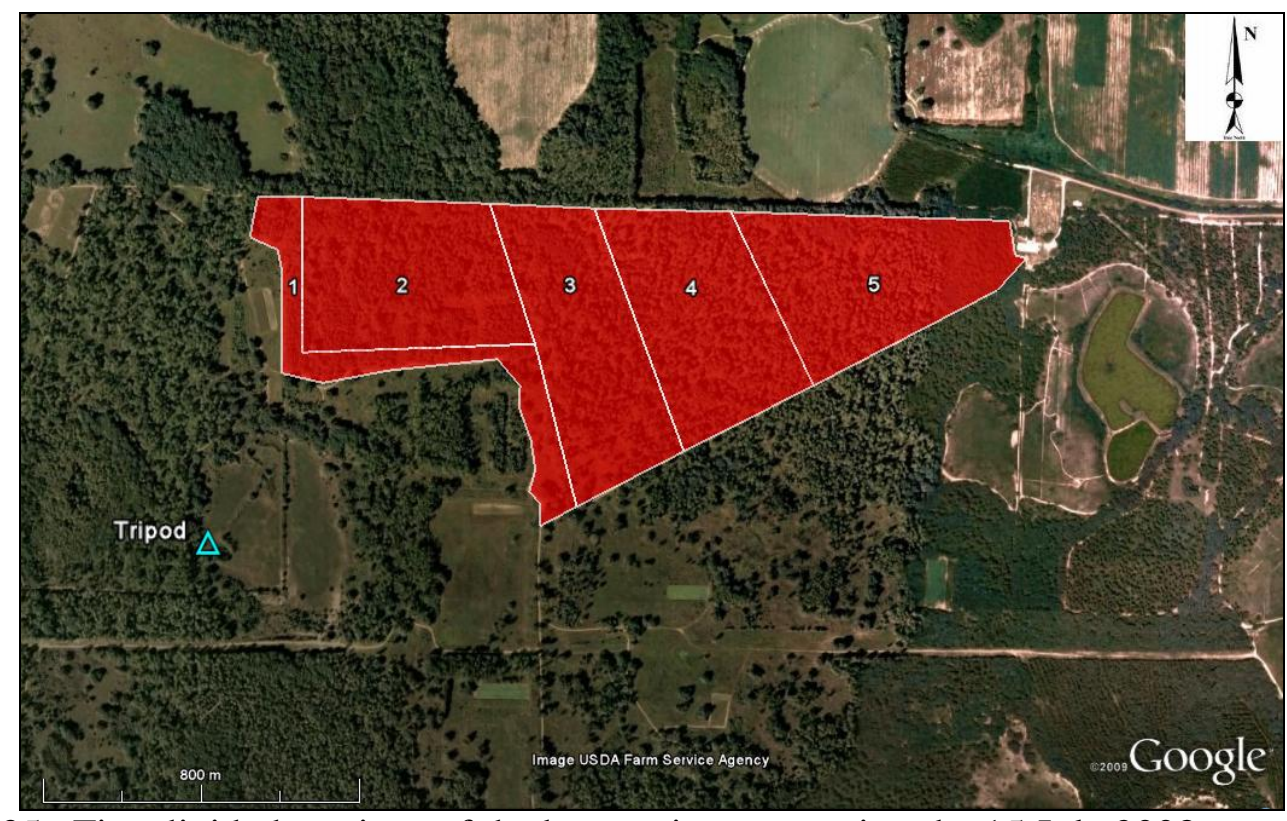

Fig. 35. Five divided sections of the burn unit representing the 15 July 2008 prescribed burn. The fire is simulated as progressing from unit 1 to 5 .

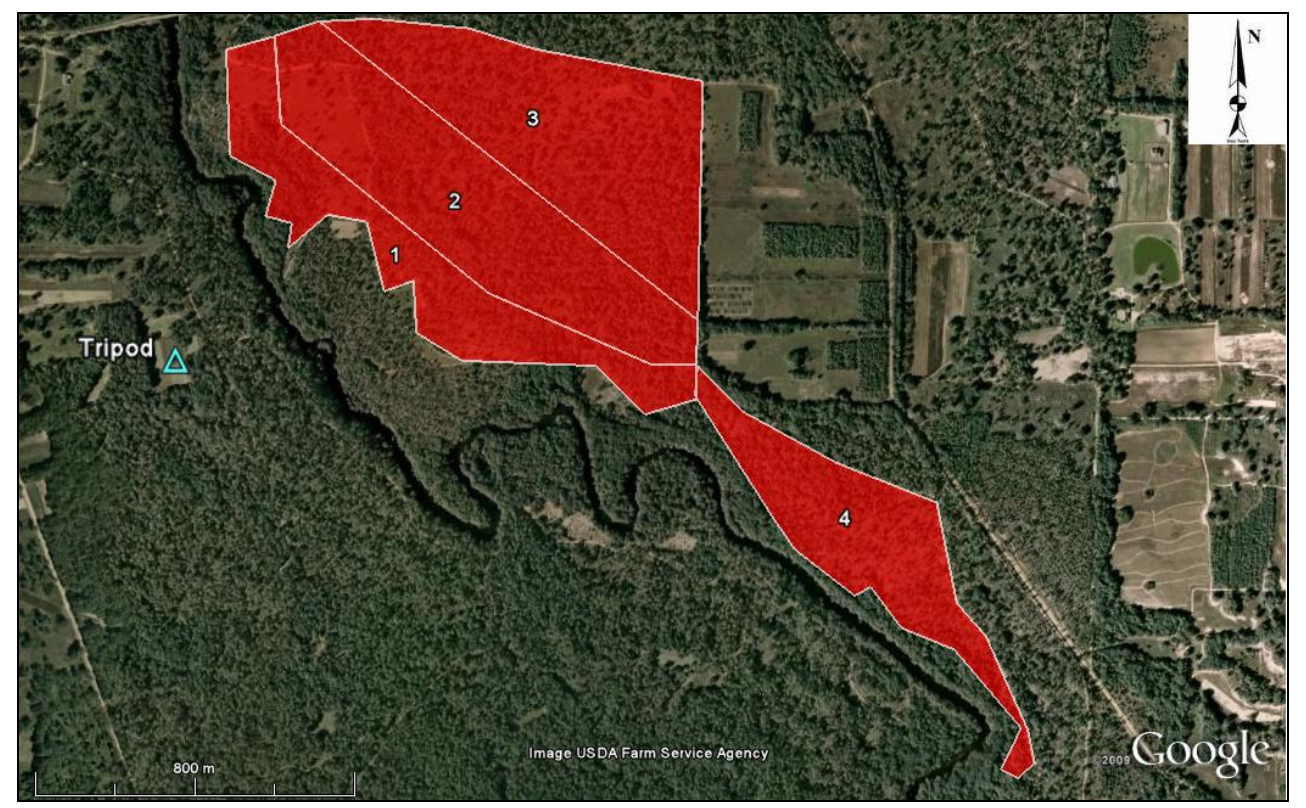

Fig. 36. Four divided sections of the burn unit representing the 12 January 2009 prescribed burn. The fire is simulated as progressing from unit 1 to 4 . 
Since emissions and impacts from flaming and smoldering are quite different, an effort was made to model both flaming and smoldering emissions. Each burn-area section corresponds to two area sources in AERMOD. Each section was represented with a flaming source and a smoldering source with the exact same dimensions such that the 15 July 2008 burn was modeled using 10 areas sources, two for each section. During the first hour of each simulation the most downwind section (section 1) is treated as both flaming and smoldering by "turning on" the flaming and smoldering area sources corresponding to that section. The emission rates of all other sources are set to zero during this hour. The next hour, the upwind adjacent section (section 2) is treated as both flaming and smoldering, while the previously flaming area source, active during the first hour in section 1, is "turned off'. Each section was allowed to smolder for three hours total, two hours of which are not accompanied by flaming emissions. The emissions from smoldering during the first two hours are equivalent while the smoldering emission rate during the third hour was assumed to be half of the emission rate of the first and second hours. By hour three of the simulation, section 1 and 2 are only smoldering while the section upwind and adjacent to section 2 (section 3) is flaming and smoldering. This procedure is repeated until the time period of the burn is complete.

The area emission rates, applied to each area source, were derived from calculated emission factors and pre and post clip-plot-derived fuel consumption by

$$
A E=\frac{E F_{t}^{*} F C}{t},
$$


where $\mathrm{AE}$ is the area emission rate in $\mathrm{g} \mathrm{s}^{-1} \mathrm{~m}^{-2}, \mathrm{EF}_{\mathrm{t}}$ is the emission factor in $\mathrm{g} \mathrm{kg}^{-1}, \mathrm{FC}$ is the fuel consumption in $\mathrm{kg} \mathrm{m}^{-2}$, and $\mathrm{t}$ is the time in seconds, where the $\mathrm{EF}_{\mathrm{t}}$ represents the emissions from both flaming and smoldering for each section. To separate flaming and smoldering emissions, $\mathrm{W}_{\mathrm{v}}$, summed during flaming and smoldering, was used. The modeled flaming emission factor was calculated by

$$
E F m_{f}=\frac{\sum W_{v f}}{\sum W_{v f}+\sum W_{v s}} * E F_{t},
$$

where $\mathrm{EFm}_{\mathrm{f}}$ is the modeled $\mathrm{EF}_{\mathrm{f}}, \Sigma \mathrm{W}_{\mathrm{vf}}$ is the sum of fuel consumption during the flaming stage, and $\Sigma \mathrm{W}_{\mathrm{vs}}$ is the sum of fuel consumption during the smoldering stage. The modeled smoldering emission factor was calculated by

$$
E F m_{s}=\frac{\sum W_{v s}}{\sum W_{v f}+\sum W_{v s}} * E F_{t},
$$

where $\mathrm{EFm}_{\mathrm{s}}$ is the modeled $\mathrm{EF}_{\mathrm{s}}$; thus, the Area Emission rates due to flaming $\left(\mathrm{AE}_{\mathrm{f}}\right)$ and smoldering $\left(\mathrm{AE}_{\mathrm{s}}\right)$ are given by

$$
\begin{aligned}
& A E_{f}=\frac{E F m_{f} * F C}{t} \\
& A E_{s}=\frac{E F m_{s} * F C}{t} .
\end{aligned}
$$


The $\mathrm{EFm}_{\mathrm{s}}$ were divided by two to account for the smoldering emissions being applied over the first and second hour of smoldering. For example, the $\mathrm{EF}_{\mathrm{t}}$ for the 15 July 2008 burn was determined to be $12.1 \pm 2.6 \mathrm{~g} \mathrm{~kg}^{-1}$. Using the mean $\mathrm{EF}_{\mathrm{t}}$ value, the $\mathrm{EFm}_{\mathrm{f}}$ was calculated to be 10.32 , and the $\mathrm{EFm}_{\mathrm{s}}$ was $1.77 / 2=0.89$. If we apply smoldering over two hours the total of each section is $10.32+0.89+0.89=12.1 \mathrm{~g} \mathrm{~kg}^{-1}$; however, since data captured during the smoldering phase could not be used to evaluate smoldering on periods longer than 20 mins, because the tower had become a downwind receptor, emissions from smoldering may be underestimated. To account for this possible underestimation, a third hour of smoldering emissions was allowed where the $\mathrm{EFm}_{\mathrm{s}}=\mathrm{EFm}_{\mathrm{s}} / 4$. In the example, this would allow an extra $0.44 \mathrm{~g} \mathrm{~kg}^{-1}$ of smoldering-type emissions from each section. The new total, for the example, is $10.32+0.89+0.89+$ $0.44=12.54 \mathrm{~g} \mathrm{~kg}^{-1}$, which is well with the range of the calculated value of $12.1 \pm 2.6 \mathrm{~g}$ $\mathrm{kg}^{-1}$.

One drawback in AERMOD is that the exit temperature and exit velocity of emissions from area sources cannot be defined. Even during a low-intensity prescribed fire, the heat liberated from flaming combustion will give the plume extra buoyancy and allow it to rise. The height to which the plume will rise is dependent on atmospheric stability, momentum, and buoyancy (Arya 1999). A simple way to account for plume rise is to specify a release height for flaming sources, some distance from the ground.

Two methods were used to estimate plume heights. During each burn a radiosonde was launched downwind of the unit into an established plume aloft. The radiosonde calculates height above the surface via GPS, as well as high-frequency 
temperature and moisture data. As the radiosonde ascended through the plume, temperatures and moisture increased. Moisture is released during combustion, so one would expect to observe enhanced moisture values in a plume. The increased moisture values were corroborated with temperature data to ensure the signature of the phenomenon was due to the plume aloft.

Additionally, the Fire Emissions Production Simulator (FEPS) (Anderson et al. 2004) was used to model each case and estimate plume rise. The FEPS system provides dynamic simulations of fuel consumption, emissions, and plume buoyancy. Fuel loading and moisture, fire growth rate, fuel consumption, and meteorology were input to FEPS for each simulation. The Briggs maximum plume rise, was solved by FEPS for each case.

From radiosonde data, the plume signature aloft on 15 July 2008 and 12 January 2009 extends from $100-200$ m, and 75 - 175 m AGL, respectively. Similarly, the Briggs maximum plume rise from FEPS on 15 July 2008 and 12 January 2009 was 202, and $187 \mathrm{~m}$, respectively. The plume heights from these two methods are in agreement, however, FEPS-derived plume heights were used to specify the release height of the flaming area sources.

The release height of all smoldering sources was assumed to be $10 \mathrm{~m}$. A sensitivity analysis was conducted to ensure the release height of the smoldering emissions does not affect the overall results by a significant margin. There was little change in the results when smoldering release heights were incremented from $0-20 \mathrm{~m}$ AGL. Emissions from smoldering do not tend to loft like flaming emissions but are subject to a more drift-like pattern. 


\section{c. Model Results}

The period averaged $\mathrm{PM}_{2.5}$ concentration distribution at $2 \mathrm{~m}$ for the AERMOD prescribed fire simulation on 15 July 2008 is displayed in Fig. 37. Due to northeasterly winds, pollutants were transported to the southwest. The observed period-averaged $\mathrm{PM}_{2.5}$ concentration at the tripod during the burn was $119 \mu \mathrm{g} \mathrm{m}^{-3}$, while the modeled periodaveraged $\mathrm{PM}_{2.5}$ concentration at the tripod-receptor was $101 \mu \mathrm{g} \mathrm{m}^{-3}$. Since the emissions were calculated by first subtracting ambient pre-fire concentrations to model fire-only impacts, pre-fire ambient concentrations were also subtracted from tripod concentrations observed during the fire. The period averaged concentrations were very well captured by AERMOD for this case.

Hourly averaged concentrations were also evaluated for the 15 July 2008 burn (Fig. 38). Modeled hourly averaged concentrations match very well to observations. The model seems to underestimate the concentration downwind during the first three hours of the burn and overestimate during the fourth hour. During Hour 6, when there is no emission due to flaming, AERMOD was able to do a reasonable job simulating the impact from smoldering, but the modeled value is a little more than half of the observed. This may indicate that emissions due to smoldering may still be underestimated. Overall, AERMOD was able to reproduce the observed hourly averaged concentration structure well. 


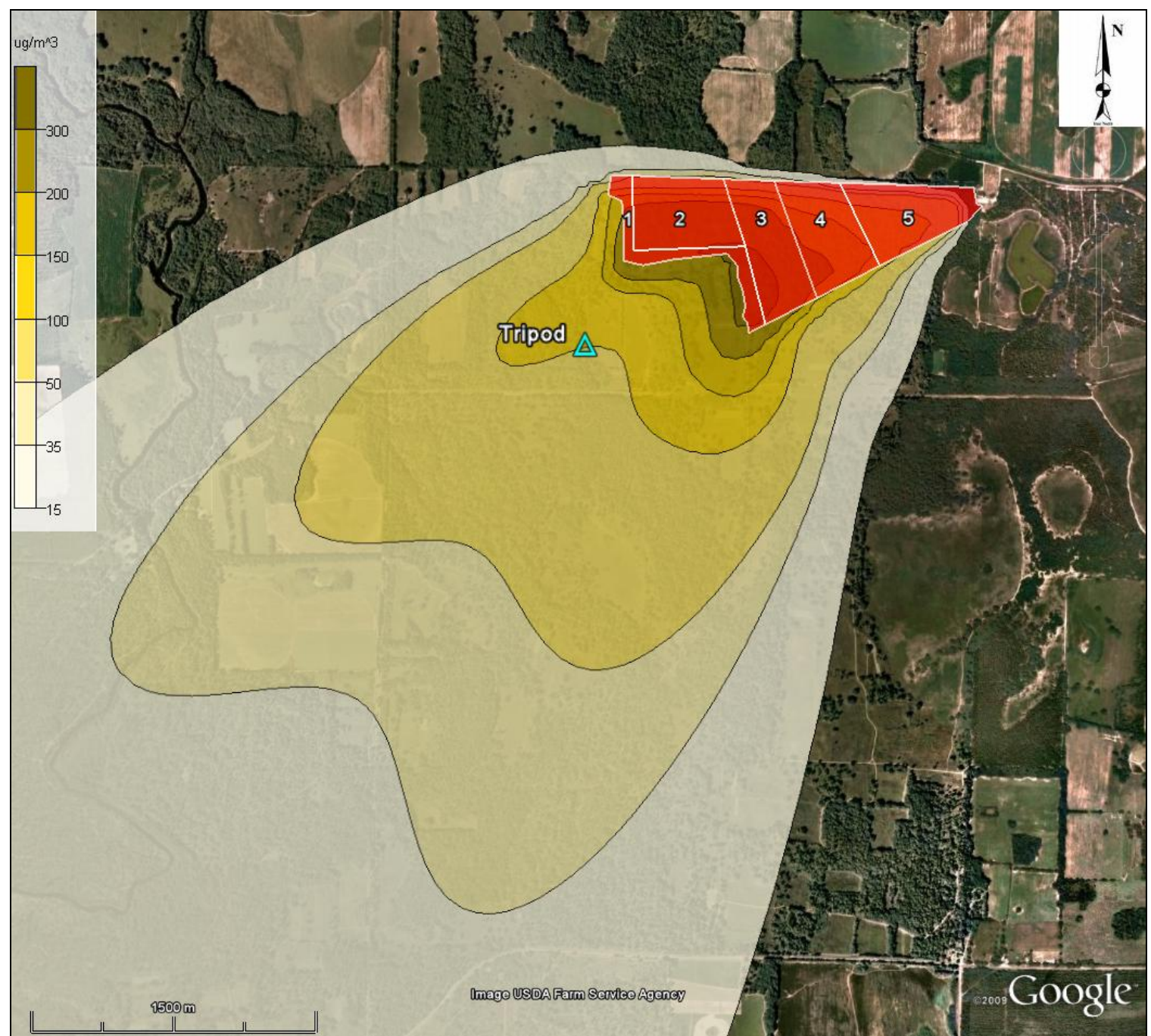

Fig. 37. Period averaged $\mathrm{PM}_{2.5}$ concentration distribution at $2 \mathrm{~m}$ for the prescribed fire AERMOD simulation on 15 July 2008. The blue triangle represents the location of the tripod and the contours are in units of $\mu \mathrm{g} \mathrm{m}^{-3}$. 


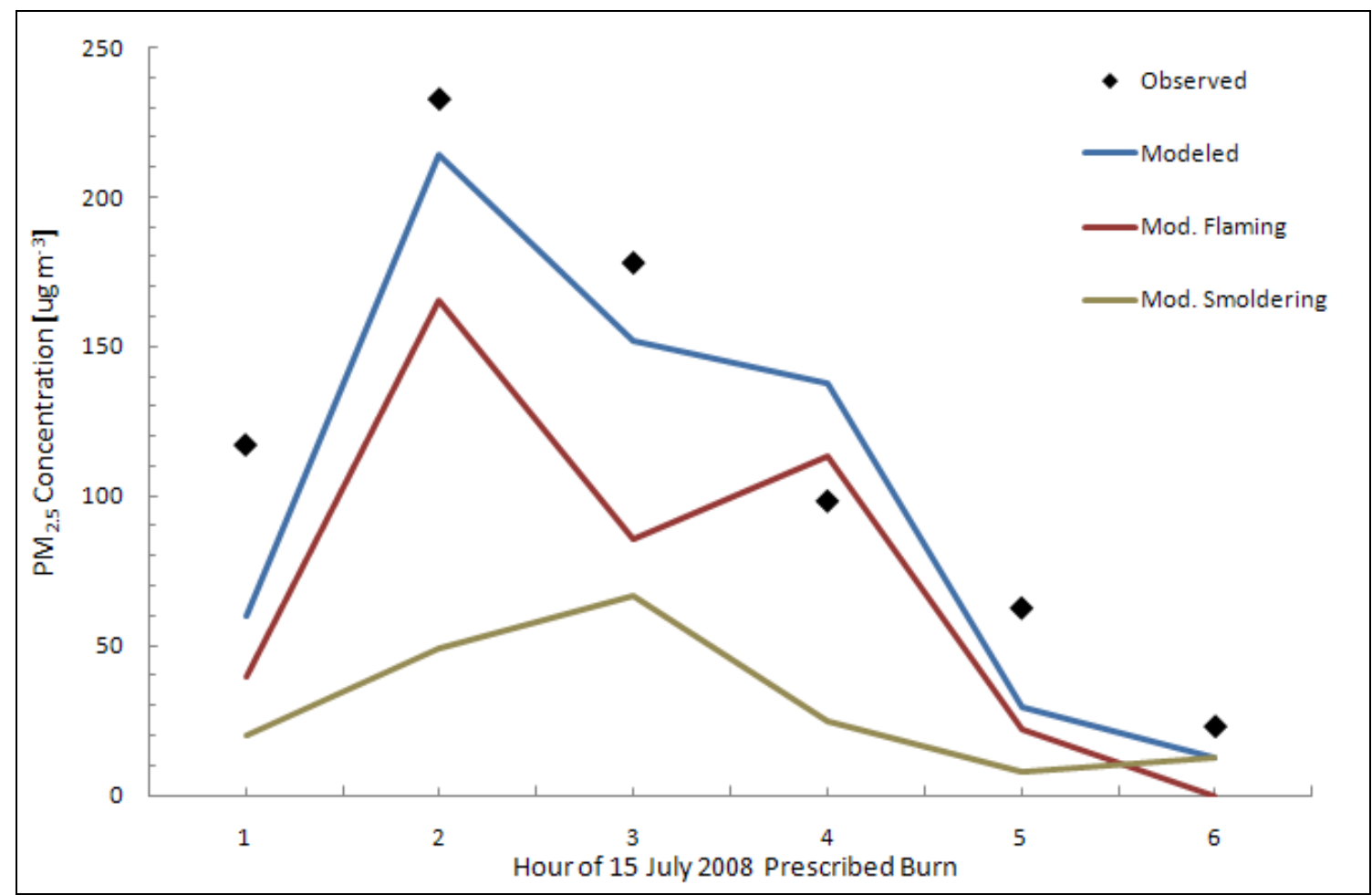

Fig. 38. Hourly averaged $\mathrm{PM}_{2.5}$ observations and AERMOD output for the 15 July 2008 burn. The blue line represents the total modeled impact due to flaming emissions (red), and smoldering (brown). The green and purple lines depict the observed and modeled period average, respectively.

The period averaged $\mathrm{PM}_{2.5}$ concentration distribution at $2 \mathrm{~m}$ for the AERMOD prescribed fire simulation on 12 January 2009 burn is shown in Fig. 39. The observed period-averaged $\mathrm{PM}_{2.5}$ concentration at the tripod during the burn was $98 \mu \mathrm{g} \mathrm{m}^{-3}$, while the modeled period-averaged $\mathrm{PM}_{2.5}$ concentration at the tripod was $89 \mu \mathrm{g} \mathrm{m}^{-3}$. The period averaged concentrations were well simulated by AERMOD for this burn.

The hourly averaged concentrations are shown in Fig. 40. Modeled hourly averaged concentrations do not seem to agree as well to observations as the first case. The model was able to capture the general pattern, where the maximum one hour concentration is observed during the second hour of the burn. The model overestimates 
concentrations during the first and third hour, while severely underestimating the concentration during the second hour. Since the exact area that was burned per hour was unknown, the sources had to be divided up equally. It is quite possible the area modeled during the first and third hour were too large and that more acres were burned during the second hour. Overall, since the modeled period average is close to the observed, AERMOD seems to be able to evaluate the dispersion very well for this case. 


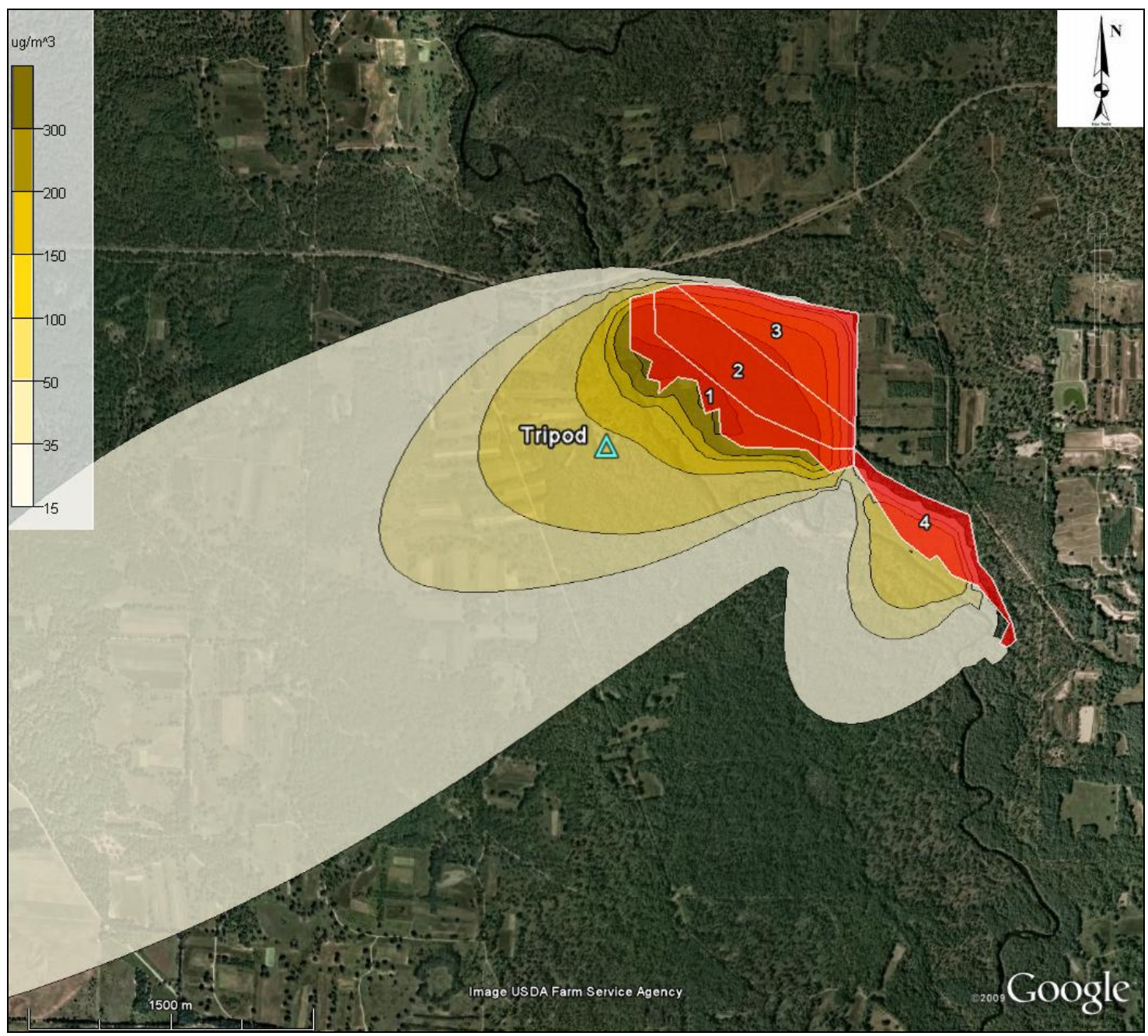

Fig. 39. Period averaged $\mathrm{PM}_{2.5}$ concentration distribution at $2 \mathrm{~m}$ for the prescribed fire AERMOD simulation on 12 January 2009. The blue triangle represents the location of the tripod and the contours are in units of $\mu \mathrm{g} \mathrm{m}^{-3}$. 


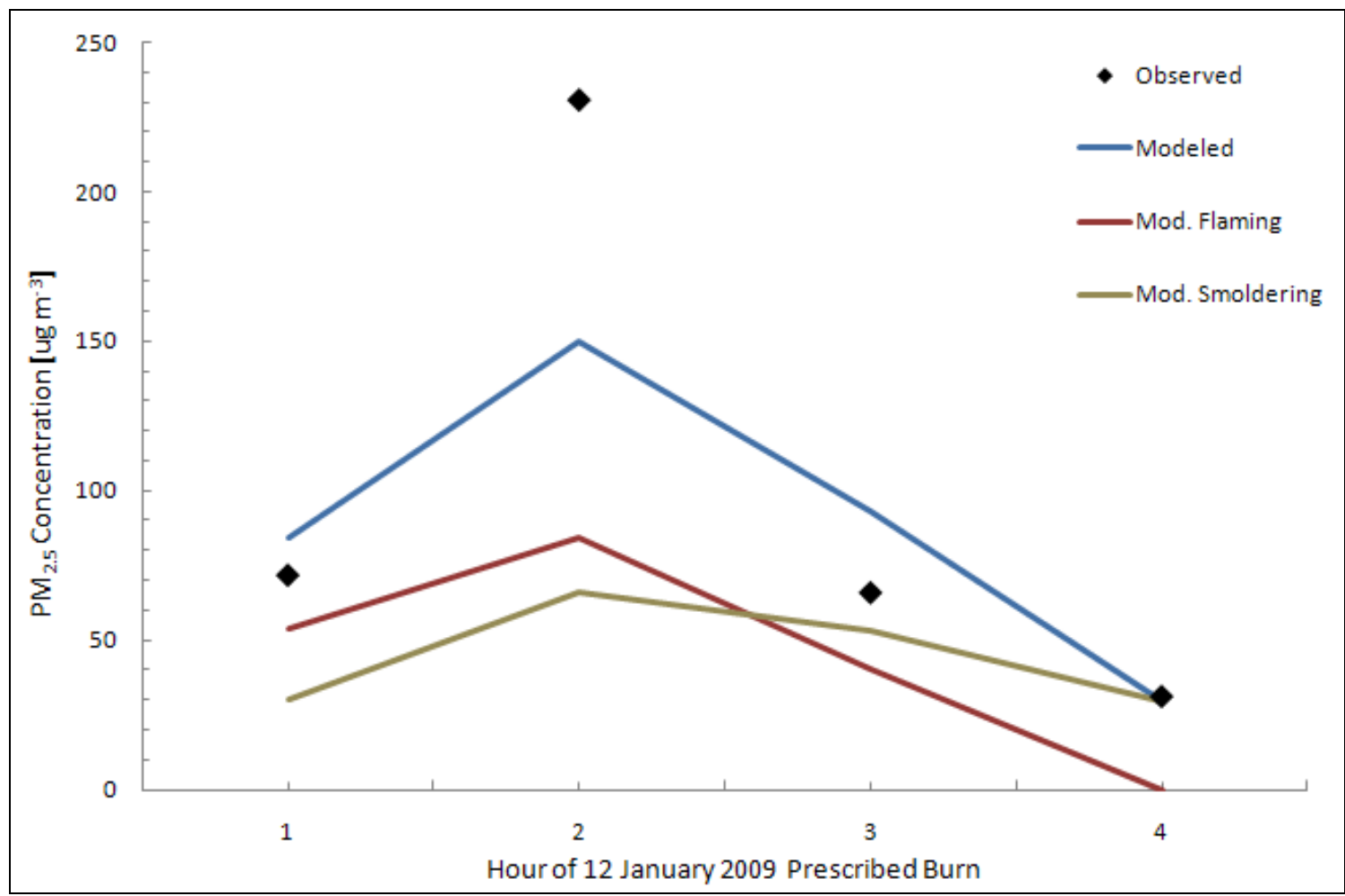

Fig. 40. Hourly averaged $\mathrm{PM}_{2.5}$ observations and AERMOD output for the 12 January 2009 burn. The blue line represents the total modeled impact due to flaming emissions (red), and smoldering (brown). The green and purple lines depict the observed and modeled period average, respectively. 


\section{Conclusion}

In this study, effects of seasonal-related variations and of turbulence generation on emissions and impacts from prescribed fires were evaluated. High frequency in situ data obtained from three summer (July 2008) and three winter (January 2009) prescribed fires were used to evaluate emissions and fire-atmosphere interactions. Two cases were selected to evaluate the performance of the EPA-approved short-range regulatory dispersion model, AERMOD, for prescribed fire. The following are the key findings of this study:

- MCE values during smoldering were lower than flaming, which suggests data segregation utilizing sensible heat flux, temperature, in situ concentrations, and MCE is applicable if a visual confirmation between flaming and smoldering cannot be made. MCE values during winter fires were larger than summer fires. This is most likely due to differences in fuel, as summer fuels were much greener and had higher moisture contents.

- The $\mathrm{PM}_{2.5} \mathrm{EFs}_{\mathrm{t}}$ for all winter fires were lower than summer fires. During the flaming stage, the mean winter $\mathrm{EF}_{\mathrm{f}}$ was about half the mean summer $\mathrm{EF}_{\mathrm{f}}$. The mean winter $\mathrm{EF}_{\mathrm{t}}$ was $7.7 \pm 1.3 \mathrm{~g} \mathrm{~kg}^{-1}$, while the mean summer $\mathrm{EF}_{\mathrm{t}}$ was $12.1 \pm$ $1.0 \mathrm{~g} \mathrm{~kg}^{-1} \cdot \mathrm{PM}_{2.5}$ emissions were thus found to lower in the winter prescribed burns, as expected, since summer MCEs were lower.

- For the winter data, a statistical analysis was performed to test the relationship between turbulence generation, TKE, and other measured quantities. The 
correlations between TKE and all concentration data, and notably, MCE, are statistically significant to the $99 \%$ confidence interval, thus suggesting turbulence generation, fire efficiency, and emissions from fires, in this experiment, are related.

- During all burns, TKE, sensible heat flux, $\mathrm{u}, \mathrm{v}$, and w wind components, and temperature increased well above background levels when the plume impacted the tower. An updraft was also observed inside the plume and a downdraft was observed as the plume propagated beyond the tower. This corroborates results found by Clements et al. (2006, 2007, 2008).

- The AERMOD dispersion model was able to reproduce the observed period averaged concentration and the hourly averaged concentration structures for prescribed fire. AERMOD may be applicable for modeling short-range impacts from low-intensity prescribed fire, and could possibly be used as a tool for land managers who prescribe fire.

For future studies, it is recommended higher-quality pollutant samplers are used. Concentrations derived from the DUSTRAK are based on an internal calibration using coarser particles than those observed during biomass combustion. Likewise, the resolution and response time of the $\mathrm{HOBO} \mathrm{CO}$ monitor was poorer than desired, and, as temperature increase above $20{ }^{\circ} \mathrm{C}$, an additional temperature-induced error may exist. Temperature readings from the tower show temperature increases well above $20{ }^{\circ} \mathrm{C}$, which could affect calculations of MCE, EFs, and fuel consumption. 
To calculate emission factors precisely requires knowledge of all species emitted containing carbon. In this study only $\mathrm{CO}$ and $\mathrm{CO}_{2}$ were measured, which thus required use of a factor to estimate the total amount of carbon contained in the other species. This introduces uncertainty in the calculations. To reduce this uncertainty, other carbonaceous species should be evaluated.

The size and location of emission sources for the AERMOD simulations had to be estimated. For future experiments, it is recommended burn crews mark their positions during ignition with a GPS unit, such that their location and the area burned per hour can be better estimated. AERMOD output could only be compared to one downwind receptor, the tripod. To better evaluate the applicability of AERMOD for prescribed fire, more experiments should be conducted with more downwind receptors. 


\section{REFERENCES}

Anderson, G. K., D. V. Sandberg, and R. A. Norheim, 2004: Fire emission production simulator (FEPS) user's guide. USDA Forest Service Pacific Northwest Research Station, Fire and Environmental Research Applications Team, Portland, OR. 97 pp.

Arya, S. P., 1999: Air Pollution Meteorology and Dispersion. Oxford University Press, Inc., New York, NY, 310 pp.

Brock, F. V., 1985: A nonlinear fit to remove impulse noise from meteorological data. $J$. Atmos. Ocean. Tech., 3, 51-58.

Bowman, M. J. S., J. K. Balch, P. Artaxo, W. J. Bond, J. M. Carlson, M. A. Cochrane, C. M. D’Antonio, R. S. DeFries, J. C. Doyle, S. P. Harrison, F. H. Johnston, J. E. Keeley, M. A. Krawchuk, C. A. Kull, J. B. Marston, M. A. Moritz, I. C. Prentice, C. I. Roos, A. C. Scott, T. W. Swetnam, G. R. van der Werf, and S. J. Pyne, 2009: Fire in the Earth system. Science., 324, 481-484.

Cachier, H., C. Liousse, P. Buat-Menard, and A. Gaudichet, 1995: Particulate content of savanna fire emissions. J. Atmos. Chem., 22, 123-148.

Clements, C. B., B. E. Potter, and S. Zhong, 2006: In situ measurements of water vapor, heat, and $\mathrm{CO}_{2}$ fluxes within a prescribed fire. Int. J. Wildland Fire, 15, 299-306.

Clements, C. B., S. Zhong, S. Goodrick, J. Li, B. E. Potter, X. Bian, W. E. Heilman, J. J. Charney, R. Perna, M. Jang, D. Lee, M. Patel, S. Street, and G. Aumann, 2007: Observing the dynamics of wildland grass fires: fireflux - a field validation experiment. Bull. Amer. Meteor. Soc., 88, 1369-1382. 
Clements, C. B., S. Zhong, X. Bian, W. E. Heilman, and D. W. Byun, 2008: First obser vations of turbulence generated by grass fires, J. Geophys. Res., 113, D22102, doi:10.1029/2008JD010014.

Clinton, N. E., P. Gong, and K. Scott, 2006: Quantification of pollutants emitted from very large wildland fires in southern California, USA. Atmos. Environ., 40, 36863695 .

Crutzen, P. J., and V. Ramanathan, 2003: The parasol effect on climate, Science, 302, 1679-1681.

Dennis, A., M. Fraser, S. Anderson, and D. Allen, 2002: Air pollutant emissions associated with forest, grassland, and agricultural burning in Texas. Atmos. Environ., 36, 3779-3792.

Dockery, D. W., C. A. Pope, X. Xu, J. D. Spengler, J. H. Ware, M. E. Fay, B. G. Ferris, and F. E. Speizer, 1993: An association between air pollution and mortality in six U.S. cities. N. Engl. J. Med., 329, 1753-1759.

Dyer, A. J., 1981: Flow distortion by supporting structures. Bound.-Lay. Meteorol., 20, $243-251$.

Garratt, J. R., 1992: The Atmospheric Boundary Layer. Cambridge University Press, Cambridge, Great Britian, 316 pp.

Hardy, C. C., S. G. Conrad, J. C. Regelbrugge, and D. R. Teesdale, 1996: Smokeemis sions from prescribed burning of southern California chaparral. USDA, Pacific Northwest Research Station, Seattle, WA, 45 pp.

Hays, M. D., C. D. Geron, K. J. Linna, N. D. Smith, and J. J. Schauer, 2002: Speciation 
of gas-phase and fine particle emissions from burning of foliar fuels. Environ. Sci. Technol., 36, 2281-2295.

Hicks, B. B., P. Hyson, and C. J. Moore, 1975: A study of eddy fluxes over a forest. J. Appl. Meteor., 14, 58-66.

Hu, Y., M. T. Odman, M. E. Chang, W. Jackson, S. Lee, E. S. Edgerton, K. Baumann, and A. G Russell, 2008: Simulation of air quality impacts from prescribed fires on an urban area. Environ. Sci. Technol., 42, 3676-3682.

Intergovernmental Panel on Climate Change (IPCC), 2007: Climate Change 2007: The Physical Science Basis, contribution of working group I to the fourth assessment report of the IPCC, Cambridge University Press, Cambridge, United Kingdom.

Janhall, S., M. O. Andreae, and U. Poschl, 2009: Biomass burning aerosol emissions from vegetation fires: particle number and mass emission factors and size distributions. Atmos. Chem. Phys. Discuss., 9, 17183-17217.

Korontzi, S., D. W. Ward, R. A. Susott, R. J. Yokelson, C. O. Justice, P. V. Hobbs, E. A. H. Smithwick, and W. M. Hao, 2003: Seasonal variation and ecosystem dependence of emission factors for selected trace gases and PM2.5 for southern African savanna fires, J. Geophys. Res.- Atmos., 108, doi:10.1029/2003JD003730.

Lee, S., K. Baumann, J. J. Schauer, R. J. Sheesley, L. P. Naeher, S. Meinardi, D. R. Blake, E. S. Edgerton, A. G. Russell, and M. Clements, 2005: Gaseous and particulate emissions from prescribed burning in Georgia. Environ. Sci. Technol., 39, 9049-9056.

Lee, S., H. K. Kim, B. Yan, C. E. Cobb, C. Hennigan, S. Nichols, M. Chamber, E.S. 
Edgerton, J. J. Jansen, Y. Hu, M. Zheng, R. J. Weber, and A. G. Russell, 2008: Diagnosis of aged prescribed burning plumes impacting an urban area. Environ. Sci. Technol., 42, 1438-1444.

Lee, X., W. Massman, and B. Law, 2004: Handbook of Micrometeorology: A Guide for Surface Flux Measurement and Analysis. Kluwer Academic Publishers, Norwell, MA, $250 \mathrm{pp}$.

Liu, Y., 2004: Variability of wildland fire emissions across the contiguous United States. Atm. Environ., 38, 3489-3499.

Marmur, A., S. Park, J. A. Mulholland, P. E. Tolbert, and A. G. Russell, 2005: Source apportionment of $\mathrm{PM}_{2.5}$ in the southeastern United States using receptor and emissions-based models: conceptual differences and implications for time-series health studies. Atm. Environ., 40, 2533-2551.

McMeeking, G. R., S. M. Kreidenweis, S. Baker, C. M. Carrico, J. C. Chow, J. L. Collett, W. M. Hao, A. S. Holden, T. W. Kirchstetter, W. C. Malm, H. Moosmuller, A. P. Sullivan, and C. E. Wold, 2009: Emissions of trace gases and aerosols during the open combustion of biomass in the laboratory. J. Geophys. Res.- Atmos., 114, doi:10.1029/2009JD011836.

Penner, J. E., R. Dickinson, and C. O’Neil, 1992: Effects of aerosol from biomass burning on the global radiation budget. Science, 256, 1432-1434.

Pope, C. A., M. J. Thun, M. M. Namboodiri, D. W. Dockery, J. S. Evans, F. E. Speizer and C. W. Heath, 1995: Particulate air pollution as a predictor of mortality in a prospective study of U.S. adults. Am. J. Respir. Crit. Care Med., 151, 669-674. 
Radke, L. F., D. A. Hegg, J. H. Lyons, and J. H. Brock, 1988: Airborne measurements on smoke from biomass burning. Aerosols and Climate, P. V. Hobbs, and M. P. McCormic, Eds., Deepak Publishing, Hampton, VA, 411-422.

Reid, J. S., and P. V. Hobbs, 1998: Physical and optical properties of smoke from individual biomass fires in Brazil. J. Geophys. Res., 103, 32013-32031.

Reid, J. S., R. Koppmann, T. F. Eck, and D. P. Eleuterio, 2005: A review of biomass burning emissions part II: intensive physical properties of biomass burning particles, Atmos. Chem. Phys., 5, 799-825.

Roy, B., G. A. Pouliot, A. Gilliland, T. Pierce, S. Howard, P. V. Bhave, and W. Benjey, 2007: Refining fire emisisons for air quality modeling with remotely sensed fire counts: A wildfire case study. Atmos. Environ., 41, 655-665.

Samet, J. M., F. Dominici, F. C. Curriero, I. Coursac, and S. L. Zeger, 2000: Fine particulate air pollution and mortality in 20 U.S. cities, $N$ Engl. J. Med., 343, 1742-1749.

Schultz, M. G., A. Heil, J. J. Hoelzemann, A. Spessa, K. Thonicke, J. G. Goldammer, A. C. Held, J. M. C. Pereira, and M. van het Bolscher, 2008: Global wildland fire emissions from 1960 to 2000. Global Biogeochem. Cycles, 22, doi:10.1029/ 2007 GB003031.

Stull, R. B., 1988: An Introduction to Boundary Layer Meteorology. Kluwer Academic Publishers, Norwell, MA, 666 pp.

Tian, D., Y. Wang, M. Bergin, Y. Hu, Y. Liu, and A. G. Russell, 2007: Air quality 
impacts from prescribed forest fires under different management practices.

Environ. Sci. Technol. doi: 10.1021/es0711213.

Tian, D., Y. Hu, Y. Wang, J. W. Boylan, M. Zheng, and A. G. Russel, 2009: Assessment of biomass burning emissions and their impacts on urban and regional $\mathrm{PM}_{2.5}$ : a Georgia case study. Environ. Sci. Technol., 43, 299-305.

Turpin, B. J., and H. J. Lim, 2001: Species contributions to PM2.5 mass concentrations: revisiting common assumptions for estimating organic mass. Aerosol Sci. Technol., 35, 602-610.

US EPA, 1995: AP-42, chapter 13.1: wildfires and prescribed burning. Research Trian gle Park, NC, USA, 14 pp.

US EPA, 1997: National ambient air quality standards for particulate matter; final rule. Environmental Protection Agency Code of Federal Regulations, 62, 102 pp.

US EPA, 1998: Interim air quality policy on wildland and prescribed fire. Office of Air Quality Planning and Standards. Research Triangle Park, NC, USA, 43 pp.

US EPA, 2002: Development of emissions inventory methods for wildland fire. Research Triangle Park, NC, USA, 91 pp.

US EPA, 2004a: User's guide for the AMS/EPA regulatory model - AERMOD. Research Triangle Park, NC, USA, 216 pp.

US EPA, 2004b: User's guide for the AERMOD meteorological preprocessor (AERMET). Research Triangle Park, NC, USA, 252 pp.

US EPA, 2004c: AERMOD: description of model formulation. Research Triangle Park, NC, USA, $91 \mathrm{pp}$. 
US EPA, 2005: Revision to the guideline on air quality models: adoption of a preferred general purpose (flat and complex terrain) dispersion model and other revisions; Final Rule. Research Triangle Park, NC, USA, 45 pp.

US EPA, 2008: AERSURFACE user's guide. Research Triangle Park, NC, USA, 36 pp.

US EPA, 2009: AERMOD implementation guide, AERMOD implementation workgroup. Research Triangle Park, NC, USA, 24 pp.

van der Werf, G. R., J. T. Randerson, L. Giglio, G. J. Collatz, P. S. Kasibhatla, and A. F. Arellano, 2006: Interannual variability in global biomass burning emissions from 1997 to 2004, Atmos. Chem. Phys., 6, 3423-3441.

Ward, D. E., 1979: Particulate matter and aromatic hydrocarbon emissions from the controlled combustion of alpha pinene, Ph.D. dissertation, University of Washington, $243 \mathrm{pp}$.

Ward, D. E., and C. C. Hardy, 1991: Smoke emissions from wildland fires. Environ. Int., 17, 117-134.

Ward, D. E., R. A. Susott, J. B. Kauffman, R. E. Babbitt, D. L. Cummings, B. Dias, B. N. Holben, Y. J. Kaufman, R. A. Rasmussen, and A. W. Setzer, 1992: Smoke and fire characteristics for cerrado and deforestation burns in Brazil: Base-B Experiment, J. Geophys. Res., 97, 14601-14619.

Ward, D. E., 2001: Combustion chemistry and smoke. Forest Fires: Behavior and Ecological Effects, A. E. Johnson and K. Miyanishi, Eds., Acedemic Press, San Diego, CA, 55-77.

Ward, D. E., and L. F. Radke, 2003: Emission measurements from vegetation fires: A 
comparative evaluation of methods and results. Fire in the Environment: The Ecological, Atmospheric, and Climatic Importance of Vegetation Fires, P. J. Crutzen and J. G. Goldammer, Eds., John Wiley, Chichester, U. K., 53-76.

Wiedinmyer, C., B. Quayle, C. Geron, A. Belote, D. McKenzie, X. Zhang, S. O’Neill, and K. K. Wynne, 2006: Estimating emissions from fires in North America for air quality modeling. Atmos. Environ., 40, 3419-3432.

Winiwarter, W., 2004: Emissions of particulate matter. Emissions of Air Pollutants: Measurements, Calculations, and Uncertainties, R. Friedrich and S. Reis, Eds., Springer-Verlag, 79-89.

Whelan, J. R., 1995: The Ecology of Fire. Cambridge University Press, Cambridge, United Kingdom, 346 pp.

World Meteorological Organization (WMO), 1966, Technical Note No. 79: Climatic Change, WMO-No, 195.TP.100, Geneva, 80 pp.

Yongtao, H., M. T. Odman, M. E. Chang, W. Jackson, S. Lee, E. S. Edgerton, K. Baumann, and A. G. Russel, 2008: Simulation of air quality impacts from prescribed fires on an urban area. Environ. Sci. Technol., 42, 3676-3682. 


\section{APPENDIX: ACRONYMS}

$\mathrm{AE}_{\mathrm{f}}$

$\mathrm{AE}_{\mathrm{s}}$

AERMAP

AERMET

AERMOD

AERSURFACE

AGL

AMS

$\mathrm{BC}$

$\mathrm{BC}_{2.5}$

CE

CMAQ

$\mathrm{CN}$

EF

$\mathrm{EF}_{\mathrm{f}}$

$\mathrm{EF}_{\mathrm{s}}$

$\mathrm{EF}_{\mathrm{t}}$

EPA

EST
Area Emission rate due to flaming

Area Emission rate due to smoldering

AMS-EPA terrain data preprocessor

AMS-EPA Meteorological preprocessing model

AMS-EPA Regulatory Model

AMS-EPA surface characteristics preprocessor

Above Ground Level

American Meteorological Society

Black Carbon

Black Carbon particulates having an aerodynamic diameter less than $2.5 \mu \mathrm{m}$

Combustion Efficiency

Community Multiscale Air Quality model

Condensation Nuclei

Emission Factor

Emission Factor from flaming emissions

Emission Factor from smoldering emissions

Effective Emission Factor representing flaming plus smoldering emissions

Environmental Protection Agency

Eastern Standard Time 


\begin{tabular}{|c|c|}
\hline $\mathrm{F}$ & Flaming \\
\hline FEPS & Fire Emissions Production Simulator \\
\hline FRI & Fire Return Interval \\
\hline GFC & Georgia Forestry Commission \\
\hline MCE & Modified Combustion Efficiency \\
\hline MODIS & Moderate Resolution Imaging Spectroradiometer \\
\hline NAAQS & National Ambient Air Quality Standards \\
\hline NWS & National Weather Service \\
\hline $\mathrm{OC}$ & Organic Carbon \\
\hline PBL & Planetary Boundary Layer \\
\hline PM & Particulate Matter \\
\hline $\mathrm{PM}_{2.5}$ & Particulate Matter having an aerodynamic diameter $<2.5 \mu \mathrm{m}$ \\
\hline $\mathrm{PM}_{10}$ & Particulate Matter having an aerodynamic diameter $<10 \mu \mathrm{m}$ \\
\hline POM & Particulate Organic Matter \\
\hline S & Smoldering \\
\hline SD & Standard Deviation \\
\hline SE & Standard Error \\
\hline TKE & Turbulent Kinetic Energy \\
\hline USGS & US Geological Survey \\
\hline VISTAS & Visibility Improvement State and Tribal Association of the \\
\hline
\end{tabular}

